UNIVERSIDADE DE SÃO PAULO

ESCOLA DE ENFERMAGEM

DANIELLA PIRES NUNES

DEMANDA ASSISTENCIAL DE PESSOAS IDOSAS RESIDENTES NO MUNICÍPIO DE SÃO PAULO:

NECESSIDADE DE CUIDADO E UTILIZAÇÃO DOS SERVIÇOS DE SAÚDE

SÃO PAULO

2015 


\section{DEMANDA ASSISTENCIAL DE PESSOAS IDOSAS RESIDENTES NO MUNICÍPIO DE SÃO PAULO: NECESSIDADE DE CUIDADO E UTILIZAÇÃO DOS SERVIÇOS DE SAÚDE}

Tese apresentada ao Programa de PósGraduação em Enfermagem na Saúde do Adulto da Escola de Enfermagem da Universidade de São Paulo, para obtenção do título de Doutora em Ciências.

Área de concentração: Enfermagem na Saúde do Adulto

Orientadora: Prof. ${ }^{\text {a }}$ Dr. ${ }^{\text {a }}$ Yeda A. de Oliveira Duarte

\section{SÃO PAULO}


AUTORIZO A REPRODUÇÃO E DIVULGAÇÃO TOTAL OU PARCIAL DESTE TRABALHO, POR QUALQUER MEIO CONVENCIONAL OU ELETRÔNICO, PARA FINS DE ESTUDO E PESQUISA, DESDE QUE CITADA A FONTE.

Assinatura:

Data:

Nunes, Daniella Pires

Demanda assistencial de pessoas idosas residentes no município de São Paulo: necessidade de cuidado e utilização dos serviços de saúde / Daniella Pires Nunes. São Paulo, 2015.

$152 \mathrm{p}$.

Tese (Doutorado) - Escola de Enfermagem da Universidade de São Paulo.

Orientadora: Prof. ${ }^{\text {a }}$ Dr. ${ }^{\text {a }}$ Yeda Aparecida de Oliveira Duarte

Área de concentração: Enfermagem na Saúde do Adulto

1. Idosos. 2. Cuidadores de idosos. 3. Enfermagem geriátrica. 4. Serviços de saúde para idosos. I. Título. 
Nome: Daniella Pires Nunes

Título: Demanda assistencial de pessoas idosas residentes no município de São Paulo: necessidade de cuidado e utilização dos serviços de saúde.

Tese apresentada ao Programa de Pós-Graduação em Enfermagem na Saúde do Adulto da Escola de Enfermagem da Universidade de São Paulo, para obtenção do título de Doutora em Ciências.

Aprovado em:

\section{Banca Examinadora}

Prof. Dr. Instituição:

Julgamento: Assinatura:

Prof. Dr. Instituição:

Julgamento: Assinatura:

Prof. Dr. Instituição:

Julgamento: Assinatura:

Prof. Dr. Instituição:

Julgamento: Assinatura:

Prof. Dr. Instituição:

Julgamento: Assinatura: 


\section{DEDICATÓRIA}

Aos meus pais, Donizete e Helenice, pelo amor e confiança nas minhas decisões. Agradeço pela simplicidade e por terem me ensinado a lutar pelas minhas conquistas.

À minha irmã Dalilla que amo tanto e à minha sobrinha Maria Antônia a qual espero ansiosamente pela sua chegada.

Ao meu amigo e esposo, Márcio Félix. Sua presença durante essa jornada foi crucial para que eu alcançasse essa vitória. As palavras de estímulo, compreensão e carinho foram o refrigério para minha alma. Simplesmente tenho a dizer: "em você, eu sei, me sinto forte". 


\section{AGRADECIMENTOS}

É com muito carinho que registro o meu agradecimento a todos que participaram, direta ou indiretamente, na construção desse trabalho. Pude experimentar ao longo desse período o cuidado de cada pessoa contribuindo no meu crescimento profissional elou suporte espiritual e emocional.

Primeiramente, agradeço a Deus e a nossa Mãezinha por conhecerem os desejos do meu coração e possibilitar a concretização desse sonho, iluminando-me e sendo o meu refúgio e fortaleza nos momentos difíceis. Obrigada, Senhor, pela Vitória!!!

À minha orientadora profa Dra Yeda Duarte que me acolheu com muito amor e por propiciar o meu amadurecimento pessoal e profissional. Agradeço pela sua orientação, pelo apoio e por todo o incentivo. Muito obrigada!

À profa Dra Maria Lúcia por permitir a minha participação no Estudo SABE, possibilitar o meu crescimento profissional e por todo o apoio ofertado nos momentos de dificuldade.

À professora, amiga e "mãe" Adélia Nakatani, que incentivou a minha vinda para São Paulo e me amparou durante essa jornada. Agradeço pelo carinho e pela sua presença durante as minhas lutas e conquistas.

Aos amigos que conquistei nessa caminhada, Tábatta, Greiciane, Ligiana, Tiago, Luciana, Gabriela e Dora, vocês são um tesouro presenteado por Deus. Obrigada pelo companheirismo, incentivos $e$ amizade. Agradeço pelos momentos de partilhas e por fazerem parte desse momento tão especial da minha vida. Vocês são muito especiais!!!

Aos amigos do grupo Jovens Sarados, em especial, às madrinhas Cíntia Japa e Denise Verdum pelo apoio emocional e espiritual.

Ao prof. Dr Jair Lício e Fernão Dias por me auxiliarem no manuseio do banco dos dados e nas questões metodológicas.

Às amigas Leidiene Santos, Joice Castro e Joana Balardin, pela amizade e apoio incondicional. 
Às profas. Dras Marília Louvison e Maria Rita Bertolozzi, agradeço pela leitura cuidadosa deste trabalho e contribuições da qualificação.

À profa Dra Terezinha Dalossi e ao prof. Sérgio Lopes pela confiança e pelo incentivo durante esse período.

À Márcia Gutierrez, Ângela Fernandes, Elisabete Ribeiro e Silvana Maximiano, obrigada pelo acolhimento, amizade e incentivo contínuo.

Aos colegas FMU e alunos pelo apoio e por tornarem os meus dias mais alegres.

À querida Sara Goldman, pela paciência e compreensão nessa etapa final do doutorado.

Aos idosos, por terem proporcionado a realização deste estudo.

À Coordenação de Aperfeiçoamento de Pessoal de Nível Superior (Capes), pelo apoio financeiro.

Em especial, às amigas Valéria Pagotto e Karina Suzuki, que não mediram esforços para que eu alcançasse essa vitória. 
"Três coisas são necessárias para a salvação do homem: saber o que deve crer, saber o que deve desejar, saber o que deve fazer.

Dê-me, Senhor, agudeza para entender, capacidade para reter, método e faculdade para aprender, sutileza para interpretar, graça $e$ abundância para falar. Dê-me, Senhor, acerto ao começar, direção ao progredir e perfeição ao concluir."

São Tomás de Aquino 
Nunes DP. Demanda assistencial de pessoas idosas residentes no município de São Paulo: necessidade de cuidado e utilização dos serviços de saúde [tese]. São Paulo: Escola de Enfermagem, Universidade de São Paulo; 2015.

\section{RESUMO}

Introdução: A presença de limitações funcionais entre os idosos determina a necessidade de cuidado. Essa necessidade aponta demandas desafiadoras para a família e para os serviços de saúde por ser um grupo complexo. Objetivo: Analisar a necessidade de cuidado, a utilização dos serviços de saúde de idosos residentes no município de São Paulo e as mudanças associadas a essa necessidade ao longo do tempo. Método: Trata-se de um estudo longitudinal e analítico, de base domiciliar, e utilizou a base de dados do Estudo SABE (Saúde, Bem estar e Envelhecimento) nos anos de 2006 e 2010. A amostra foi constituída por 1413 idosos ( $\geq 60$ anos). Considerou-se como necessidade de cuidado, a dificuldade do idoso no desempenho das atividades básicas e instrumentais de vida diária de acordo com demandas de auxílio nessas atividades. Para identificar os níveis de necessidade de cuidado, utilizou-se o Escalonamento de Guttman. Para avaliar os fatores associados à necessidade de cuidados e os determinantes da mudança utilizaram-se as análises de Regressão Logística e Multinomial Múltiplas. Resultados: Quanto à hierarquia das atividades de vida diária, encontraram boa consistência interna $(\alpha=0,92)$, coeficiente de reprodutibilidade igual a $98 \%$, uma probabilidade de erro de $2 \%$, um coeficiente de escalabilidade de 0,84 e reprodutibilidade mínima marginal de 0,87 . Em relação à classificação da necessidade de cuidados, 53,3\% eram independentes para o cuidado, 26,7\% apresentavam necessidade mínima, 10,5\% necessidade moderada e 9,4\% necessidade máxima. Entre os idosos com necessidade de cuidado, 73,0\% referiram ajuda de alguém para as suas demandas. Maiores proporções de idosos com necessidade máxima foram encontradas entre aqueles que utilizaram os serviços de saúde como consulta médica, urgência/emergência e internação $(43,8 \%)$ e naqueles que usaram somente serviço de urgência/emergência e internação $(54,1 \%)$. Entre os idosos 
independentes, os fatores determinantes para necessidade mínima foram sexo feminino ( $R R R=1,81$; IC 95\%:1,05-3,13), ter 80 anos e mais (RRR=2,84; IC 95\%: 1,17-6,86), mobilidade física prejudicada (RRR=2,94; IC 95\%: 1,02-8,43); para necessidade moderada, idosos com 80 anos e mais 5,58 [1,55-20,00] e declínio cognitivo (RRR=7,83; IC 95\%:1,60-38,24); e, necessidade máxima, ter entre 70 a 79 anos $(R R R=2,60$; IC 95\%: 1,13$5,96)$, ter 80 anos e mais (RRR=5,59; IC 95\%: 1,87-16,62) e multimorbidade (RRR=3,50; IC 95\%: 1,32-9,30). Processo de fragilização $(\mathrm{OR}=2,12$; IC 95\%: 1,05-4,27) e mobilidade física prejudicada $(\mathrm{OR}=1,77$; IC 95\%: 1,01-3,12) foram determinantes para a piora da necessidade de cuidado entre os idosos. Conclusão: A classificação da necessidade de cuidados possibilita a identificação de idosos demandantes de auxílio nas atividades cotidianas e, direcionará os profissionais de saúde na elaboração de uma linha de cuidados. Políticas públicas devem ser elaboradas aos cuidadores, considerando os serviços de saúde e sociais como suporte aos provedores de cuidado.

PALAVRAS-CHAVE: Idoso. Idoso de 80 Anos ou mais. Idoso Fragilizado. Cuidadores. Enfermagem Geriátrica. Serviços de Saúde para Idosos. 
Nunes DP. Assistance requirements of elderly residents in the city of São Paulo: the need for care and use of health services [thesis]. São Paulo: Escola de Enfermagem, Universidade de São Paulo; 2015.

\begin{abstract}
Introduction: The presence of functional limitations in the elderly determines the need for care. This necessity represents challenging demands for the family and the health services as it presents a complex group. Objective: To analyze the need for care, utilization of health care services of elderly residents in the city of São Paulo and the changes associated with this need over time. Method: This was a longitudinal and analytical homebased study, which used the database of the SABE study (Health, Wellbeing and Aging) in the years 2006 and 2010. The sample consisted of 1.413 elderly individuals ( $\geq 60$ years). It was considered as the need for care, the difficulty of the elderly in the performance of basic and instrumental activities of daily living according to aid demands in these activities. To identify the care need levels, we used the Guttman Scaling. To evaluate factors associated with the need for care and determinants of change, the analysis of Multiple Logistic and Multiple Multinomial regression were used. Results: Regarding the hierarchy of activities of daily living, good internal consistency was found $(\alpha=0.92)$, a coefficient of reproducibility of $98 \%$, an error probability of $2 \%$, a scalability factor of 0.84 and minimum marginal reproducibility of 0.87 . In relation to the classification of the need for care, $53.3 \%$ were independent for care, $26.7 \%$ had minimal need, $10.5 \%$ moderate need and 9.4\% maximum need. Among the elderly in need of care, $73.0 \%$ reported having someone to help with requirements. The largest proportion of elderly maximum need were found between those used those who used health services such as medical consultations, urgent/emergency and hospitalization (43.8\%) and those who used only emergency service/emergency and hospitalization (54.1\%). Among the independent elderly, the determining factors for minimum need were female $(\mathrm{RRR}=1.81$, CI 95\%: $1.05-3.13)$, have 80 and over $(\mathrm{RRR}=$
\end{abstract}


2.84, CI 95\%: 1.17 - 6.86), impaired physical mobility $(\mathrm{RRR}=2.94$, CI 95\%: 1.02 - 8.43); for moderate need, aged 80 years and over $(\mathrm{RRR}=5.58$; CI 95\%: 1.55 - 20.00) and cognitive decline (RRR $=7.83,95 \%$ CI: $1.60-$ $38.24)$; and maximum need, be between 70 to 79 years $(\mathrm{RRR}=2.60$; $\mathrm{CI}$ 95\%: 1.13 - 5.96), have 80 and over $(\mathrm{RRR}=5.59$, CI 95\%: $1.87-16.62)$ and multimorbidity $(\mathrm{RRR}=3.50$; CI 95\%: $1.32-9.30)$. Process of frailty $(\mathrm{OR}=$ 2.12; $95 \%$ CI: 1.05 - 4.27) and impaired physical mobility (OR $=1.77 ; 95 \%$ CI: 1.01 - 3.12) Conclusion: Classifying the need for care enables identification of elderly individuals requiring help in the activities of daily living and directs health professionals when developing a range of care. Public policies should be developed for caregivers, considering the health and social services as support for the providers of care.

KEYWORDS: Aged. Aged, 80 and over. Frail Elderly. Caregivers. Geriatric Nursing. Health services for the aged. 


\section{LISTA DE FLUXOGRAMA}

Fluxograma 1- Idosos acompanhados no período de quatro anos. Município de São Paulo, 2006-2010. (n=1413) .89

Fluxograma 2- Idosos independentes acompanhados no período de quatro anos. Município de São Paulo, 2006-2010. (n=615).......... 90

Fluxograma 3- Idosos com necessidade de cuidado (mínima, moderada e máxima) acompanhados no período de quatro anos. Município de São Paulo, 2006-2010. (n=798) .97 


\section{LISTA DE FIGURAS}

Figura 1 - Esquema das múltiplas coortes do Estudo SABE. 2000 a 2010. 51

Figura 2 - Distribuição dos setores censitários de acordo com os índices de vulnerabilidade social. São Paulo, 2000 .56 


\section{LISTA DE GRÁFICOS}

Gráfico 1 - Modalidades de atendimento ofertadas à população pelos municípios brasileiros. 34

Gráfico 2 - Distribuição (\%) dos idosos segundo a presença das dificuldades nas atividades de vida diária de idosos. Município de São Paulo, 2006. $(n=1413)$. .70

Gráfico 3 - Distribuição (\%) dos idosos segundo a necessidade de cuidado. Município de São Paulo. Estudo SABE, 2006. (n=1413)....... 73

Gráfico 4 - Distribuição (\%) dos idosos segundo necessidade de cuidado e recebimento de ajuda de alguma pessoa. Município de São Paulo, 2006. $(n=798)$ 80

Gráfico 5 - Distribuição (\%) dos idosos segundo necessidade de cuidado e dificuldade no acesso aos serviços de saúde. Município de São Paulo, 2006. $(\mathrm{n}=1413)$ 82

Gráfico 6 - Distribuição (\%) dos idosos com dificuldade de acesso aos serviços de saúde segundo os motivos da dificuldade e necessidade de cuidado. Município de São Paulo. Estudo SABE. 2006-2010 (n=438*) .83

Gráfico 7 - Distribuição (\%) dos idosos segundo necessidade de cuidado e realização de consulta nos últimos 12 meses. Município de São Paulo, 2006. $(n=1413)$ .84

Gráfico 8 - Distribuição (\%) dos idosos segundo necessidade de cuidado e utilização dos serviços de urgência/emergência no último ano. Município de São Paulo, 2006. (n=1413) .85

Gráfico 9 - Distribuição (\%) dos idosos segundo necessidade de cuidado e procedência após a utilização do serviço de urgência/emergência. Município de São Paulo, 2006. (n=205*) 
Gráfico 10 - Distribuição (\%) dos idosos segundo necessidade de cuidado e tempo de uso do serviço de acesso à urgência/emergência. Município de São Paulo, 2006. (n=205) .86

Gráfico 11 - Distribuição (\%) dos idosos segundo necessidade de cuidado e internação no último ano. Município de São Paulo, 2006. $(n=1413)$ .87

Gráfico 12 - Distribuição (\%) dos idosos segundo necessidade de cuidado e serviços de saúde utilizados no último ano. Município de São Paulo, 2006. $(\mathrm{n}=1413)$ .88

Gráfico 13 - Distribuição (\%) dos idosos segundo óbito e necessidade de cuidado. Município de São Paulo. Estudo SABE. 2006-2010 $(n=1413)$ 90

Gráfico 14 - Distribuição (\%) dos idosos sem necessidade de cuidado na linha de base segundo necessidade de cuidado após quatro anos. Município de São Paulo. Estudo SABE, 2006-2010. $(n=459)$ 


\section{LISTA DE QUADROS}

Quadro 1 - Classificação da necessidade de cuidados de longa duração proposta pelo Ministério da Saúde da Alemanha................29

Quadro 2 - Classificação de dependência proposto pela Espanha.............. 32

Quadro 3 - Habilidades cognitivas envolvidas no desempenho das

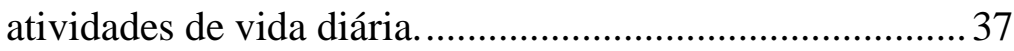

Quadro 4 - Seções e conteúdos do questionário utilizado no Estudo SABE, 2000 49

Quadro 5 - Frequência de ajuda para realização das atividades de vida diária. 53

Quadro 6 - Classificação dos grupos de vulnerabilidade social e classificação adotada no estudo.

Quadro 7 - Pontos de corte adotados para operacionalização do fenótipo de fragilidade. Estudo SABE. São Paulo, 2006. 60

Quadro 8 - Variáveis utilizadas para avaliar os serviços de saúde no Estudo SABE. 61

Quadro 9 - Níveis de cuidado segundo frequência da realização das atividades e auxílio de um cuidador. .71 


\section{LISTA DE TABELAS}

Tabela 1 - Distribuição do número de idosos segundo o status. Município de São Paulo (SP), 2000-2010 .50

Tabela 2 Distribuição (\%) dos idosos segundo características socioeconômicas e demográficas. Município de São Paulo. Estudo SABE, 2006. $(\mathrm{n}=1413)$ 67

Tabela 3 - Distribuição (\%) dos idosos segundo condições de saúde e utilização dos serviços de saúde. Município de São Paulo, 2006. $(n=1413)$ 68

Tabela 4 - Distribuição (\%) dos idosos segundo necessidade de cuidado e características sociodemográficas e econômicas. Município de São Paulo, 2006. (n=1413) .74

Tabela 5 - Distribuição (\%) dos idosos segundo necessidade de cuidado e condições de saúde. Município de São Paulo, 2006. (n=1413)

Tabela 6 - Distribuição (\%) dos idosos segundo necessidade de cuidado e utilização dos serviços de saúde. Município de São Paulo, 2006. $(n=1413)$ .77

Tabela 7 - Fatores associados à necessidade de cuidados de idosos. Município de São Paulo, 2006. (n=1413) .78

Tabela 8 - Distribuição (\%) dos idosos com necessidade de cuidado segundo recebimento de ajuda de outra pessoa, características socioeconômicas, demográficas e multimorbidade. Município de São Paulo, 2006. (n=798).

Tabela 9 - Distribuição (\%) dos idosos sem necessidade de cuidado no baseline segundo características sociodemográficas e condições de saúde. Município de São Paulo. Estudo SABE, $2006(n=615)$ 
Tabela 10 - Distribuição (\%) dos idosos sem necessidade de cuidado no baseline segundo necessidade de cuidado e características socioeconômicas e demográficas. Município de São Paulo, 2006-2010. $(n=459)$ 92

Tabela 11 - Distribuição (\%) dos idosos sem necessidade de cuidado no baseline de acordo necessidade de cuidado e condições de saúde. Município de São Paulo, 2006-2010. (n=459) 94

Tabela 12 - Distribuição (\%) dos idosos sem necessidade de cuidado no baseline de acordo segundo necessidade de cuidado e serviços de saúde. Município de São Paulo, 2006-2010. (n=459) .95

Tabela 13 - Fatores determinantes para a necessidade de cuidado em idosos independentes. Município de São Paulo. Estudo SABE, 20062010. $(n=459)$ .96

Tabela 14 - Distribuição (\%) dos idosos segundo classificação de necessidade de cuidado no baseline e no acompanhamento. Município de São Paulo, 2006-2010. (n=456) .98

Tabela 15 - Distribuição (\%) dos idosos de acordo com a piora da necessidade de cuidado e características socioeconômicas e demográficas. Município de São Paulo, 2006-2010. $(n=456$. .98

Tabela 16 - Distribuição (\%) dos idosos de acordo com a piora da necessidade de cuidado e condições de saúde. Município de São Paulo, 2006-2010. $(\mathrm{n}=456)$ 99

Tabela 17 - Distribuição (\%) dos idosos de acordo com a piora da necessidade de cuidado e utilização dos serviços de saúde. Município de São Paulo, 2006-2010. (n=456) 101

Tabela 18 - Fatores determinantes para a piora da necessidade de cuidado entre os idosos. Município de São Paulo. Estudo SABE, 20062010. $(n=456)$ 102 


\section{SUMÁRIO}

1. INTRODUÇÃO

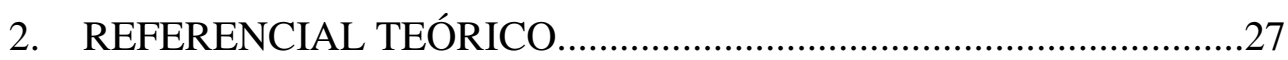

2.1 Necessidade de cuidado.......................................................27

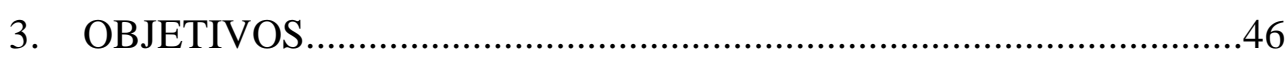

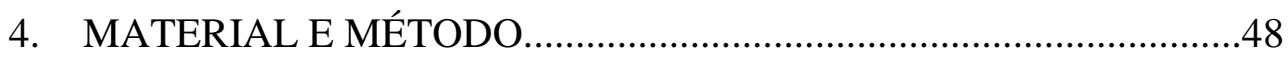

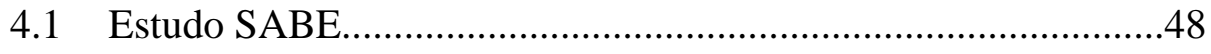

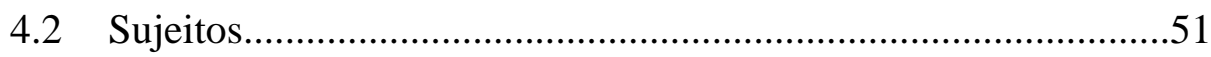

4.3 Delineamento do Estudo.............................................................51

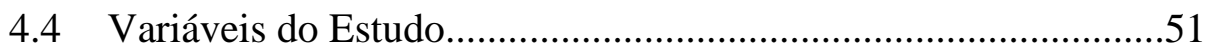

4.4.1 Variável dependente - necessidade de cuidado..............51

4.4.2 Variáveis independentes............................................54

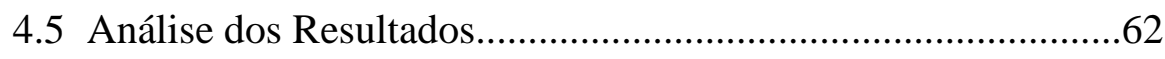

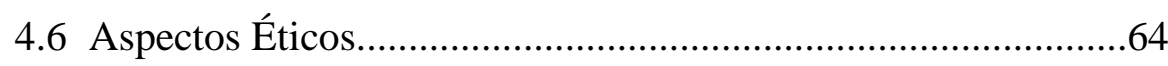

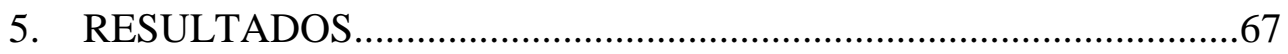

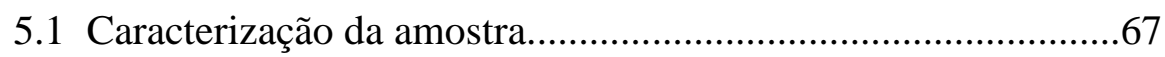

5.2 Necessidade de cuidados.....................................................69

5.2.1 Classificação da necessidade de cuidado........................69

5.2.2 Necessidade de cuidado e fatores associados...................73

5.2.3 Necessidade de cuidado e recebimento de ajuda..............79

5.2.4 Necessidade de cuidado e acesso e utilização dos serviços

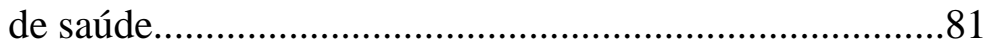

5.3 Transição entre os níveis de cuidado.....................................89

5.3.1 Fatores determinantes para a necessidade de cuidado...90

5.3.2 Fatores determinantes para a piora entre os níveis de

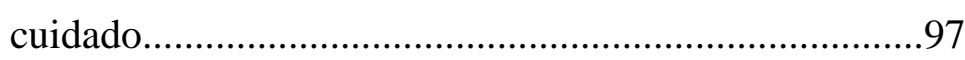

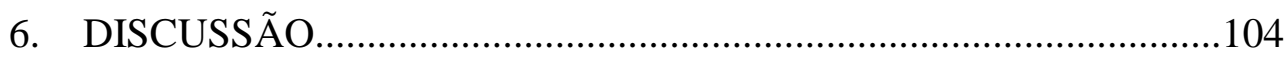

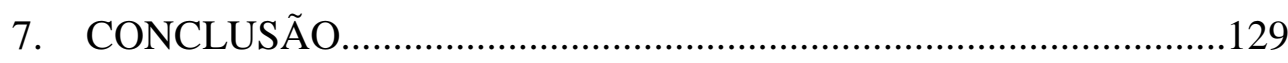

8. REFERÊNCIAS BIBLIOGRÁFICAS...........................................133

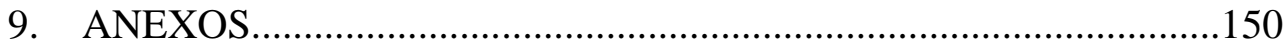


Anexo I. Aprovação do Comitê de Ética do Estudo SABE 2000...150

Anexo II. Aprovação do Comitê de Ética do Estudo SABE

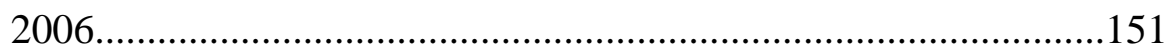

Anexo III. Aprovação do Comitê de Ética do Estudo SABE

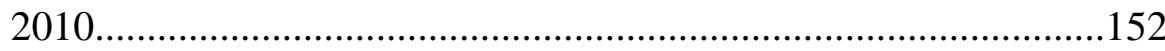


INTRODUÇÃO

ב.20




\section{INTRODUÇÃO}

O envelhecimento da população é um fenômeno mundial e representa uma importante conquista da humanidade. Vem ocorrendo de forma rápida tendendo a se multiplicar nos próximos anos. Atualmente, no Brasil, a proporção de pessoas idosas $(\geq 60$ anos $)$ representa aproximadamente $11 \%$ da população, tornando a oferta de oportunidades de aproveitamento máximo de sua capacidade de participação em todos os aspectos da vida, um importante desafio (ONU, 2003; IBGE, 2010a).

Para que o envelhecimento seja uma experiência positiva para as pessoas idosas, políticas foram desenvolvidas e leis foram criadas. Em seu conjunto, buscam garantir seus direitos, promover sua autonomia, otimizar a utilização de serviços sociais e de saúde para assistir suas necessidades e garantir a integração e a participação efetiva dos mesmos na comunidade.

Nesse sentido, em 2005, a Organização Mundial de Saúde (OMS), desenvolveu uma proposta política com foco no que foi denominado "Envelhecimento Ativo" visando melhorar a qualidade de vida das pessoas idosas com base em três pilares: saúde, participação social e segurança (OMS, 2005) e tendo como principal meta a manutenção, pelo maior tempo possível, da capacidade funcional das pessoas em processo do envelhecimento, ou seja, a manutenção das habilidades físicas e mentais necessárias para uma vida autônoma e independente (Brasil, 2006a).

$\mathrm{Na}$ prática, o nível de funcionalidade das pessoas idosas é avaliado por meio do seu desempenho das atividades cotidianas, denominadas atividades de vida diária (AVDs). Entende-se por desempenho a execução habitual, em ambiente conhecido dessas atividades que, didaticamente, são subdivididas em: básicas (ABVDs), relacionadas ao autocuidado; e instrumentais (AIVDs) relacionadas à participação do idoso em seu entorno social e manutenção de uma vida comunitária independente (Buñuales, Diego, Moreno, 2002; Brasil, 2006a).

Várias são as condições que podem impactar na funcionalidade das pessoas idosas. Entre as condições clínicas, encontram-se o declínio funcional (Stuck et al., 1999; Perneczky et al., 2006), a depressão (Penninx 
et al., 1998; Stuck et al., 1999), a multimorbidade (Fried et al., 1999; Landia et al., 2010), a polifarmácia (Nogueira et al., 2010), os déficits sensoriais como dificuldade auditiva e visual (Rubin et al., 1994; Alexandre et al., 2014), e a mobilidade física prejudicada (Rosso et al., 2013). Já entre fatores socioeconômicos e demográficos tem-se: idade (Stuck et al., 1999; Alexandre et al., 2012), gênero (Rosa et al., 2003; Nunes et al., 2010), etnia (Kail, Taylor, 2014), escolaridade (Parahyba, Veras, Melzer, 2005), pobreza (Braithwaite, Mont, 2009) e engajamento social (Mendes de Leon et al., 2001; Nogueira et al., 2010).

O conhecimento dos fatores associados é fundamental na identificação dos idosos de risco para o desenvolvimento de comprometimento funcional (Buchner, Wagner, 1992; Gill, Kurland, 2003). Um dos indicadores desse comprometimento é a necessidade de auxílio de outrem manifestado pela pessoa idosa para a realização das atividades cotidianas, normalmente classificado como dependência, em diferentes níveis (Néri, Sommerhalder, 2002; Caldas, 2003; Giacomini et al., 2005). O grupo de idosos que apresenta alguma dependência e requeira cuidados, traz demandas desafiadoras para a família e para os serviços de saúde.

A literatura traz, comumente, estudos relacionados à identificação da dependência nas pessoas idosas, mas não necessariamente, tal classificação é acompanhada pela descrição da necessidade de cuidados gerada por tal demanda. Da mesma forma, a avaliação das necessidades geradas não é estratificada em que cuidados seriam necessários, quais seriam prioritários, quem deveria ser responsável por assisti-los adequadamente, que tipo de serviços demandariam e como esses serviços poderiam ser organizados para atender tais demandas. Por exemplo: avaliando-se uma pessoa idosa, a presença de dificuldades para o desempenho de pelo menos três ABVDs, poderá ser classificada como com dependência moderada (dependendo do instrumento ou referencial utilizado). A partir desse momento, a estratificação dos cuidados demandados e a divisão de responsabilidades relacionadas à assistência (por parte da família e dos profissionais de saúde) não é claramente estabelecida. 
A Espanha apresenta um exemplo exitoso de organização assistencial com base no nível de dependência apresentado pelas pessoas idosas e necessidade presencial de um cuidador para auxiliar nas atividades cotidianas. A partir da avaliação funcional, são estabelecidos os cuidados e, consequentemente, os serviços a serem ofertados (IMSERSO, 2004).

É sabido que a provisão de cuidados das pessoas idosas representa um grande desafio para as políticas de saúde, frente ao rápido e progressivo envelhecimento populacional, as significativas alterações nas estruturas familiares e as peculiaridades assistenciais relativas a esse grupo em um país, ainda, com muitas desigualdades. Segundo a OMS (2005), a provisão de cuidados necessários às pessoas idosas envolve um equilíbrio entre o apoio ao próprio idoso, ainda independente, denominado apoio ao autocuidado (pessoas que cuidam de si mesmas), o apoio informal (fornecido por familiares e amigos) e, o cuidado formal, relacionado aos serviços social e de saúde. Tal medida deve ser realizada devido à disparidade no investimento dos recursos ofertado aos cuidados. A maioria dos países destina seus recursos aos cuidados formais, no entanto, os cuidados realizados pelos próprios indivíduos ou por cuidadores familiares representam maiores proporções comparado à utilização dos cuidados formais.

A presença de limitações funcionais entre os idosos determina a necessidade de cuidado. Tais necessidades ainda não estão bem elucidadas em nosso meio e reforçam algumas inquietações: Qual a prevalência de idosos que necessitam de cuidados na população? Quais os fatores associados à necessidade desses cuidados? Essa necessidade é atendida? Em que proporção? Quais os fatores determinantes da mudança na necessidade de cuidado ao longo do tempo?

Esses questionamentos surgiram a partir da crença de que uma parcela dos idosos demandantes de cuidados pode não estar recebendo o suporte ou a assistência necessária. Além disso, acredita-se que a necessidade de cuidados está associada com as condições de saúde apresentadas pelos idosos e também com as condições sociais e com a organização de serviços de saúde a eles disponibilizada. 
O envelhecimento é acompanhado pelo aumento na prevalência de doenças crônicas que, dadas suas características, exigem acompanhamento e monitoramento contínuos. A gravidade de tais condições e/ou o monitoramento inadequado das mesmas podem ocasionar sequelas incapacitantes aumentando, assim, as demandas assistenciais e a necessidade de cuidados para o desempenho das atividades cotidianas. Classificar tais necessidades em termos de cuidados a serem ministrados parece útil para direcionar as ações das famílias e dos profissionais (para que reconheça as particularidades do idoso e saiba orientar a família), tornando-as mais efetivas e resolutivas. Tal classificação pode, ainda, contribuir com a construção de uma linha de cuidado específica para assistir as demandas das pessoas idosas, levando em consideração a família (provedora informal de cuidado) e os recursos disponíveis com vistas à adaptação e adequação das circunstâncias individuais visando garantir a melhor qualidade de vida do idoso e de seu entorno. 
REFERENCIAL TEÓRICO

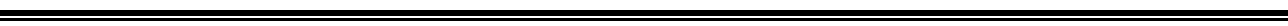




\section{REFERENCIAL TEÓRICO}

\subsection{Necessidade de Cuidado}

O cuidado pode ser compreendido como "um modo de fazer na vida cotidiana que se caracteriza pela atenção, responsabilidade, zelo e desvelo com pessoas e coisas em lugares e tempos distintos de sua realização". Sua importância na vida cotidiana está relacionada às condições sociais e ao contex to histórico de cada individuo (Pinheiro, 2009).

Define-se cuidado em saúde como tratar, respeitar, acolher e atender o ser humano em suas necessidades, com qualidade e resolutividade. Faz-se necessária uma ação integral decorrente das 'entre-relações' de pessoas, ou seja, efeitos e repercussões de interações positivas entre usuários, profissionais e instituições, que são traduzidas em atitudes como acolhimento, vínculo, tratamento digno, respeitoso e com qualidade, (Pinheiro, 2009).

Para Boff (2002) cuidar é mais que um ato, é uma atitude. Abrange mais que um momento de atenção, de zelo e de desvelo, pois representa uma atitude de ocupação, preocupação, responsabilização e envolvimento afetivo e efetivo com o outro.

O cuidado é resultado de um processo de cuidar. Esse refere-se aos comportamentos e ações que envolvem conhecimento, valores, habilidades e atitudes empreendidas para favorecer as potencialidades das pessoas para manter ou melhorar sua condição humana no processo de viver e morrer. O conhecimento prévio de hábitos, padrões e comportamentos auxiliam no desenvolvimento do processo de cuidar (Waldow, 1995).

O processo de cuidar pode, também, ser compreendido como um fenômeno intencional e essencial à vida, sendo as necessidades dos indivíduos a principal condição que antecede o cuidado (Vale, Pagliuca, 2011).

O cuidado representa uma atitude ou ação direcionada para atender as necessidades dos indivíduos, a fim de lhes proporcionar uma melhor qualidade de vida. As necessidades dos indivíduos podem ser físicas, 
psicológicas, emocionais e sociais. A avaliação da necessidade de cuidado ainda não está consolidada em nosso meio, bem como sua repercussão na vida do idoso, da família e o impacto nos sistemas social e de saúde.

Em alguns países como Alemanha, Japão, Estados Unidos e Espanha foram desenvolvidas políticas específicas para determinar o grau da dependência das pessoas idosas. A partir de uma classificação estabelecida, a prestação de cuidados necessária foi organizada. Na Alemanha, Japão e Estados Unidos a provisão de serviços de cuidados aos idosos com dependência é financiada por meio de contribuições para seguros sociais (Batista et al., 2008).

Na Alemanha, o nível de necessidade de cuidados de longa duração tem sido avaliado pelo grau de dependência da pessoa segundo suas necessidades de ajuda em relação a 24 atividades cotidianas específicas e subdividas em grupos de acordo com frequência e tempo de cuidados demandados. Essas atividades englobam mobilidade, cognição, comunicação, comportamentos e problemas psicológicos, autocuidado, gerenciamento da vida cotidiana e contatos sociais e manutenção do lar (Alemanha, 2009).

O instrumento é destinado a identificar a necessidade de cuidados de longa duração, e considera tanto o comprometimento físico como déficits cognitivos e distúrbios psicológicos, que também implicam em demandas assistenciais. Para estimar a necessidade de cuidados, considera-se o grau de independência para a realização das AVDs em função do tempo de ajuda diária de que a pessoa com limitações funcionais necessita para a realização das mesmas (Alemanha, 2009). Essa avaliação determina três graus de dependência, sendo cada um deles correspondente a um nível de proteção social oferecido (Quadro 1):

» Grau I (necessidade assistencial moderada): inclui pessoas com necessidade de assistência de 90 minutos por dia sendo metade desse tempo para cuidado pessoal. Essas pessoas exigem, pelo menos uma vez por dia, ajuda na sua higiene pessoal, alimentação e locomoção; também precisam de ajuda com as tarefas domésticas várias vezes por semana. 
» Grau II (necessidade assistencial grave): precisam de ajuda principal (pelo menos três horas por dia sendo duas delas dedicadas aos cuidados pessoais). Pessoas nessa categoria necessitam de ajuda na higiene pessoal, na alimentação e mobilização pelo menos três vezes por dia; também precisam de ajuda com as tarefas domésticas várias vezes por semana.

» Grau III (necessidade assistencial muito grave): extrema necessidade de ajuda (pelo menos cinco horas por dia, quatro delas dedicadas a cuidados pessoais). Eles são pessoas que necessitam de ajuda com a higiene pessoal, alimentação e mobilização, permanentemente; também precisam de ajuda fazendo tarefas domésticas várias vezes por semana (Batista et al., 2008; Alemanha, 2009).

Quadro 1 - Classificação da necessidade de cuidados de longa duração proposta pelo Ministério da Saúde da Alemanha.

\begin{tabular}{|l|c|c|c|}
\hline \multirow{2}{*}{$\begin{array}{l}\text { Necessidade de } \\
\text { cuidado }\end{array}$} & \multicolumn{3}{|c|}{ Graus de dependência } \\
\cline { 2 - 4 } $\begin{array}{l}\text { Cuidados pessoais } \\
\text { básicos (higiene } \\
\text { pessoal, alimentação, } \\
\text { locomoção) }\end{array}$ & $\begin{array}{c}\text { Ao menos uma } \\
\text { vez ao dia }\end{array}$ & Três vezes ao dia & Todo dia \\
\hline $\begin{array}{l}\text { Tempo de cuidado } \\
\text { estimado }\end{array}$ & $\begin{array}{c}\text { 1 hora e meia por } \\
\text { dia }\end{array}$ & 3 horas por dia & $\begin{array}{c}5 \text { horas por } \\
\text { dia }\end{array}$ \\
\hline $\begin{array}{l}\text { Tarefas domésticas } \\
\text { Várias vezes por } \\
\text { semana }\end{array}$ & $\begin{array}{c}\text { Várias vezes por } \\
\text { semana }\end{array}$ & $\begin{array}{c}\text { Várias vezes } \\
\text { por semana }\end{array}$ \\
\hline $\begin{array}{l}\text { Dentre o tempo de } \\
\text { cuidado estimado, } \\
\text { quanto tempo é } \\
\text { dedicado aos cuidados } \\
\text { pessoais básicos }\end{array}$ & $\begin{array}{c}\text { 45 minutos } \\
\text { 2 horas }\end{array}$ & 4 horas \\
\hline
\end{tabular}

Fonte: Batista et al., 2008.

O financiamento desse tipo de serviço é garantido pela contribuição social dos salários por meio de cotização obrigatória. Há três modalidades de assistência para o dependente: auxílio financeiro (serviços ofertados pelo setor privado), serviços de assistência domiciliar ou centros-dia/noite e serviços de cuidado institucional em residências especializadas para idosos, em casos de ausência de cuidador ou idosos com demência avançada. 
Em 2000, no Japão, foi implementado o sistema de seguro para a cobertura dos cuidados de longa duração onde idosos ( $\geq 65$ anos) são elegíveis para os benefícios (serviços institucionais e comunitárias) de acordo com as necessidades apresentadas que são avaliadas e, posteriormente, os serviços são estabelecidos (Tsutsui, Muramatsu, 2005). Nesse sistema, a dependência do idoso por meio de duas dimensões: estados físico (paralisia ou limitação articular; equilíbrio e movimento, atividades básicas e instrumentais de vida diária) e psicológico (cognição e comunicação, problemas comportamentais) e utilização de procedimentos médicos (diálise, oxigenoterapia, acompanhamento dos sinais vitais e outros).

Seis níveis de cuidado, agrupados em duas categorias (auxílio e cuidado demandados) estão previstos. O nível mais leve é classificado na categoria "auxílio demandado", relativo a serviços preventivos; e, os outros cinco, enquadram-se na categoria "cuidado demandado".

O "auxílio demandado" requer de 30 a 50 minutos de cuidados diários. A categoria "cuidado demandado", por sua vez, comporta cinco níveis de classificação. O nível 1 agrupa pessoas que demandam mais de 50 minutos de cuidados diários; no outro extremo, o nível 5 reúne as pessoas que requerem o dobro de tempo de auxílio (110 minutos/dia). As pessoas agrupadas nesta categoria têm direito a todos os serviços: residenciais, comunitários e institucionais (Tsutsui, Muramatsu, 2005).

Nos Estados Unidos (EUA), o cuidado de longa duração é oferecido pelo Estado ao idoso dependente por meio de seguros privados. Esse seguro tem como objetivo responder às necessidades específicas das pessoas idosas. Um dos seguros contém apólices que cobrem uma quantidade máxima de recursos, cujo montante depende do valor negociado. Tratam-se de apólices que cobrem uma quantidade máxima de benefícios monetários segundo o valor contratado pelo usuário (Batista et al., 2008).

Há, ainda, outras duas formas de seguro que podem atender aos idosos nos EUA: Medicare e o Medicaid. O primeiro exige a participação do usuário no financiamento dos serviços e oferece primordialmente cuidados de curta duração, enquanto o outro, é financiado pelo governo 
federal e pelos governos estaduais e oferece à população de baixa renda parte dos cuidados de longa duração de que necessita (Batista et al., 2008). Segundo o National Institute on Aging (NIA), tal configuração indica que nos Estados Unidos a maior parte da responsabilidade pelos cuidados demandados pela situação de dependência identificada nos idosos é atribuída aos próprios indivíduos e suas famílias (NIA, 2014).

Em 2001, também nos EUA foi inaugurado oficialmente o Programa Nacional de Apoio para os Cuidadores Familiares, que atua em conjunto com as agências da área de envelhecimento e os provedores de serviços das comunidades locais. Oferece para os cuidadores familiares informações sobre os serviços, organização de grupos de apoio, apoio ao cuidado proporcionado, orientações sobre modificações no lar, tecnologias assistivas, transporte e outras (Batista et al., 2008; NIA, 2014).

$\mathrm{Na}$ Espanha, a Secretaria de Estado de Serviços Sociais, Família e Deficiência da Espanha elaborou o "Libro Blanco de la Dependencia en España" que orientou o desenvolvimento de um projeto de lei visando à promoção da autonomia pessoal e da atenção às pessoas em situação de dependência (IMSERSO, 2004).

Em 2006, esse projeto foi aprovado e criou-se o "Sistema de Autonomía y Atención a la Dependencia" (SAAD) com intuito de promover a autonomia pessoal e garantir a atenção e proteção às pessoas em situação de dependência em todo território espanhol, sem restrição de idades. Esse sistema estabeleceu três graus de dependência a partir da ajuda de pessoas para auxiliar o idoso a realizar as atividades básicas da vida diária, como levantar-se da cama, realizar higiene pessoal ou alimentar-se (Quadro 2).

Em 2009, entre os países europeus estabeleceu-se uma crise financeira desencadeada pela desregulação do mercado financeiro nos Estados Unidos. A partir desse período, verificou-se nesses países um elevado endividamento e déficits públicos como decorrente da publicização das dívidas privadas bancárias, ao mesmo tempo, como consequência aumentou o desemprego e houve redução das receitas governamentais. A Espanha foi o país mais atingido com a crise, gerando repercussões no seu sistema de saúde. Uma delas foi o aumento do copagamento dos serviços 
transferindo assim a responsabilidade do Estado às famílias (Giovanella, Stegmüller, 2014).

Quadro 2 - Classificação de dependência proposto pela Espanha.

\begin{tabular}{|l|l|}
\hline Classificação de dependência & \multicolumn{1}{|c|}{ Definição } \\
\hline Grau I - dependência moderada & $\begin{array}{l}\text { A pessoa necessita de ajuda para realizar mais } \\
\text { de uma das atividades básicas de vida diária, } \\
\text { pelo menos uma vez ao dia. }\end{array}$ \\
\hline Grau II - dependência severa & $\begin{array}{l}\text { A pessoa necessita de ajuda para realizar mais } \\
\text { de uma das atividades básicas de vida diária } \\
\text { duas ou três vezes ao dia, mas não requer a } \\
\text { presença permanente de um cuidador. }\end{array}$ \\
\hline Grau III - grande dependência & $\begin{array}{l}\text { A pessoa necessita de ajuda para realizar mais } \\
\text { de um das atividades básicas de vida diária } \\
\text { muitas vezes ao dia e, por sua perda total de } \\
\text { autonomia mental ou física, necessita da } \\
\text { presença indispensável e contínua de outra } \\
\text { pessoa. }\end{array}$ \\
\hline
\end{tabular}

Fonte: IMSERSO, 2004; Batista et al., 2008.

No Brasil, os direitos à saúde para a pessoa idosa sempre estiveram assegurados em nossa Constituição Federal (Brasil, 1988) e reafirmados com a criação do Sistema Único de Saúde (SUS), por meio da Lei Orgânica da Saúde $n^{\circ}$ 8.080/90 (Brasil, 1990). Esse direito, universal e integral, é garantido por meio de políticas que visem à redução de doenças e outros agravos e ao acesso às ações e serviços para promoção, proteção e recuperação.

A fim de assegurar os direitos sociais e amparar os direitos legais à pessoa idosa, em 1994, foi promulgada a Lei 8.842 (Brasil, 1994), que instituiu a Política Nacional do Idoso (PNI) e regulamentada pelo Decreto $\mathrm{n}^{\circ}$ 1.948, em julho de 1996 (Brasil, 1996). Essa política designa condições para promover autonomia, integração e participação efetiva na sociedade e reafirmando o direito à saúde nos diversos níveis de atendimento do SUS. Além disso, objetiva atender às necessidades básicas da população no 
tocante a educação, saúde, habitação e urbanismo, esporte, trabalho assistência social e previdência, justiça.

Em 2003, foi regulamentado e aprovado o Estatuto do Idoso que assegura de forma legal de maior potencial da perspectiva de proteção e regulamentação dos direitos da pessoa idosa (Brasil, 2003). Também ampara o direito de atenção integral à saúde do idoso, por meio do SUS, garantindo o acesso universal e igualitário para prevenção, promoção e proteção, bem como a recuperação da saúde.

No âmbito das políticas de saúde, no ano de 1999 foi aprovada a Política Nacional de Saúde do Idoso (PNSI) que visa promover o envelhecimento saudável, manter a capacidade funcional, assistir as necessidades do idoso, reabilitar a capacidade funcional comprometida, capacitar os recursos humanos, apoiar os cuidadores informais e apoiar estudos e pesquisas (Brasil, 1999). Em 2005, a OMS em seu documento sobre o "Envelhecimento Ativo" reforça que a manutenção autonomia e independência, o controle das múltiplas doenças, a provisão de cuidados, as iniquidades durante o envelhecimento são metas fundamentais para indivíduos e governantes (OMS, 2005).

O Pacto pela Vida, consolidado em 2006, é uma das prioridades, articuladas e integradas proposta pelo governo federal, no qual a saúde do idoso é colocada como prioridade. A Área Técnica Saúde do Idoso do Ministério da Saúde (Brasil, 2010) tem desenvolvido algumas ações, baseadas na PNSPI e no Pacto pela Vida, visando a implantação de estratégias que contribuam com o envelhecimento ativo, a partir da realização de ações de atenção integral e integrada e de ações intersetoriais de fortalecimento da participação popular e de educação permanente (Brasil, 2006a).

O Suplemento da Pesquisa de Informações Básicas Municipais (MUNIC) aponta que políticas, programas e ações municipais destinadas à população idosa ocupam o segundo lugar em frequência e quase $60 \%$ dos municípios brasileiros informaram possuir algum tipo de ação destinada aos idosos (IBGE, 2010b). No gráfico 1, observa-se alguns serviços sociais ofertados à população idosa e cerca de $30 \%$ dos municípios apontaram a 
modalidade de atendimento institucional (Instituições de Longa Permanência - ILPIs) e pouco mais de $13 \%$ contam com centros-dia e casas-lares.

Gráfico 1 - Modalidades de atendimento ofertadas à população pelos municípios brasileiros.

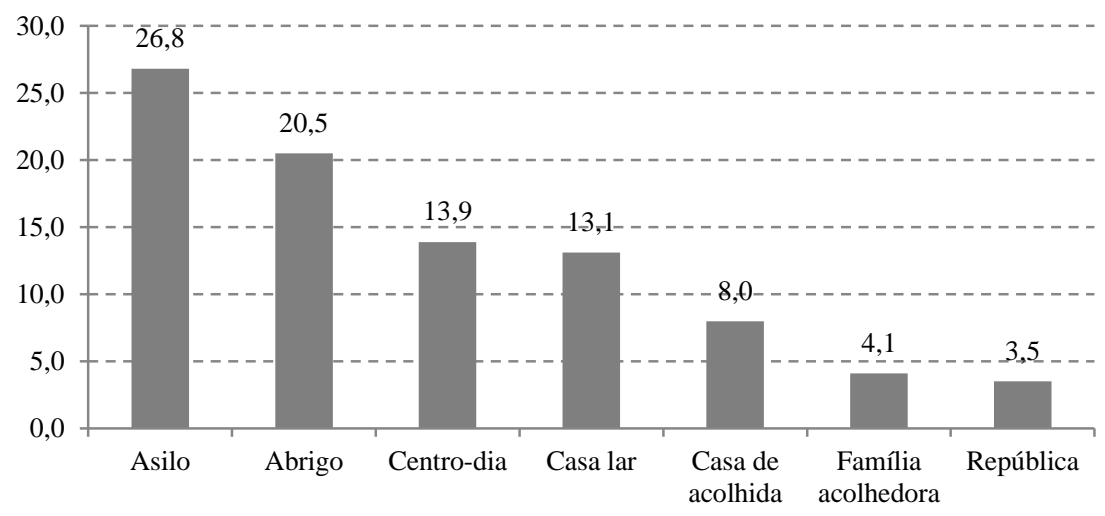

Fonte: IBGE (2006)

No Brasil, as ILPIs governamentais ou não governamentais devem ser instituições de caráter residencial, destinada ao domicilio coletivo de pessoas idosas, com ou sem suporte familiar, em condição de liberdade, dignidade e cidadania (Anvisa, 2005).

Para fins de fiscalização, a Agência Nacional de Vigilância Sanitária - ANVISA - classificou a dependência funcional nas ILPIs em três graus (Anvisa, 2005):

a) Grau de Dependência I - idosos independentes, mesmo que requeiram uso de dispositivos assistivos.

b) Grau de Dependência II - idosos com dependência em até três atividades básicas de vida diária tais como alimentação, mobilidade, higiene; sem comprometimento cognitivo ou com alteração cognitiva controlada.

c) Grau de Dependência III - idosos com dependência que requeiram assistência em todas as atividades básicas de vida diária e/ou com comprometimento cognitivo.

Mediante essa classificação é estabelecido um número mínimo de cuidadores destinados à assistência dos: 
a) Grau de Dependência I: um cuidador para cada 20 idosos;

b) Grau de Dependência II: um cuidador para cada 10 idosos;

c) Grau de Dependência III: um cuidador para cada 6 idosos.

Diferentes políticas, em âmbito nacional e internacional, consideram a avaliação de dependência como determinante das necessidades de cuidados.

A PNSPI, em sua reedição de 2006, estabeleceu que a funcionalidade da pessoa idosa é avaliada a partir da dificuldade no desempenho de alguma das atividades de básicas (ABVDs) e instrumentais de vida diária (AIVDs), devendo ser esse o principal direcionador da organização assistencial desse grupo. As ABVDs envolvem a capacidade do indivíduo em autocuidar-se, atividades como: tomar banho, vestir-se, usar o banheiro, transferir-se, ser continente e alimentar-se. Já o desempenho das AIVDs envolvem tarefas relacionadas com a participação ativa do idoso na comunidade como preparar refeições, administrar a própria medicação, fazer compras, controlar o próprio dinheiro, usar o telefone, fazer tarefas domésticas leves e pesadas e utilizar meios de transporte (Brasil, 2006a).

Vários são os instrumentos utilizados para avaliação funcional cujo resultado mostrará o grau de funcionalidade do indivíduo classificando-os como independente ou dependente (total ou parcialmente) (Paixão Jr, Reichenheim, 2005). A primeira escala desenvolvida foi a Escala de Katz que avalia o nível de dependência para o desempenho das ABVDs. Posteriormente, desenvolveu-se a Escala de Lawton para avaliação das AIVDs. Ambas com ampla utilização em serviços de saúde e pesquisas.

Ressalta-se que essas atividades envolvem execução e exigem organizada habilidade locomotora, funções neurológicas complexas e vegetativas simples preservadas, envolvendo aspectos culturais e de aprendizagem (Katz et al., 1963).

As habilidades motoras podem ser classificadas como de coordenação motora grossa que envolve participação de todo o corpo como, por exemplo, no caminhar e no correr; e, de coordenação motora fina, que requerem precisão para realizar tarefas como abotoar botões, cortar, manuseio de objetos. Ambas são adquiridas por meio da interação do 
organismo com a tarefa e o ambiente. Na habilidade motora denominada grossa, o movimento é coordenado e suave e utiliza os grandes grupos musculares, enquanto na fina, há mobilização de pequenos grupos musculares e os movimentos controlados exigem um nível de alta destreza (Crepeau; Neistadt, 2002; Simões; Murijo; Pereira, 2008).

Os aspectos cognitivos envolvidos requerem uma série de funções mentais: aquisição, armazenamento, retenção e uso do conhecimento. Envolvem memória (armazenamento das informações), função executiva (capacidade de planejamento, antecipação, sequenciamento e monitoramento de tarefas complexas), linguagem (capacidade de compreensão e expressão da linguagem escrita ou oral), praxia (capacidade de executar um ato motor), gnosia/percepção (capacidade de reconhecimento de estímulos visuais, auditivos e táteis) e função visuoespacial (capacidade de localização no espaço e percepção das relações dos objetos entre si). (Freitas; Aguiar, 2011; Moraes, 2012).

No processo do envelhecimento, o declínio e a estabilidade de diferentes funções cognitivas são afetados por diferenças interindividuais, que envolvem aspectos sociodemográficos, genéticos, de estilo de vida e de saúde física (Ribeiro et al., 2010).

Dodge et al. (2006) avaliaram as funções cognitivas (aprendizagem, evocação, funções visuoespacial e executiva, fluência, velocidade psicomotora e nomeação) e o desenvolvimento de dependência em idosos residentes em uma comunidade da Pensilvânia. Durante o seguimento por dez anos, classificaram o declínio no desempenho das AIVD em três categorias (sem declínio, declínio moderado e declínio grave). O declínio cognitivo, menor engajamento social e o aumento no número de medicamentos utilizados foram associados ao maior declínio funcional. Os autores concluíram ainda, que a velocidade psicomotora e nomeação foram os domínios com deterioração mais precoce, iniciando o declínio gradual das AIVDs até a morte.

Pressupõe-se assim, existir uma hierarquização do comprometimento do desempenho das AVDs com o transcorrer da vida, ou seja, a pessoa idosa irá apresentar, primeiramente, dificuldade no desempenho de atividades 
mais complexas e, gradativamente, irá apresentando comprometimento nas outras menos complexas. Observa-se no Quadro 3, que as AIVDs são consideradas mais complexas por necessitarem, para sua execução, múltiplas funções cognitivas como memória, função executiva e linguagem. Da mesma forma, também podem ser consideradas complexas, atividades como banhar-se, vestir-se e uso do banheiro por serem atividades influenciadas pela cultura e aprendizado. Transferir-se e alimentar-se podem ser consideradas mais simples, e por essa razão, o comprometimento em sua execução é postergado (Moraes, Lana, 2010; Moraes, 2012).

Paula et al (2014) corroboram essa hipótese ao identificar o início das perdas funcionais de idosos, com indícios quadros demenciais, pelas AIVD como administração e controle financeiro, preparo de refeições e realização de compras sozinho.

Quadro 3 - Habilidades cognitivas envolvidas no desempenho das atividades de vida diária.

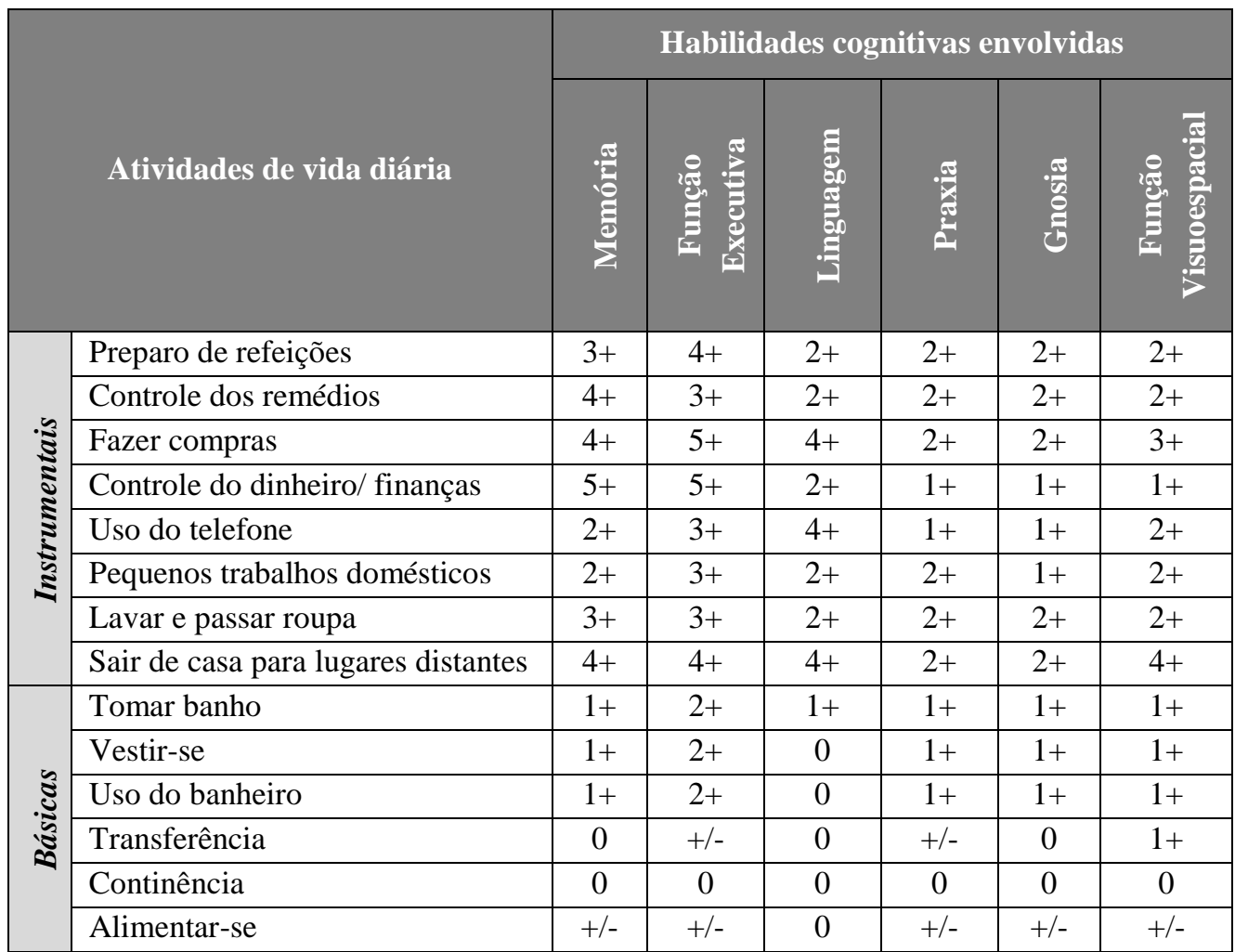

Nenhum; +/- Mais ou menos; 1+ Muito pouco; 2+ Pouco; 3+ Moderado; 4+ Intenso e 5+ Muito intenso

Fonte: Moraes, Lanna (2010). 
Inicialmente Katz et al. identificaram uma hierarquia no comprometimento das atividades básicas de vida diária (banhar-se, vestir-se, ir ao banheiro, transferir-se, ser continente e alimentar-se). Tal hipótese foi verificada a partir da semelhança da recuperação do desempenho funcional dessas atividades em idosos incapacitados à sequência observada no processo de desenvolvimento da criança. Também constataram ou, por meio de estudos antropológicos, a existência de similaridade entre essas funções e o comportamento das pessoas nas sociedades primitivas, o que sugeria que tais funções eram biológica e psicologicamente primárias, refletindo uma hierarquização das respostas neurológicas e locomotoras (Katz et al., 1963; Duarte, Andrade, Lebrão, 2007).

Outros autores corroboram a existência de uma hierarquia nas dificuldades no desempenho das atividades básicas de vida diária por meio de métodos matemáticos (Katz et al., 1963; Spector et al., 1987; Dunlop, Hughes, Manheim, 1997). Outros autores incluem as ABVDs e AIVDs na avaliação da hierárquica com intuito de identificar a gravidade da dependência e das necessidades do idoso em relação ao seu autocuidado e à participação em sua comunidade (Spector et al., 1987; Kempen, Suumeijer, 1990).

Siu, Reuben e Hays (1990) avaliaram a confiabilidade, utilidade e validade de quatro medidas hierárquicas de funcionalidade em 123 idosos atendidos em ambulatório. A maioria dos indivíduos foi totalmente independente nas escalas, no qual três delas apresentaram coeficientes limítrofes ou mais aceitáveis de escalabilidade.

Estudo canadense examinou as propriedades de medida de escalas de atividades básicas e instrumentais de vida diária utilizadas com idosos e encontraram uma estrutura multidimensional com três níveis de habilidade funcional. O primeiro nível engloba o autocuidado no qual o idoso apresenta dificuldade para ir ao banheiro, vestir, comer, transferir-se e realizar higiene pessoal; autocuidado intermediário, tomar banho, caminhar, tarefas domésticas, preparar refeições, fazer compras e realizar tarefas fora do domicílio; e, autogestão que inclui cuidar das finanças, usar telefone e tomar medicamentos. Por fim, os autores sugerem uma avaliação padrão de 
medição com intuito de reduzir o viés devido à complexidade do item e especificidade da tarefa (Thomas, Rockwood, McDowell, 1998).

Estudo longitudinal avaliou 617 idosos e observou as mudanças no comprometimento funcional ao longo do tempo buscando identificar o risco institucionalização. Os resultados demonstraram que idosos que necessitavam de assistência para preparar refeições ou chá, realizar tarefas domésticas leves e tomar banho apresentam maior risco para admissão em uma instituição de longa permanência (Finlaysona, Mallinsonb, Barbosac, 2005).

No Brasil, estudo transversal com idosos no município de São Paulo utilizou o escalonamento de Guttman para verificar a existência de hierarquização na apresentação de dificuldade de desempenho nas AVDs. Os resultados mostraram que os idosos perdiam inicialmente as habilidades para desempenho de AIVDs e posteriormente para as ABVDs na seguinte ordem: fazer compras, utilizar transporte, cuidar das finanças, manusear os medicamentos, incontinência, caminhar, vestir, tomar banho, comer, ir ao banheiro, levantar da cama para a cadeira (Ramos et al., 1993).

Ainda no município de São Paulo, um estudo de longitudinal avaliou o padrão de mudança da dificuldade de desempenho nas atividades cotidianas. No baseline em 2000, foram avaliados 2143 e encontraram o seguinte padrão dificuldades: ser continente, utilizar transporte, fazer compras, vestir-se, mobilizar-se, tomar o próprio medicamento, administrar as próprias finanças, tomar banho, locomover-se, ir ao banheiro e comer. Após dez anos de acompanhamento, observaram o aumento na proporção de todas as dificuldades referidas (Torres, 2009).

As atividades inicialmente comprometidas são as AIVDs que estão relacionadas com a participação social do idoso e manutenção de uma vida comunitária independente e, quando comprometidas, requerem uma reorganização familiar para auxiliar a pessoa idosa de forma intermitente. Quando esse comprometimento funcional evolui e atinge as ABVDs, um cuidador presencial passa a ser requerido (Paz, Santos, Eidt, 2006; Duarte, 2009). 
Diante disso, um dos desafios a ser enfrentado pelas políticas públicas é a provisão de cuidados para os próximos anos. Denomina-se cuidadores, as pessoas que cuidam de idosos com dependência, que podem ser familiares, agregados à família ou profissionais. Suas ações visam proporcionar uma melhor qualidade de vida à pessoa idosa a partir da prestação da melhor assistência possível (Duarte, 2009; Conceição, 2010).

Giacomin et al. (2005) verificaram que $23 \%$ dos idosos necessitavam de um cuidador em decorrência da presença de dificuldade no desempenho de atividades como comer, vestir-se, ir ao banheiro, banhar-se, levantar-se de uma cadeira sem apoio; e/ou presença de declínio cognitivo em idosos residentes no município de Bambuí.

Duarte et al. (2013) em estudo com 329 cuidadores de idosos residentes no município de São Paulo observaram que 91,3\% desses eram familiares, sendo $54,7 \%$ filhos e $75,6 \%$ eram do sexo feminino, confirmando ser a família a principal provedora de cuidados aos idosos.

A família é um sistema dinâmico que pretende ajudar a pessoa de forma afetiva, contribuindo de maneira significativa na manutenção e na integridade física e psicológica do indivíduo. Seu efeito é tido como benéfico, pelo membro da família que o recebe, à medida em que o suporte é percebido como disponível e satisfatório (Duarte, 2001).

A prestação de cuidados a um idoso pode, muitas vezes, exigir uma reestruturação na vida de seu cuidador, alterando costumes, rotinas, hábitos e até mesmo a natureza de sua relação com o idoso (Giraldo et al, 2005; Duarte et al., 2013). Essa reestruturação nem sempre ocorre de forma fácil, podendo ser acompanhada por sentimento de tensão, angustia e sobrecarga (Neri, Carvalho, 2011), o que pode levar o cuidador por um lado, ignorar suas próprias necessidades e, por outro, levar à negligência assistencial daqueles por quem são responsáveis.

A estrutura familiar tem sofrido alterações devido à redução da taxa de fecundidade e à inserção da mulher no mercado de trabalho. A redução do número de filhos, e as demandas familiares são crescentes, o que limita a disponibilidade dos pais de cuidar de seus filhos quanto dos filhos de cuidar de seus pais (Moraes, Caldas, 2014). O ato de cuidar ainda é visto como 
função feminina, pois, ao longo da história, a mulher não desempenhava funções fora de casa, cabendo a ela o cuidado do lar, das crianças e dos pais (Gonçalves, Silva, Pfeiffer, 1996). No entanto, essa realidade tem mudado com a inserção progressiva da mulher no mercado de trabalho, o que pode repercutir em um suporte de cuidados deficiente ao idoso.

Frente a essa questão, a prestação de cuidados aos idosos dependentes e o suporte apropriado aos cuidadores familiares, representam desafios para o sistema de saúde do Brasil, exigindo novas formas de assistência e novos enfoques por parte das políticas públicas de saúde (Karsch, 2003).

A incapacidade funcional é um indicador importante sobre saúde do idoso, que leva maior utilização dos serviços de saúde e institucionalização de longo prazo (Guralnik, Fried, Salive, 1996; Rodrigues et al., 2009)

O sistema e os profissionais de saúde ainda estão organizados para o atendimento ao cuidado agudo. As condições crônicas que necessitam de um manejo continuado, ainda necessitam de atenção, mesmo frente à transição de saúde (Mendes, 2011). Urge uma reorganização do modelo e da rede de atenção à saúde, que certamente, repercutirá nos custos dos sistemas e nos processos de trabalho dos serviços de saúde (Louvison, Rosa, 2012).

$\mathrm{O}$ envelhecimento populacional vem ao encontro dessa nova demanda reforçando-a, dado que os idosos tendem apresentar mais doenças e condições crônicas que demandam cuidados de longa duração.

Tais cuidados envolvem "apoio material, instrumental e emocional, formal ou informalmente oferecido por longo período às pessoas que o necessitam". Podem ser oferecidos no domicílio, na comunidade ou em instituições de longa permanência por meio de serviços públicos e/ou privados organizados para esse fim (Camarano, Mello, 2010). Embora o início da prestação desse tipo de serviços possa ser desencadeado por uma doença aguda, é a incapacidade de realizar atividades cotidianas, de forma independente, que gera a necessidade da continuidade dos cuidados (Moraes, Caldas, 2014).

Segundo Camarano e Mello (2010) o cuidado familiar pode ser complementado com uma oferta de pessoal qualificado para o cuidado 
direto ao idoso dependente nos seus domicílios. No Brasil, são escassas as políticas e os programas de cuidado formal domiciliar, embora a oferta dessa modalidade de serviço pelo setor público esteja prevista nas legislações pertinentes.

Os serviços comunitários, continua as autoras, ainda são escassos no Brasil, como por exemplo, os centros-dias que propiciam ao idosos independente e/ou semidependente ser adequadamente assistido durante o dia, retornando à noite para casa (Camarano, Mello, 2010).

Os serviços de Assistência Domiciliar (AD) surgiram em decorrência da necessidade de racionalizar o uso dos leitos hospitalares, evitar infecções, humanizar o atendimento, monitorar as doenças crônicas e reduzir os custos assistenciais (Duarte, Diogo, 2011).

Segundo determinação do Programa "Melhor em Casa" do Ministério da Saúde, a organização do AD se dá em três modalidades: AD1, $\mathrm{AD} 2$ e AD3, de acordo com grau de complexidade e frequência das visitas domiciliares necessárias para o cuidado a ser prestado (Brasil, 2011).

A modalidade AD1 envolve ações de promoção à saúde, prevenção de doenças e complicações, abrangendo assistência e reabilitação desenvolvidas no domicílio. A modalidade A2 envolve o conjunto de atividades de caráter ambulatorial, programadas e contínuas, por meio de ações preventivas e/ou assistenciais com a participação da equipe multiprofissional. Já a AD3 caracteriza a atenção em tempo integral para pacientes com quadros clínicos mais complexos e com necessidade de tecnologia especializada de recursos humanos, equipamentos, materiais, medicamentos, atendimento de urgência/emergência e transporte (Brasil, 2011, 2012).

Essas ações deverão ser desenvolvidas por um Serviço ou Programa de Assistência Domiciliar (SAD) que assumirá o gerenciamento e operacionalização da atenção requerida. Considera-se elegível a receber assistência domiciliar a pessoa que apresentar limitações funcionais em maior ou menor grau, temporária ou permanente. Será necessariamente o seu estado de saúde e sua necessidade de auxílio que determinarão o modelo assistencial mais adequado (Brasil, 2012). 
Os propósitos da assistência domiciliar vão ao encontro das políticas públicas e leis que priorizam o atendimento do idoso em seu ambiente, com objetivo de mantê-lo autônomo e independente em seu meio.

Em suma, os idosos requerem uma variedade de serviços de saúde que possam responder às suas necessidades, agudas ou crônicas. Doenças agudas, de maior gravidade e lesões estão mais relacionadas ao aumento da hospitalização, enquanto, os serviços ambulatoriais destinam-se ao gerenciamento contínuo de problemas de saúde agudos e crônicos (Young, 2003).

Os idosos tendem a utilizar mais os serviços de emergência/urgência. Em análise descritiva de 1647 indivíduos adultos que foram atendidos pelo serviço público de emergência de Pelotas (RS), 17,4\% dos indivíduos eram idosos ( $\geq 65$ anos). Entre esses, o principal diagnóstico identificado foi relacionado às condições crônicas do aparelho circulatório. Mais da metade deles retornou para casa após a consulta atual (Carret et al., 2011).

Os serviços de urgência/ emergência têm como característica o alto custo, bem como, na maioria das vezes, a falta de continuidade no atendimento, levando à baixa adesão ao tratamento e solicitação de exames complementares desnecessários (Stein, 1998). Estudo realizado por Oliveira (2008) apontou que os idosos tinham maiores chances de serem hiper utilizadores dos serviços de urgência e o motivo relatado pela procura do serviço foi o seu estado grave, embora no último ano anterior à entrevista tiveram acesso à consulta. A proporção de hospitalização entre os hiper utilizadores foi de 3,5\%, embora os idosos com mais de três visitas à unidade foram mais susceptíveis de internamento hospitalar. Nota-se que não há comunicação entre os prestadores de cuidados (atenção primária e urgência), ocasionando cuidados inadequados ou fragmentados $\mathrm{e}$ incoerentes e gera descontinuidade do cuidado no domicílio.

É sabido que os idosos consomem mais dos serviços de saúde, suas taxas de internação são bem mais elevadas e o tempo médio de permanência é muito maior quando comparados a qualquer outro grupo etário. A falta de serviços domiciliares e/ou ambulatoriais ou a dificuldade de acesso aos serviços faz com que o primeiro atendimento ocorra em estágios mais 
avançados das doenças, aumentando os custos e diminuindo as chances de prognóstico favorável. Uma vez que, dado o avanço da idade, há progressiva diminuição das reservas funcionais dificultando ou lentificando as respostas terapêuticas (Lima et al., 2009).

Não há uma articulação eficiente dentro do sistema de saúde (ambulatório e hospital) e de assistência social (instituições de longa permanência), funcionando com poucos pontos de atenção. Em geral, os pacientes entram nessa rede desarticulada num estágio muito avançado. A maioria dos casos, a porta de entrada se dá pela emergência do hospital. Além disso, o modelo está centrado no hospital com uso intensivo de tecnologias de alto custo, gerando sobrecarga de usuários nos níveis de maior complexidade, pela carência de cuidado nos primeiros níveis. Nota-se que o modelo atual é inadequado e anacrônico com uma péssima relação custo-benefício (Veras et al., 2013).

A solução para esse problema do SUS consiste em restabelecer integração entre as necessidades de cuidado com o sistema de atenção à saúde, que exige mudanças profundas no sistema fragmentado vigente a partir da implantação de redes de atenção à saúde (Mendes, 2008).

Os idosos com necessidade de cuidado requerem uma rede de suporte (família, serviços sociais e de saúde) para prover o cuidado de forma adequada e em longo prazo. No entanto, prioritariamente a rede de atenção às necessidades do idoso disponibilizada ainda é insuficiente para atender as demandas de todo esse grupo (Duarte et al., 2010).

Contudo, espera-se esse estudo possibilite o reconhecimento dos serviços de saúde utilizados pelos idosos de acordo com a necessidade de cuidado. A partir disso, guie os gestores na construção de uma linha de cuidado para assistir os idosos envolvendo a família e serviços de saúde e social disponibilizados, a fim de garantir uma melhor qualidade de vida durante o processo do envelhecimento. 
OBJETIVOS 


\section{OBJETIVO GERAL}

Analisar a necessidade de cuidado, a utilização dos serviços de saúde de idosos residentes no município de São Paulo e as mudanças associadas a essa necessidade ao longo do tempo.

\subsection{OBJETIVOS ESPECÍFICOS}

- Identificar a hierarquização do desempenho das dificuldades das atividades de vida diária dos idosos;

- Elaborar uma classificação para avaliação de necessidade de cuidados entre idosos;

- Identificar a prevalência de necessidade de cuidados e seus fatores associados em 2006;

- Descrever a ajuda recebida de acordo com os níveis de necessidade de cuidados em 2006;

- Relacionar a necessidade de cuidado e a utilização dos serviços de saúde em 2006;

- Analisar os fatores determinantes de mudança entre os níveis de cuidado em um período de quatro anos (2006-2010). 
MATERIAL E MÉTODOS 


\section{MATERIAL E MÉTODOS}

O presente estudo pode ser descrito como analítico, de base domiciliar, e utilizou a base de dados do Estudo SABE (Saúde, Bem estar e Envelhecimento) nos anos de 2006 e 2010.

\subsection{Estudo SABE}

O Estudo SABE 2000 (Saúde, Bem-estar e Envelhecimento) foi proposto e coordenado pela Organização Pan-Americana da Saúde (OPAS) caracterizando-se como um inquérito multicêntrico, epidemiológico, de base domiciliar com objetivo de traçar o perfil das condições de vida e saúde da população idosa de sete centros urbanos da América Latina e Caribe: Buenos Aires (Argentina), Bridgetown (Barbados), São Paulo (Brasil), Santiago (Chile), Havana (Cuba), Cidade do México (México) e Montevidéu (Uruguai) (Palloni; Peláez, 2003).

Os diferentes locais escolhidos para o desenvolvimento do estudo representavam, na época (2000), uma combinação dos vários estágios do envelhecimento na região. Argentina, Barbados, Cuba e Uruguai apresentavam estágios muito avançados do processo de envelhecimento, enquanto, Brasil, Chile e México estavam ligeiramente atrás dos precursores, podendo, no entanto, ultrapassar os primeiros devido à velocidade com que o processo de envelhecimento está ocorrendo nesses locais (Palloni; Peláez, 2003).

Em São Paulo, em 2000, a população do estudo foi constituída por 2.143 indivíduos (coorte A) não institucionalizados, com idade igual e superior a 60 anos, ambos os sexos, residentes em domicílios na área urbana. A amostra final foi composta por dois segmentos: o primeiro, resultante do sorteio, corresponde à amostra probabilística formada por 1.568 entrevistas. O segundo, formado por 575 residentes nos distritos em que se realizaram as entrevistas anteriores, corresponde ao acréscimo efetuado para compensar a mortalidade na população mais longeva $(\geq 75$ 
anos) e completar o número desejado de entrevistas nesta faixa etária. (Silva, 2003).

Os dados do Estudo SABE foram obtidos por meio de entrevista domiciliar com questionário específico realizada por equipe treinada. $\mathrm{O}$ questionário proposto pela OPAS foi traduzido e adaptado para o Brasil e apresenta onze seções (Quadro 4).

Quadro 4 - Seções e conteúdos do questionário utilizado no Estudo SABE, 2000.

\begin{tabular}{|cl|}
\hline Seções & \multicolumn{1}{c|}{ Conteúdo } \\
\hline A & Informações pessoais \\
B & Avaliação cognitiva \\
C & Estado de saúde \\
D & Estado funcional \\
E & Medicamentos \\
F & Uso e acesso a serviços \\
G & Rede de apoio familiar e social \\
H & História de trabalho e fontes de receita \\
J & Características de moradia \\
K & Antropometria \\
L & Flexibilidade, mobilidade e equilíbrio \\
\hline
\end{tabular}

Fonte: Lima, 2003. Disponível: www.fsp.usp.br/sabe

A obtenção dos dados foi realizada em duas etapas separadas:

1. Primeira etapa: seções A a J.

2. Segunda etapa: seções K e L.

Tal estratégia foi adotada, pois, na segunda etapa eram realizados testes de desempenho motor (flexibilidade, equilíbrio e força) e a antropometria podendo gerar um cansaço excessivo entre os entrevistados, comprometendo os resultados da entrevista.

Em 2006, o Estudo SABE tornou-se um estudo longitudinal, somente no município de São Paulo, tendo por objetivo verificar as alterações, com o passar do tempo, das condições de vida e de saúde dos idosos e seus fatores determinantes. Os idosos da coorte $\mathrm{A}_{00}$, entrevistados em 2000, foram revisitados e reavaliados. O instrumento de base foi revisto 
e atualizado aos propósitos do estudo sendo acrescentas as seções $\mathrm{M}$ (maus tratos) e N (avaliação da sobrecarga dos cuidadores).

Do total de 2.143 idosos avaliados em 2000, 1.115 foram localizados e reentrevistados, sendo definido neste momento como coorte $\mathrm{A}_{06}$. A diferença no número de entrevistados foi devido à ocorrência de óbitos, mudanças, institucionalizações, não localizações e recusas (Tabela 1). Também, nesse período, realizou-se um novo sorteio probabilístico $(\mathrm{n}=298)$, para a inclusão de uma nova coorte com indivíduos com idade entre 60 e 64 anos (coorte $\mathrm{B}_{06}$ ), totalizando neste ano, 1.413 idosos. Assim, o estudo SABE tornou-se um estudo longitudinal de múltiplas coortes (Figura 1).

Tabela 1 - Distribuição do número de idosos segundo o status. Município de São Paulo (SP), 2000-2010.

\begin{tabular}{lcccccc}
\hline Status do idoso & A00 & A06 & A10 & B06 & B10 & C10 \\
\hline Entrevistados & 2143 & 1115 & 685 & 298 & 216 & 355 \\
\hline \hline Óbitos & - & 649 & 268 & - & 13 & - \\
Recusas & 87 & 177 & 77 & 78 & 32 & 38 \\
Não localizados & - & 140 & 40 & - & 23 & - \\
Mudanças para outro município & - & 51 & 35 & - & 14 & - \\
Institucionalizações & - & 11 & 10 & - & - & - \\
\hline
\end{tabular}

Fonte: Estudo SABE, 2000-2010.

Dentro desta metodologia, no ano de 2010, os indivíduos das coortes A e B foram localizados para entrevista, totalizando 990 idosos. Novamente foi adicionada uma nova coorte de idosos com 60 a 64 anos de idade, chamada coorte $\mathrm{C}$, com uma amostra de 355 idosos. 
Figura 1 - Esquema das múltiplas coortes do Estudo SABE. 2000 a 2010.

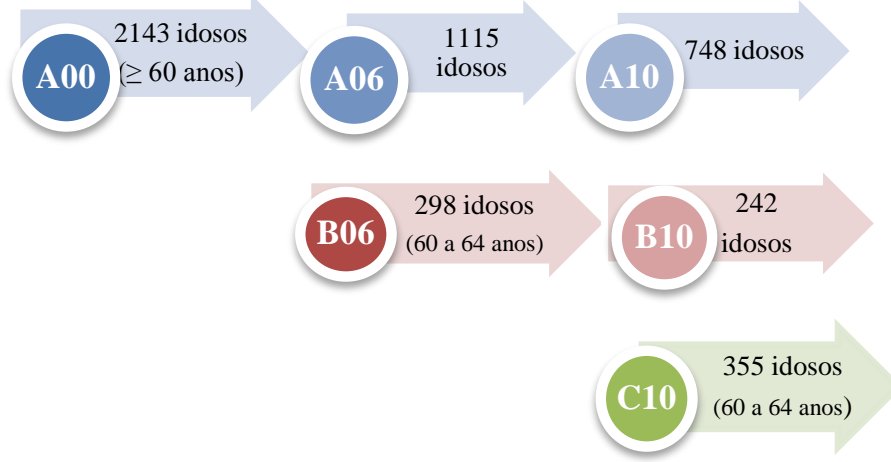

\subsection{Sujeitos}

A amostra do presente estudo foi composta pelos 1413 idosos $(\geq 60$ anos) das coortes A e B, participantes do Estudo SABE, nos anos de 2006 e 2010 .

\subsection{Delineamento do Estudo}

$\mathrm{O}$ estudo se divide em dois capítulos. O primeiro constitui seu baseline, cuja amostra foi composta pelos idosos entrevistados em 2006 onde foi construída a variável necessidade de cuidado e foram identificados os seus respectivos fatores associados.

No segundo capítulo, foi realizada uma análise longitudinal considerando a mudança nos níveis de cuidado buscando os fatores desencadeantes desse processo.

\subsection{Variáveis do Estudo}

\subsubsection{Variável dependente - Necessidade de cuidado}

Nesse estudo, "necessidade de cuidados" é definida como a demanda da pessoa idosa para a realização das AVDs devido à presença de comprometimento no seu desempenho funcional. 
Para avaliar o desempenho funcional do idoso utilizou-se o relato de dificuldade no desempenho das atividades básicas e instrumentais de vida diária. As ABVDs avaliadas foram: tomar banho, vestir-se, realizar higiene pessoal, ir ao banheiro, transferir-se, locomover-se, comer. As AIVDs foram preparar refeições, administrar a própria medicação, fazer compras, controlar o próprio dinheiro, usar o telefone, realizar tarefas domésticas leves e pesadas e utilizar meios de transporte. Optou-se por não incluir a "continência" como em outros estudos, porque isoladamente não implica obrigatoriamente, em um maior comprometimento funcional, podendo gerar um viés de análise (Guralnik, Simonsick, 1993; Moraes, 2012).

Partindo-se do pressuposto que há uma hierarquização do declínio funcional de tarefas mais complexas para as mais simples, desenvolveu-se o Escalonamento de Guttman, buscando verificar tal hierarquia ao desempenho funcional das pessoas idosas avaliadas (Guttman, 1950).

A construção desse escalonamento ocorre por meio de um ordenamento das respostas segundo a frequência de seu aparecimento. Trata-se de um método matemático desenvolvido por Louis Guttman, caracterizado por um escalonamento unidimensional, onde as respostas são determinadas por itens e ordenadas em um único entendimento. Assim, a resposta a um item selecionado incorpora a ideia da resposta a um item anterior a ele na escala. Caso essa resposta não siga a lógica de respostas esperada será classificada como “erro" (Guttman, 1950).

Ao hierarquizar a dificuldade no desempenho das AVDs, as respostas são organizadas de acordo com a proporção de dificuldade referida em ordem decrescente. Nesse sentido, um indivíduo que refere dificuldade em uma atividade posicionada no alto da escala, provavelmente não conseguirá realizar as atividades posicionadas níveis mais inferiores da escala (atividades com menores proporções de dificuldade). Da mesma maneira, se o indivíduo não apresenta dificuldade em níveis inferiores provavelmente conseguirá realizar as atividades posicionadas acima da atividade (Rosow; Breslaw, 1965; Ferrucci et al., 1998; Torres, 2009)

A partir desse pressuposto, foi desenvolvida a hierarquização das dificuldades referidas no desempenho das AVDs, cujo resultado se traduz 
em um retrato do comprometimento do estado funcional das pessoas idosas com repercussão direta na necessidade de auxílio de outra pessoa de acordo com a frequência para oferta desse cuidado.

Após a hierarquização das atividades classificaram-se os níveis de necessidade de cuidado. Para classificar os níveis, estabeleceu-se a frequência de ajuda que o idoso requererá quando houver dificuldade em realizá-la. No Quadro 5, notou-se que a maioria das AIVD não necessita ser realizadas diariamente, enquanto, atividades básicas como comer, ir ao banheiro apresentam uma frequência diária (IMSERSO, 2004; Alemanha, 2009).

A frequência de cuidado necessária das atividades comprometidas e do grau de comprometimento funcional. Idosos com dificuldades em ABVD como comer, tomar banho, locomover-se requerem a ajuda de um cuidador presencial devido às demandas exigidas por tais atividades. Já para fazer compras, por exemplo, pode haver uma reorganização da família no sentido de atender a essas demandas quando, não sendo necessária a presença de um cuidador em tempo integral.

Quadro 5 - Frequência de ajuda para realização das atividades de vida diária.

\begin{tabular}{|c|c|c|}
\hline \multicolumn{2}{|c|}{ Atividades de vida diária } & $\begin{array}{c}\text { Frequência da realização das } \\
\text { atividades }\end{array}$ \\
\hline \multirow{7}{*}{ 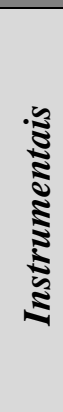 } & Realizar tarefas leves e pesadas & Pelo menos uma vez na semana \\
\hline & Cuidar das finanças & Pelo menos uma vez na semana \\
\hline & Utilizar transporte & Pelo menos uma vez na semana \\
\hline & Fazer compras & Pelo menos uma vez na semana \\
\hline & Utilizar telefone & Diário \\
\hline & Tomar medicamentos & Diário \\
\hline & Preparar refeições & Diário \\
\hline \multirow{7}{*}{ 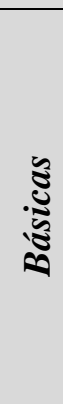 } & Tomar banho & Diário \\
\hline & Vestir-se & Diário \\
\hline & Ir ao banheiro & Diário \\
\hline & Transferência & Diário \\
\hline & Locomover-se & Diário \\
\hline & Realizar higiene pessoal & Diário \\
\hline & Alimentar-se & Diário \\
\hline
\end{tabular}

Fonte: Adaptado de Imserso (2004) e Alemanha (2009) 
Assim, a variável "necessidade de cuidados" foi subdividida em quatro categorias:

- Sem necessidade: o idoso não necessita de ajuda de outra pessoa para realizar suas atividades cotidianas.

- Necessidade mínima: o idoso necessita de ajuda para o desempenho algumas atividades esporadicamente e, portanto não requer um cuidador em tempo integral.

- Necessidade moderada: a pessoa idosa necessita de ajuda diária para realizar algumas atividades e requer a presença de um cuidador de forma intermitente, ou seja, não é necessária a presença do mesmo em tempo integral.

- Necessidade máxima: idoso necessita de um cuidador presencial permanente, ou seja, requer sua presença de forma integral.

A mudança da necessidade de cuidados, no período de quatro anos, foi avaliada em dois momentos:

- idosos sem necessidade de cuidado, no baseline (2006), que evoluíram para necessidade mínima, moderada e máxima em 2010;

- idosos classificados, no baseline (2006), com alguma necessidade de cuidado (mínima, moderada e máxima). E, após quatro anos, verificou-se se melhoraram ou pioraram entre os níveis de cuidados estabelecidos. Nesse último momento, considerou-se a piora entre os níveis de cuidado sendo a variável categorizada em sim e não (idoso que permaneceu na mesma condição ou mudou de posição para uma com menos demanda assistencial).

\subsubsection{Variáveis independentes}

Foram utilizadas as seguintes variáveis para a investigação da associação entre necessidade de cuidado.

- Socioeconômicas: insuficiência de renda (sim e não); escolaridade em anos de estudo (analfabeto; 1 a 3 anos; 4 a 7 anos; 8 anos e mais); vulnerabilidade social (segundo Índice Paulista de Vulnerabilidade 
Social); engajamento social; funcionalidade familiar (segundo o APGAR de Família).

A vulnerabilidade social foi avaliada pelo Índice Paulista de Vulnerabilidade Social (IPVS). Trata-se de um indicador elaborado pela Fundação Seade e retrata o fenômeno da pobreza, no qual não considera apenas a renda, mas outros fatores determinantes da situação de vulnerabilidade social (escolaridade, saúde, arranjo familiar, possibilidades de inserção no mercado de trabalho, acesso a bens e serviços públicos). Esse indicador foi construído a partir de informações socioeconômicas e demográficas existentes no banco de dados do Censo Demográfico. Nova versão do IPVS foi realizada com dos dados do Censo Demográfico do ano de 2010, sendo revisadas as classificações do índice, no entanto, possibilita a comparação com a versão anterior (Fundação Seade, 2013).

Para esse estudo, utilizou-se o IPVS versão 2000 vigente no período da coleta de dados do baseline (2006). Primeiramente, identificaram-se os setores censitários através dos endereços dos idosos. Em seguida, foi realizada a consulta ao mapa do IPVS, com o Índice Paulista de Vulnerabilidade Social atribuído àquele setor censitário (Figura 2). Assim, os idosos foram classificados da seguinte forma:

- Grupo 1 - Nenhuma Vulnerabilidade: engloba os setores censitários em melhor situação socioeconômica (muito alta), com os responsáveis pelo domicílio possuindo os mais elevados níveis de renda e escolaridade. Apesar de o estágio das famílias no ciclo de vida não ser um definidor do grupo, seus responsáveis tendem a ser mais velhos, com menor presença de crianças pequenas e de moradores nos domicílios, quando comparados com o conjunto dos outros setores.

- Grupo 2 - Vulnerabilidade Muito Baixa: abrange os setores censitários que se classificam a dimensão socioeconômica (média ou alta), onde se concentram, em média, as famílias mais velhas.

- Grupo 3 - Vulnerabilidade Baixa: formado pelos setores censitários que se classificam nos níveis altos ou médios da dimensão socioeconômica e seu perfil demográfico caracteriza-se pela predominância de famílias jovens e adultas. 
- Grupo 4 - Vulnerabilidade Média: composto pelos setores que apresentam níveis médios na dimensão socioeconômica, estando em quarto lugar na escala em termos de renda e escolaridade do responsável pelo domicílio. Nesses setores concentram-se famílias jovens, isto é, com forte presença de chefes jovens (com menos de 30 anos) e de crianças pequenas.

- Grupo 5 - Vulnerabilidade Alta: engloba os setores censitários que possuem as piores condições na dimensão socioeconômica (baixa), estando entre os dois grupos em que os chefes de domicílios apresentam, em média, os níveis mais baixos de renda e escolaridade. Concentra famílias mais velhas, com menor presença de crianças pequenas.

- Grupo 6 - Vulnerabilidade Muito Alta: o segundo dos dois piores grupos em termos da dimensão socioeconômica (baixa), com grande concentração de famílias jovens. A combinação entre chefes jovens, com baixos níveis de renda e de escolaridade e presença significativa de crianças pequenas permite inferir ser este o grupo de maior vulnerabilidade à pobreza.

Figura 2 - Distribuição dos setores censitários de acordo com os índices de vulnerabilidade social. São Paulo, 2000.

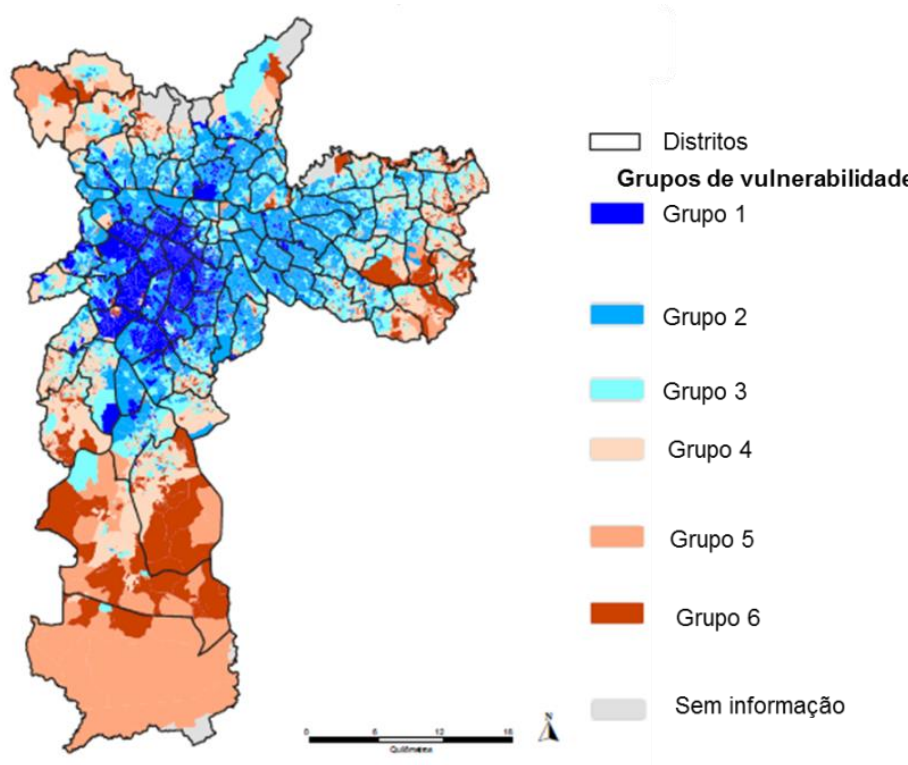

Fonte: Fundação Seade, 2000.

Disponível em: http://www9.prefeitura.sp.gov.br/sempla/mm/mapas/indice6_1.pdf 
Com intuito de verificar diferenças entre os grupos sem vulnerabilidade e com vulnerabilidade baixa e alta vulnerabilidade, reagruparam-se em três categorias (Maia, 2011): 1) sem vulnerabilidade; 2) vulnerabilidade muito baixa/baixa; 3) vulnerabilidade média/alta/muito alta (Quadro 6).

Quadro 6 - Classificação dos grupos de vulnerabilidade social e classificação adotada no estudo.

\begin{tabular}{|c|c|}
\hline Grupo de vulnerabilidade & $\begin{array}{c}\text { Classificação adotada no } \\
\text { estudo }\end{array}$ \\
\hline Grupo 1: nenhuma vulnerabilidade & Jenhuma vulnerabilidade \\
\hline $\begin{array}{l}\text { Grupo 2: vulnerabilidade muito } \\
\text { baixa } \\
\text { Grupo 3: vulnerabilidade baixa }\end{array}$ & $\begin{array}{l}\text { Vulnerabilidade muito baixa/ } \\
\text { baixa }\end{array}$ \\
\hline $\begin{array}{l}\text { Grupo 4: vulnerabilidade média } \\
\text { Grupo 5: vulnerabilidade alta } \\
\text { Grupo 6: vulnerabilidade muito } \\
\text { alta }\end{array}$ & $\begin{array}{c}\text { Vulnerabilidade } \\
\text { média/alta/muito alta }\end{array}$ \\
\hline
\end{tabular}

Fonte: Adaptado de Fundação SEADE, 2000.

A variável "engajamento social" foi construída considerando as seguintes atividades: a) mantém contato com outras pessoas por meio de cartas, telefone ou e-mail; b) realiza visitas a familiares e amigos; convida pessoas para ir à sua casa; c) sai com outras pessoas para lugares públicos; d) participa de atividades organizadas. As respostas para as questões eram: 1 = sempre, $2=$ frequentemente, $3=$ ocasionalmente, $4=$ raramente, $5=$ nunca. Idosos que responderam " 1 ", “2" e "3" em pelo menos uma das perguntas pontuavam positivamente para o engajamento social.

A funcionalidade familiar foi avaliada pelo APGAR de Família. Este teste de "screening" é composto por cinco domínios (adaptação, companheirismo, desenvolvimento, afetividade e capacidade resolutiva) que resultam em um escore que classifica a funcionalidade familiar (boa funcionalidade, moderada ou alta disfuncionalidade). Os escores de 0 a 8 classificam a família como de elevada disfunção familiar; de 9 a 12, 
moderada disfunção familiar e de 13 a 20, boa funcionalidade familiar (Duarte, 2001). Nesse estudo, as categorias moderada e elevada foram consideradas como "disfunção familiar".

- Demográficas: sexo, idade (contínua e categórica), estado marital (com companheiro e sem companheiro), morar sozinho (sim e não).

- Condicões de saúde do idoso: declínio cognitivo; sintomas depressivos; autoavaliação da saúde (ótima/boa, regular, ruim/muito ruim); doenças crônicas (hipertensão arterial, diabetes, doença pulmonar obstrutiva crônica, doença cardiovascular, doença cerebrovascular, doença osteoarticular e osteoporose); multimorbidade; polifarmácia; mobilidade física; fragilidade e relato de queda no último ano.

O declínio cognitivo foi avaliado usando a versão modificada do Mini Exame do Estado Mental (MEEM) validada por Icaza e Albala (1999) devido ao baixo nível de escolaridade da população idosa brasileira. Esse instrumento tem 13 itens que não dependem de escolaridade e totalizam 19 pontos, sendo 12 ou menos o ponto de corte.

A presença de sintomas depressivos foi avaliada pela Escala de Depressão Geriátrica, versão breve (15 itens) da escala original elaborada por Sheikh e Yesavage (1986), a partir dos itens que mais fortemente se correlacionavam com o diagnóstico de depressão. Essa versão reduzida apresenta boa acurácia para rastreamento dos transtornos de humor em ambulatórios gerais. No Brasil essa escala foi aplicada por Almeida e Almeida (1999). Para este estudo, o ponto de corte adotado foi semelhante ao proposto pelos autores (ponto de corte $>5$ ).

Multimorbidade foi definida pela presença simultânea de duas ou mais doenças crônicas (Van Den Akker, Buntinx, Knottnerus, 1996). Considerou-se polifarmácia, o consumo de cinco ou mais medicamentos (Secoli, 2010; Carvalho et al., 2012).

A mobilidade foi avaliada por meio do equilíbrio, força, marcha e resistência, através do Short Physical Performance Battery Assessing Lower Extremity Function (Guralnik et al., 1994). O resultado dessa performance é resultante de três testes: caminhada de três metros no ritmo usual, levantar e sentar da cadeira cinco vezes mais rapidamente possível, com os braços 
cruzados na frente do peito, equilíbrio em pé com os pés juntos ou um à frente do outro. Os testes recebem pontuação de 0 (não conseguiu fazer) a 4 (melhor performance), e a soma dos três compõe a pontuação final (que varia de 0 a 12 pontos), classificada como: desempenho bom ou moderado (7 a 12 pontos) e desempenho baixo ou muito ruim (0 a 6 pontos mobilidade física prejudicada).

A síndrome de fragilidade foi identificada pelo fenótipo proposto por Fried et al (2001). Este fenótipo envolve cinco componentes: 1) perda de peso não intencional; 2) fadiga autorreferida; 3) redução na força de preensão palmar; 4) baixo nível de atividade física; 5) diminuição da velocidade de caminhada. Idosos que apresentarem um ou dois componentes do fenótipo serão considerados pré-frágeis e aqueles com três ou mais componentes, frágeis.

- Perda de peso não intencional: foi utilizada uma pergunta subjetiva ("no último ano, o sr (a) perdeu três ou mais quilos de peso sem fazer dieta?"). Se sim, pontuava-se neste componente.

- Fadiga referida: Obtido por meio de duas questões do Center Epidemiological Studies - Depression (CES-D), validado para idosos brasileiros (Batistoni, Neri, Cupertino, 2007): (a) "Com que frequência, na última semana, o (a) $\mathrm{Sr}$ (a) sentiu que tudo que fez exigiu um grande esforço?"; (b) "Com que frequência, na última semana, o (a) Sr (a) sentiu que não conseguia levar adiante as suas coisas?" As respostas para ambas as questões eram: $0=$ raramente ou nenhum tempo $(<1$ dia $), 1=$ alguma parte do tempo (1-2 dias), 2= uma parte moderada do tempo (3-4 dias), ou 3=o todo tempo. Idosos que responderam "2" ou " 3 " em pelo menos uma das duas perguntas pontuavam positivamente para o componente.

- Redução na força: A força de preensão manual foi mensurada por meio do dinamômetro. Pontuaram para este componente os idosos no quintil mais baixo de distribuição, estratificado por sexo e quartil do índice de massa corporal (Quadro 7).

- Baixa velocidade de caminhada: Obtida pelo teste de caminhada de três metros, parte do Short Physical Performance Battery Assessing Lower Extremity Function (Guralnik et al., 1994). Pontuaram para este 
componente os idosos que estiveram no maior quintil da distribuição, estratificados por sexo e pelo valor mediano da estatura (Quadro 7).

- Baixo nível de atividade física: Identificada pela versão curta (traduzida) do International Physical Activity Questionnaire - IPAQ (Benedetti, Mazo, Barros, 2004; Benedetti et al., 2007), que avalia três tipos específicos de atividades: caminhada, atividades de intensidade moderada e vigorosa, abrangendo a realização de atividades físicas de lazer, domésticas e/ou de trabalho onde é obtida uma estimativa do dispêndio calórico semanal (kcal). Pontuaram para este componente os idosos no menor quintil de gasto calórico, estratificado por sexo (Quadro 7).

Quadro 7- Pontos de corte adotados para operacionalização do fenótipo de fragilidade. Estudo SABE. São Paulo, 2006.

\begin{tabular}{|c|c|}
\hline Componentes & Definição Operacional \\
\hline Redução da força & $\begin{array}{l}20 \% \text { com menores valores na força de preensão } \\
\text { manual, segundo sexo e IMC }\left(\mathrm{kg} / \mathrm{m}^{2}\right): \\
\frac{\text { Homens }}{\text { - }} \text { Força } \leq 14,0 \mathrm{~kg} \text { para IMC } \leq 23,1 \mathrm{~kg} / \mathrm{m}^{2} \\
\text { - } \text { Força } \leq 17,0 \mathrm{~kg} \text { para IMC } 23,2-25,5 \mathrm{~kg} / \mathrm{m}^{2} \\
\text { - Força } \leq 20,0 \mathrm{~kg} \text { para IMC } 25,6-28,1 \mathrm{~kg} / \mathrm{m}^{2} \\
\text { - Força } \leq 23 \mathrm{~kg} \text { para IMC }>28,1 \mathrm{~kg} / \mathrm{m}^{2} \\
\text { Mulheres } \\
\text { - Força } \leq 14,0 \mathrm{~kg} \text { para IMC } \leq 23,8 \mathrm{~kg} / \mathrm{m} 2 \\
\text { - Força } \leq 17,0 \mathrm{~kg} \text { para IMC } 23,9-27,1 \mathrm{~kg} / \mathrm{m} 2 \\
\text { - Força } \leq 20,0 \mathrm{~kg} \text { para IMC } 27,2-30,8 \mathrm{~kg} / \mathrm{m} 2 \\
\text { - Força } \leq 23,0 \mathrm{~kg} \text { para IMC }>30,8 \mathrm{~kg} / \mathrm{m} 2\end{array}$ \\
\hline $\begin{array}{l}\text { Baixa velocidade } \\
\text { de caminhada }\end{array}$ & $\begin{array}{l}\frac{\text { Homens }}{\bullet \quad>5,0 \text { segundos para altura } \leq 1,66 \mathrm{~m}} \\
\cdot>5,0 \text { segundos para altura }>1,66 \mathrm{~m} \\
\text { Mulheres } \\
\quad>6,0 \text { segundos para altura } \leq 1,53 \mathrm{~m} \\
\cdot \quad>5,0 \text { segundos para altura }>1,53 \mathrm{~m}\end{array}$ \\
\hline $\begin{array}{l}\text { Baixo nível de } \\
\text { atividade física }\end{array}$ & $\begin{array}{l}20 \% \text { com menor gasto calórico, segundo sexo } \\
\text { Homens } 390,5 \mathrm{kcal} \\
\text { Mulheres } 478,1 \mathrm{kcal}\end{array}$ \\
\hline
\end{tabular}

Considerou-se "não frágil" o idoso que não apresentava qualquer dos cinco componentes do fenótipo, "pré-frágil" o que apresentava um ou dois componentes, e "frágil" o idoso que apresentava de três a cinco 
componentes (Fried et al., 2001). Criou-se também uma nova variável denominada "processo de fragilização", onde foram agrupados idosos préfrágeis e frágeis, a fim de detectar a magnitude dessa síndrome.

- Auxílio de outra pessoa para as demandas de cuidado: A variável foi construída a partir do relato dos idosos sobre o recebimento de ajuda de outra pessoa para auxiliá-lo na realização das AVDs para as quais referiram dificuldade em fazê-lo.

Para os cuidadores familiares, avaliou-se a presença de "sobrecarga", por meio da Escala Zarit Burden Interview (ZBI). A escala permite avaliar a sobrecarga objetiva e subjetiva do cuidador informal e inclui informações sobre saúde, vida social, vida pessoal, situação financeira, situação emocional e tipo de relacionamento. $\mathrm{O}$ instrumento é composto por 22 itens, sendo cada um pontuado de forma qualitativa/quantitativa: $1=$ nunca; $2=$ raramente; 3 = algumas vezes; $4=$ frequentemente; e, $5=$ sempre. Obtém-se um escore global que varia entre 22 e 110, onde um maior escore corresponde a uma maior percepção de sobrecarga (Scazufca, 2002).

- Plano de saúde, acesso e utilizacão dos servicos de saúde: presença de plano de saúde, dificuldade no acesso aos serviços de saúde e a utilização dos serviços. Considerou-se utilização dos serviços de saúde a referência do uso dos mesmos nos 12 meses anteriores à entrevista. Os serviços de saúde avaliados foram: consultas médicas, serviços de urgência/emergência e internação hospitalar (Quadro 8).

Quadro 8 - Variáveis utilizadas para avaliar os serviços de saúde no Estudo SABE.

\begin{tabular}{|c|c|}
\hline Variáveis & Descrição no questionário do Estudo SABE \\
\hline édica & $\begin{array}{l}\text { Com relação ao seu último atendimento, com quem o(a) } \\
\text { Sr(a) o realizou? Considerou-se a resposta "médico". }\end{array}$ \\
\hline Internação hospitalar & $\begin{array}{l}\text { Durante os últimos } 12 \text { meses, quantas vezes diferentes } \\
\text { esteve internado, pelo menos uma noite (excluindo em } \\
\text { casa de repouso)? }\end{array}$ \\
\hline $\begin{array}{l}\text { Serviços de urgência/ } \\
\text { emergência }\end{array}$ & $\begin{array}{l}\text { Quantas vezes, nos últimos } 12 \text { meses, o(a) } \operatorname{Sr}(a) \\
\text { necessitou de atendimento de urgência/emergência pelo } \\
\text { mesmo motivo? }\end{array}$ \\
\hline
\end{tabular}


Para a descrição da dificuldade referida de acesso aos serviços de saúde apontaram-se os motivos do "não acesso". Quanto aos serviços de urgência/emergência descreveu-se o tempo do último acesso e o encaminhamento após o atendimento.

É sabido que os idosos podem utilizar mais de um serviço de saúde no período de um ano. A partir disso, construiu-se uma variável de utilização de serviços de saúde que considerou todos os serviços utilizados pelos idosos e foi classificada da seguinte forma:

- Cons =Utilizou somente a consulta médica (Cons);

- Urg = Utilizou somente os serviços de urgência/emergência;

- Int = Utilizou somente a internação hospitalar;

- Cons + Urg $=$ Utilizou a consulta médica e serviços de urgência/emergência;

- Cons + Int = Utilizou a consulta médica e a internação;

- Urg+Int = Utilizou os serviços de urgência/emergência e a internação;

- Cons+Urg+Int = Utilizou a consulta médica, serviços de urgência/emergência e a internação;

- Não cons+Urg+Int = Não utilizou nenhum dos serviços de saúde.

\subsection{Análise dos Resultados}

A relação hierárquica das atividades foi avaliada em dois passos. $\mathrm{O}$ primeiro passo determinou se as atividades estavam relacionadas entre si por meio da consistência interna. A consistência interna foi obtida pelo Coeficiente Alfa de Cronbach, adotando-se como referência valores de alfa entre 0,70 e 0,90 para representar consistência interna considerada "boa". Valores abaixo de 0,70 determinam uma consistência interna "fraca", e valores acima de 0,90 indicam uma concordância "excessivamente alta", decorrente, possivelmente, da redundância dos itens (Streiner; Norman, 2003). 
O segundo passo foi testar a hierarquia das atividades de vida diária usando o Escalonamento de Guttman e obtiveram-se três índices:

- Coeficiente de Reprodutibilidade (CR): mede o grau de adequação da distribuição dos itens da escala em relação aos padrões de uma escala ideal. O CR é calculado a partir do número total de erros e do total de respostas apresentados pelos indivíduos. Considera-se erro, as respostas apresentadas pelos indivíduos que não condizem com o padrão de respostas condizente aos pressupostos do escalonamento.

$$
\text { Coeficiente de Reprodutibilidade }(C R)=1-\frac{\text { Total de erros }}{\text { Total de respostas }}
$$

Estabeleceram-se como um CR desejável valores superiores a 0,90 (90\%) e um erro igual ou menor que 0,10 . Caso a escala apresente valores inferiores aos estabelecidos por Guttman (1950), supõe-se que a escala não aceita a lógica da hierarquia.

- Reprodutibilidade Marginal Mínima (Minimal Marginal Reproducibility - MMR): esse cálculo mede o pior coeficiente de reprodutibilidade, ou seja, quando todos os indivíduos apresentassem erros em todas as questões. A MMR é calculada a partir do total de erros em cada item (cada atividade) e pelo total de respostas em cada item, sendo, considerada um qualificador do CR.

$$
M M R=1-\frac{\text { Total de erros em cada item }}{\text { Total de respostas em cada item }}
$$

- Coeficiente de escalabilidade (CE): é uma medida do máximo por cento da reprodutibilidade associado à escalabilidade após o ajuste da assimetria dos dados. Coeficientes com valores a partir de 0,60 ( $\geq 60 \%)$ representam a melhor leitura da realidade por meio da ordenação proposta por Guttman (1950).

$$
C E=\frac{\mathrm{CR}-\mathrm{MMR}}{100-\mathrm{MMR}}
$$


Para a análise descritiva dos dados foram estimadas distribuições de frequências relativas, médias e erros-padrão para as variáveis contínuas do estudo. Para as variáveis categóricas, foram estimadas as proporções. As diferenças entre as médias foram testadas pelo Teste Wald e, entre as proporções foram testadas pelo teste do $\chi^{2}$ de Pearson, com a correção de Rao-Scott, levando em consideração os pesos amostrais para estimativas com ponderações populacionais (Rao, Scott, 1984).

Para avaliar os fatores associados à necessidade de cuidado (análise transversal) e os fatores determinantes da necessidade de cuidado (análise longitudinal) utilizou-se a Regressão Logística Multinomial Múltipla. Para avaliar os fatores determinantes da piora da necessidade de cuidado (variável dicotômica) utilizou-se a Regressão Logística Múltipla. Foram selecionadas para cada modelo múltiplo, as variáveis que obtiveram um valor p menor a 0,20 na análise univariada. As variáveis foram mantidas no modelo quando apresentou um valor p menor ou igual a 0,05 ou quando houve mudanças na razão de risco relativo ou na razão de chances ajustadas maiores de $10 \%$.

A amostra deste estudo é representativa do município de São Paulo, por isso, foram atribuídos pesos amostrais a cada indivíduo nas análises. Adotou-se como nível de significância para os testes um valor de $\mathrm{p}<0,05$. O processamento dos dados do Escalonamento de Guttman foi realizado no software Statistical Package for the Social Sciences for Windows-SPSS $20.0{ }^{\circledR} \mathrm{e}$, as outras análises dos dados foram realizadas no pacote estatístico Stata® versão 11 .

\subsection{Aspectos Éticos}

O Estudo SABE de 2000 foi submetido e aprovado pela Comissão Nacional de Ética em Pesquisa (CONEP) em 17 de junho de 1999. A segunda onda (2006) foi submetida ao Comitê de Ética em Pesquisa (COEP) da Faculdade Saúde Pública da Universidade de São Paulo e aprovada em 14 de março de 2006 e a terceira onda (2010) foi aprovada em 5 de março 
de 2010, pelo Comitê de Ética em Pesquisa (COEP) da Faculdade Saúde Pública da Universidade de São Paulo (pareceres no 315/99, no 83/06 e n 2044/10, respectivamente). 
RESULTADOS

(2) 


\section{RESULTADOS}

\subsection{CARACTERIZAÇÃO DA AMOSTRA}

A amostra desse estudo foi constituída por 1413 idosos residentes no Município de São Paulo avaliados no ano de 2006. Nessa população, 59,4\% eram do sexo feminino, $58,7 \%$ tinham entre 60 a 69 anos, 57,4\% referiram a presença de companheiro(a), 38,6\% referiram ter quatro a sete anos de escolaridade, $55,1 \%$ relataram não ter renda suficiente para as suas necessidades, $86,8 \%$ não residiam sozinhos, $91 \%$ apresentavam engajamento social ativo, 65,2\% apresentaram vulnerabilidade social muito baixa/baixa e $88,9 \%$ referiram boa funcionalidade familiar (Tabela 2).

Tabela 2 - Distribuição (\%) dos idosos segundo características socioeconômicas e demográficas. Município de São Paulo. Estudo SABE, 2006. $(\mathrm{n}=1413)$ (continua)

\begin{tabular}{lc}
\hline Características & \% \\
\hline Sexo & \\
$\quad$ Homem & 40,6 \\
$\quad$ Mulher & 59,4 \\
Idade &
\end{tabular}

60 a 69 anos $\quad 58,7$

70 a 79 anos 30,1

80 anos e mais $\quad 11,2$

Idade (média $\pm \mathrm{EP}$ ) $\quad 69,6 \pm 0,6$

Estado marital

Com companheiro (a) $\quad 57,4$

Sem companheiro (a) $\quad 42,6$

Escolaridade (em anos de estudo)

Analfabeto

1 a 3 anos

26,5

4 a 7 anos

38,6

8 anos e mais

19,2

Vulnerabilidade social

Sem vulnerabilidade $\quad 12,0$

Vulnerabilidade muito baixa/baixa $\quad 65,2$

Vulnerabilidade média/alta/muito alta $\quad 22,8$

Insuficiência de renda

$\begin{array}{lr}\text { Não } & 55,1 \\ \text { Sim } & 44,9\end{array}$


(continuação)

\begin{tabular}{|c|c|}
\hline Características & $\%$ \\
\hline \multicolumn{2}{|l|}{ Mora sozinho } \\
\hline Não & 86,8 \\
\hline Sim & 13,2 \\
\hline \multicolumn{2}{|c|}{ Engajamento social } \\
\hline Não & 9,0 \\
\hline Sim & 91,0 \\
\hline \multicolumn{2}{|c|}{ Funcionalidade familiar } \\
\hline Funcional & 88,9 \\
\hline Disfuncional & 11,1 \\
\hline
\end{tabular}

Entre os idosos avaliados as doenças referidas mais prevalentes foram hipertensão arterial $(62,7 \%)$ e doença osteoarticular $(33,1 \%)$. Mais da metade da população relatou a presença simultânea de duas ou mais doenças crônicas $(55,0 \%)$ e realizaram pelo menos uma consulta no último ano (81,5\%). Parte dos idosos apresentou declínio cognitivo (12,2\%), sintomas depressivos $(14,3 \%)$ e síndrome de fragilidade $(8,5 \%) ; 14,6 \%$ utilizaram serviços de urgência/emergência e 9,6\% foram hospitalizados nos 12 meses anteriores à entrevista (Tabela 3).

Tabela 3 - Distribuição (\%) dos idosos segundo condições de saúde e utilização dos serviços de saúde. Município de São Paulo, 2006. $(n=1413)$

(continua)

\begin{tabular}{lc}
\hline Características & \% \\
\hline Declínio cognitivo & 87,8 \\
Não & 12,2 \\
Sim & \\
Sintomas depressivos & 85,7 \\
$\quad$ Não & 14,3 \\
Sim & \\
Autoavaliação de saúde & 44,7 \\
Excelente/muito boa/boa & 46,5 \\
Regular & 8,8 \\
Ruim/muito ruim & \\
Autorrelato de doenças crônicas (sim) & 62,7 \\
Hipertensão & 21,1 \\
Diabetes & 12,0 \\
Doença pulmonar obstrutiva crônica & 22,2
\end{tabular}


(continuação)

\begin{tabular}{|c|c|}
\hline Características & $\%$ \\
\hline Doença cerebrovascular & 8,3 \\
\hline Doença osteoarticular & 33,1 \\
\hline Osteoporose & 22,3 \\
\hline \multicolumn{2}{|l|}{ Multimorbidade } \\
\hline Não & 45,0 \\
\hline Sim & 55,0 \\
\hline \multicolumn{2}{|l|}{ Polifarmácia } \\
\hline Não & 65,3 \\
\hline Sim & 34,7 \\
\hline \multicolumn{2}{|l|}{ Fragilidade } \\
\hline Não frágil & 50,0 \\
\hline Pré-frágil & 41,5 \\
\hline Frágil & 8,5 \\
\hline \multicolumn{2}{|c|}{$\begin{array}{l}\text { Utilização dos serviços de saúde (12 } \\
\text { meses anteriores à entrevista) }\end{array}$} \\
\hline Consulta médica & 81,5 \\
\hline Serviços de urgência/emergência & 14,6 \\
\hline Hospitalização & 9,6 \\
\hline
\end{tabular}

\section{2 NECESSIDADE DE CUIDADO}

Nessa primeira etapa dos resultados avaliaram-se os idosos no ano de 2006. Primeiramente, classificaram-se os níveis de cuidado, em seguida, identificaram-se os fatores associados, o recebimento de ajuda e a utilização dos serviços de saúde.

\subsubsection{Classificação da necessidade de cuidado}

O primeiro passo, para o Escalonamento de Guttman, foi identificar se as atividades relacionavam entre si por meio da consistência interna, e encontrou índice satisfatório $(\alpha=0,92)$.

Entre esses idosos avaliados, a hierarquia da proporção da dificuldade nas atividades cotidianas foi: realizar tarefas domésticas pesadas $(28,8 \%)$, administrar as próprias finanças $(25,0 \%)$, utilizar transporte $(22,7 \%)$, fazer compras $(17,4 \%)$, realizar tarefas leves $(13,2 \%)$, utilizar o telefone $(12,4 \%)$, tomar o próprio medicamento $(11,3 \%)$, vestir $(9,1 \%)$, 
transferir-se $(8,8 \%)$, preparar refeição $(7,2 \%)$, tomar banho $(6,2 \%)$, ir ao banheiro $(5,8 \%)$, realizar higiene pessoal $(4,6 \%)$, locomover-se $(3,6 \%)$ e comer $(2,9 \%)$ (Gráfico 1).

Gráfico 2 - Distribuição (\%) dos idosos segundo a presença das dificuldades nas atividades de vida diária de idosos. Município de São Paulo, 2006. (n=1413).

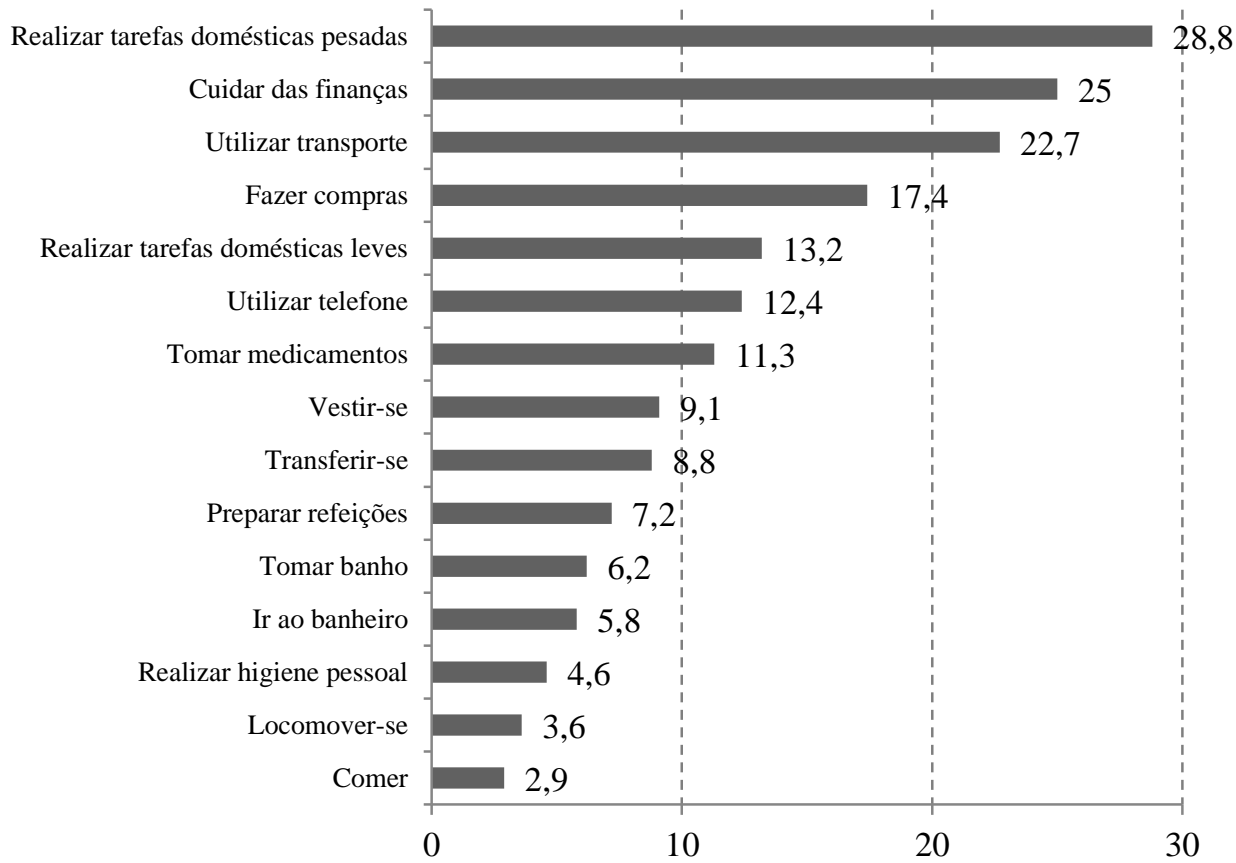

Fonte: Estudo SABE, 2006.

Essa escala apresentou um coeficiente de reprodutibilidade (CR) igual a 98\%, uma probabilidade de erro de $2 \%$, um coeficiente de escalabilidade de 0,84 e reprodutibilidade mínima marginal de 0,87. Segundo esse escalonamento, uma dificuldade posicionada em determinado nível, implica que, com $98 \%$ de reprodutibilidade, as atividades acima dessa estarão também comprometidas. Por exemplo, se o idoso apresentar dificuldade para utilizar um meio de transporte provavelmente terá dificuldade para cuidar das finanças e/ou realizar tarefas domésticas pesadas. Tendo em vista, esses índices satisfatórios procederam-se a classificação da necessidade de cuidado.

A hierarquia de dificuldade das tarefas aponta o comprometimento do estado funcional do idoso e a necessidade de auxílio de outra pessoa, 
para desempenhar as atividades consideradas, de acordo com o tempo/frequência para oferta desse cuidado (Quadro 9).

As AIVDs, com exceção de usar o telefone, tomar medicamentos e preparar refeições requerem uma frequência de ajuda de, pelo menos uma vez na semana. Para essas atividades é necessária uma reorganização dos familiares visando auxiliar o idoso em seu desempenho, uma vez que, a necessidade instalada é de cuidado intermitente.

O uso do telefone envolve o ato de ligar e receber ligações. Quanto ao ato de ligar, o idoso pode apresentar dificuldades sensoriais ou ainda devido às tecnologias existentes nos aparelhos. Se no momento do uso tiver alguma pessoa para auxiliá-lo demandará essa ajuda. Por isso, essa atividade foi incluída na categoria necessidade mínima, no qual demandará uma ajuda de outra pessoa esporadicamente.

As atividades administrar medicamentos, vestir-se, transferir-se e preparar refeições demandam uma frequência de realização diária e quando comprometidas requerem o auxílio de uma outra pessoa, mas não necessitam de um cuidador em tempo integral. As atividades tomar banho, locomover-se, ir ao banheiro, realizar higiene pessoal e comer também requerem um cuidado diário, no entanto, há necessidade de um cuidador presencial em tempo integral.

Quadro 9 - Níveis de cuidado segundo frequência da realização das atividades e auxílio de um cuidador.

\begin{tabular}{|c|c|c|}
\hline Atividades comprometidas & $\begin{array}{l}\text { Frequência da } \\
\text { realização das } \\
\text { atividades }\end{array}$ & $\begin{array}{l}\text { Níveis de cuidado } \\
\text { (auxílio de uma outra pessoa }\end{array}$ \\
\hline \multicolumn{3}{|l|}{ Necessidade mínima } \\
\hline $\begin{array}{l}\text { Realizar tarefas leves e } \\
\text { pesadas } \\
\text { ¿ Cuidar das finanças } \\
\text { Utilizar transporte } \\
» \text { Fazer compras } \\
\text { Utilizar telefone }\end{array}$ & $\begin{array}{l}\text { Pelo menos uma } \\
\text { vez na semana }\end{array}$ & $\begin{array}{l}\text { Idoso apresenta uma dependência } \\
\text { mínima e, necessita de ajuda } \\
\text { esporádica para execução das } \\
\text { atividades. }\end{array}$ \\
\hline \multicolumn{3}{|l|}{ Necessidade moderada } \\
\hline $\begin{array}{l}\text { Administrar } \\
\text { medicamentos } \\
» \quad \text { Vestir-se } \\
» \quad \text { Transferir-se } \\
» \quad \text { Preparar refeição }\end{array}$ & Diário & $\begin{array}{l}\text { Idoso apresenta uma dependência } \\
\text { moderada, requerendo um cuidador } \\
\text { presencial no momento da execução } \\
\text { da atividade, não sendo necessária } \\
\text { sua presença em tempo integral. }\end{array}$ \\
\hline
\end{tabular}


(continuação)

\begin{tabular}{|l|c|l|}
\hline Atividades comprometidas & $\begin{array}{l}\text { Frequência da } \\
\text { realização das } \\
\text { atividades }\end{array}$ & $\begin{array}{l}\text { Níveis de cuidado } \\
\text { (auxílio de uma outra pessoa }\end{array}$ \\
\hline $\begin{array}{l}\text { Necessidade máxima } \\
\text { Tomar banho } \\
\text { Locomover-se } \\
\text { Ir ao banheiro } \\
\text { Realizar higiene pessoal } \\
\text { Comer }\end{array}$ & Diário & $\begin{array}{l}\text { Idoso com grande dependência e } \\
\text { requer um cuidador presencial em } \\
\text { tempo integral. }\end{array}$ \\
\hline \multicolumn{2}{|l|}{} & \multicolumn{2}{|c}{ (conclusão) } \\
\hline
\end{tabular}

Os níveis de cuidado foram estabelecidos a partir da frequência de auxílio e tempo permanência do cuidador na prestação dos cuidados, portanto, a seguir apresentam-se os níveis:

» Sem necessidade: Não referem dificuldade para desenvolvimento de ABVDs ou AIVDs. Nesse caso, o idoso pode necessitar de adaptações ou mesmo de um tempo maior para executá-las, mas não necessita de ajuda de outra pessoa para realizar suas atividades cotidianas.

»Necessidade mínima: Relata dificuldade para o desenvolvimento de pelo menos uma das seguintes atividades (realizar tarefas pesadas, cuidar das finanças, utilizar transporte, fazer compras, realizar tarefas leves e utilizar telefone) e não relata dificuldade para nenhuma outra atividade. O idoso de um cuidador em tempo esporádico para o desempenho para essas atividades e, portanto, não requer um cuidador presencial em tempo integral.

»Necessidade moderada: Relata dificuldade para o desenvolvimento de pelo menos uma das atividades (tomar medicamentos, vestir-se, transferir-se e preparar refeições); e, também pode ter referido dificuldade em algumas das atividades como: realizar tarefas pesadas, cuidar das finanças, utilizar transporte, fazer compras, realizar tarefas leves e utilizar telefone. Mas não relata dificuldade para tomar banho, ir ao banheiro, realizar higiene pessoal, locomover-se e comer. A pessoa idosa necessita de ajuda diária para realizar as atividades e requer a presença de um cuidador presencial, porém não em tempo integral, apenas no momento de realização $\mathrm{da}(\mathrm{s})$ atividade(s);

» Necessidade máxima: Relata dificuldade para o desenvolvimento de pelo menos uma das seguintes atividades (tomar banho, ir ao banheiro, 
realizar higiene pessoal, locomover-se e comer) e também em algumas das atividades como: realizar tarefas pesadas, cuidar das finanças, utilizar transporte, fazer compras, realizar tarefas leves e utilizar telefone, tomar medicamentos, vestir-se, transferir-se e preparar refeições. $\mathrm{O}$ idoso necessita de um cuidador presencial em tempo integral.

A partir dessa classificação, 53,3\% eram independentes para o cuidado, 26,7\% apresentavam necessidade mínima, 10,5\% necessidade moderada e 9,4\% necessidade máxima (Gráfico 2).

Gráfico 3 - Distribuição (\%) dos idosos segundo a necessidade de cuidado. Município de São Paulo. Estudo SABE, 2006. (n=1413)
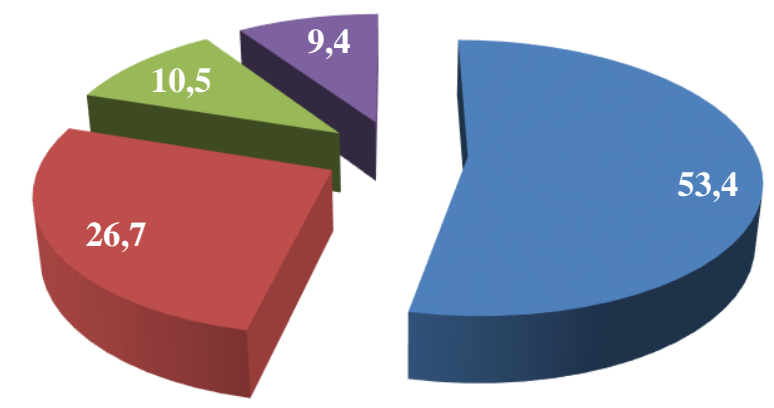

$$
\begin{aligned}
& \text { Sem necessidade } \\
& \text { Necessidade moderada }
\end{aligned}
$$$$
\text { - Necessidade mínima }
$$$$
\text { - Necessidade máxima }
$$

Fonte: Estudo SABE, 2006.

\subsubsection{Necessidade de cuidado e fatores associados}

Encontraram-se maiores proporções de necessidade mínima, moderada e máxima nas mulheres e entre as categorias de idade. Manter engajamento social, autorrelato de suficiência de renda e nível de escolaridade mais elevado também foram associadas à necessidade de cuidado, apresentando menores proporções de indivíduos com necessidade máxima. Ter companheiro apresentou maior proporção de idosos categorizados como sem necessidade, enquanto, que idosos sem companheiro apresentaram maior proporção de necessidade máxima (Tabela $4)$. 
Tabela 4 - Distribuição (\%) dos idosos segundo necessidade de cuidado e características sociodemográficas e econômicas. Município de São Paulo, 2006. $(n=1413)$

\begin{tabular}{|c|c|c|c|c|c|}
\hline \multirow[t]{2}{*}{ Características } & \multicolumn{4}{|c|}{ Necessidade } & \multirow[t]{2}{*}{$\mathbf{p}$} \\
\hline & $\begin{array}{c}\text { Sem } \\
\text { necessidade }\end{array}$ & Mínima & Moderada & Máxima & \\
\hline Sexo & & & & & $\mathbf{0 , 0 0 0}$ \\
\hline Homem & 66,6 & 18,6 & 8,5 & 6,3 & \\
\hline Mulher & 44,3 & 32,3 & 11,9 & 11,5 & \\
\hline Idade & & & & & $\mathbf{0 , 0 0 0}$ \\
\hline 60 a 69 anos & 63,1 & 24,0 & 7,9 & 5,0 & \\
\hline 70 a 79 anos & 46,6 & 31,3 & 11,7 & 10,4 & \\
\hline 80 anos e mais & 20,9 & 29,0 & 20,6 & 29,5 & \\
\hline Estado marital & & & & & $\mathbf{0 , 0 0 0}$ \\
\hline $\begin{array}{c}\text { Com } \\
\text { companheiro }\end{array}$ & 59,9 & 24,5 & 9,4 & 6,2 & \\
\hline $\begin{array}{c}\text { Sem } \\
\text { companheiro }\end{array}$ & 44,6 & 29,8 & 12,0 & 13,6 & \\
\hline Escolaridade & & & & & $\mathbf{0 , 0 0 0}$ \\
\hline Analfabeto & 26,6 & 35,3 & 18,5 & 19,6 & \\
\hline 1 a 3 anos & 48,3 & 31,7 & 10,2 & 9,8 & \\
\hline 4 a 7 anos & 58,2 & 24,9 & 10,2 & 6,7 & \\
\hline 8 anos e mais & 72,0 & 17,3 & 5,3 & 5,4 & \\
\hline Mora sozinho & & & & & 0,733 \\
\hline Não & 53,8 & 26,3 & 10,5 & 9,4 & \\
\hline Sim & 50,3 & 30,4 & 10,1 & 9,2 & \\
\hline $\begin{array}{l}\text { Insuficiência de } \\
\text { renda }\end{array}$ & & & & & 0,004 \\
\hline Não & 60,3 & 23,6 & 9,2 & 7,9 & \\
\hline Sim & 48,8 & 30,0 & 10,8 & 10,4 & \\
\hline $\begin{array}{l}\text { Vulnerabilidade } \\
\text { social }\end{array}$ & & & & & 0,188 \\
\hline $\begin{array}{l}\text { Sem } \\
\text { vulnerabilidade }\end{array}$ & 61,1 & 22,2 & 7,1 & 9,6 & \\
\hline $\begin{array}{l}\text { Muito } \\
\text { baixa/baixa }\end{array}$ & 54,2 & 25,9 & 10,3 & 9,3 & \\
\hline $\begin{array}{l}\text { Média/Alta/ } \\
\text { Muito alta }\end{array}$ & 46,4 & 32,1 & 12,7 & 8,8 & \\
\hline $\begin{array}{l}\text { Engajamento } \\
\text { social }\end{array}$ & & & & & $\mathbf{0 , 0 0 0}$ \\
\hline Não & 20,7 & 24,1 & 23,0 & 32,2 & \\
\hline Sim & 56,6 & 27,0 & 9,3 & 7,1 & \\
\hline $\begin{array}{l}\text { Funcionalidade } \\
\text { familiar }\end{array}$ & & & & & 0,185 \\
\hline Funcional & 58,3 & 28,4 & 7,7 & 5,6 & \\
\hline Disfuncional & 53,0 & 26,6 & 10,6 & 9,8 & \\
\hline Total & 53,4 & 26,7 & 10,5 & 9,4 & \\
\hline
\end{tabular}

Fonte: Estudo SABE, 2006. 
A necessidade de cuidado (mínima, moderada e máxima) foi mais prevalente entre os idosos que referiram hipertensão arterial, diabetes, doença osteoarticular, osteoporose, apresentavam multimorbidade, sintomas depressivos, relataram pior autoavaliação de saúde, estavam em processo de fragilização, faziam uso da polifarmácia, relataram queda no último ano e mobilidade física prejudicada. A presença de declínio cognitivo, doenças cardiovascular e cerebrovascular se relacionaram às maiores proporções na necessidade de cuidados moderada e máxima. A presença de doença pulmonar obstrutiva crônica apresentou maior proporção de necessidade máxima quando comparada aos que não a referiram (Tabela 5).

Tabela 5 - Distribuição (\%) dos idosos segundo necessidade de cuidado e condições de saúde. Município de São Paulo, 2006. (n=1413)

(continua)

\begin{tabular}{|c|c|c|c|c|c|}
\hline \multirow[t]{2}{*}{ Características } & \multicolumn{4}{|c|}{ Necessidade } & \multirow[t]{2}{*}{$\mathbf{P}$} \\
\hline & $\begin{array}{c}\text { Sem } \\
\text { necessidade }\end{array}$ & Mínima & Moderada & Máxima & \\
\hline $\begin{array}{l}\text { Hipertensão } \\
\text { arterial }\end{array}$ & & & & & $\mathbf{0 , 0 0 0}$ \\
\hline Não & 63,6 & 22,1 & 7,6 & 6,7 & \\
\hline Sim & 47,4 & 29,4 & 12,2 & 11,0 & \\
\hline Diabetes & & & & & 0,001 \\
\hline Não & 56,0 & 26,0 & 10,0 & 8,0 & \\
\hline Sim & 44,9 & 28,2 & 12,1 & 14,8 & \\
\hline $\begin{array}{l}\text { Doença pulmonar } \\
\text { obstrutiva crônica }\end{array}$ & & & & & 0,004 \\
\hline Não & 54,7 & 26,5 & 10,5 & 8,2 & \\
\hline Sim & 44,5 & 27,7 & 10,2 & 17,6 & \\
\hline $\begin{array}{l}\text { Doença } \\
\text { cardiovascular }\end{array}$ & & & & & $\mathbf{0 , 0 0 0}$ \\
\hline Não & 56,7 & 26,3 & 9,5 & 7,5 & \\
\hline Sim & 43,0 & 27,1 & 14,3 & 15,6 & \\
\hline $\begin{array}{l}\text { Doença } \\
\text { cerebrovascular }\end{array}$ & & & & & $\mathbf{0 , 0 0 0}$ \\
\hline Não & 56,1 & 27,1 & 9,1 & 7,7 & \\
\hline Sim & 23,2 & 23,1 & 25,6 & 28,0 & \\
\hline $\begin{array}{l}\text { Doença } \\
\text { osteoarticular }\end{array}$ & & & & & $\mathbf{0 , 0 0 0}$ \\
\hline Não & 59,7 & 24,5 & 9,2 & 6,6 & \\
\hline Sim & 42,0 & 31,1 & 12,8 & 14,1 & \\
\hline
\end{tabular}




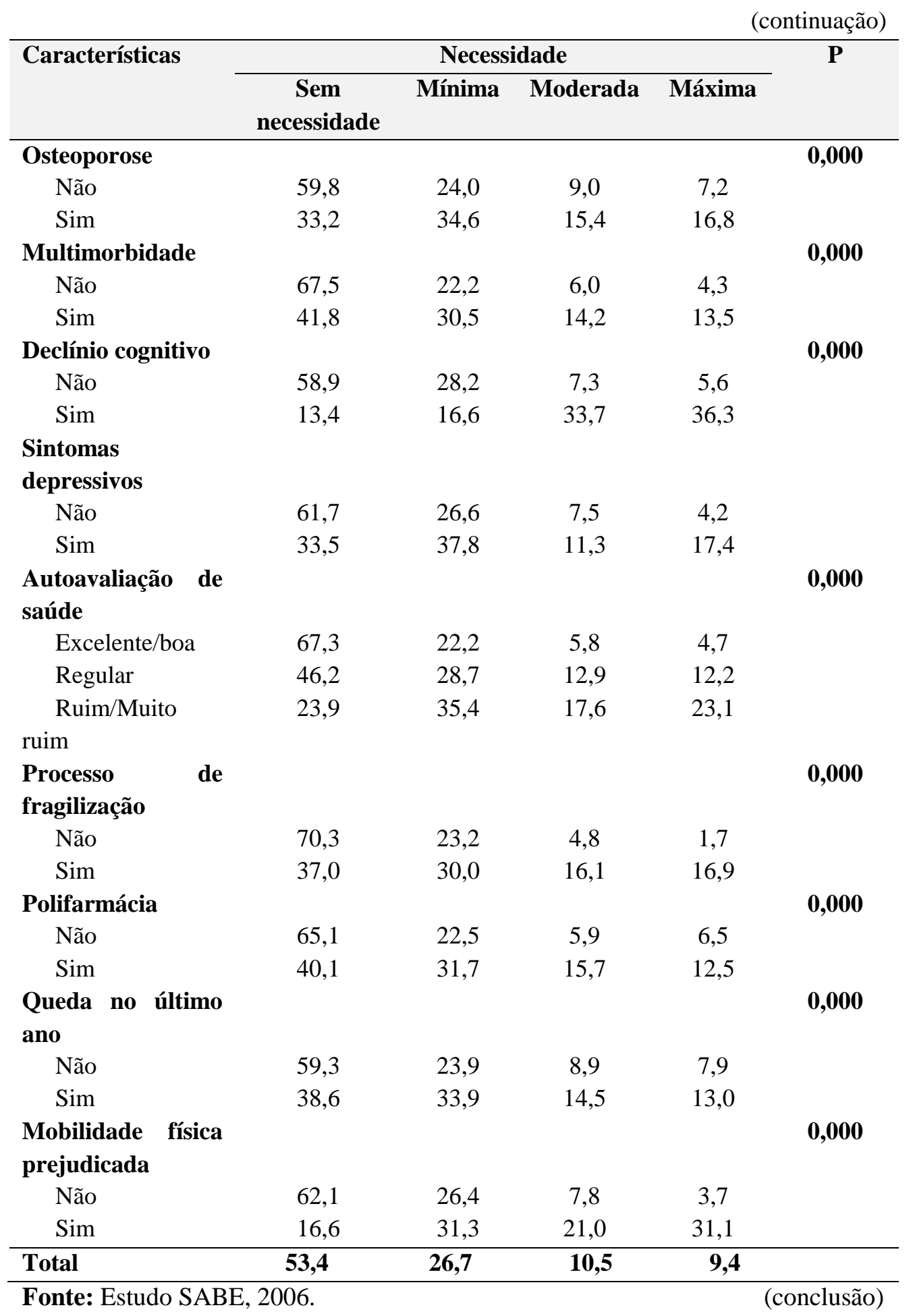

A dificuldade no acesso aos serviços de saúde, utilizar serviços de urgência/emergência e internação nos últimos 12 meses foram associados à necessidade de cuidado (Tabela 6). 
Tabela 6 - Distribuição (\%) dos idosos segundo necessidade de cuidado e utilização dos serviços de saúde. Município de São Paulo, 2006. $(n=1413)$

\begin{tabular}{|c|c|c|c|c|c|}
\hline \multirow[t]{2}{*}{ Características } & \multicolumn{4}{|c|}{ Necessidade } & \multirow[t]{2}{*}{$\mathbf{p}$} \\
\hline & $\begin{array}{c}\text { Sem } \\
\text { necessidade }\end{array}$ & Mínima & Moderada & Máxima & \\
\hline $\begin{array}{l}\text { Possui plano de } \\
\text { saúde }\end{array}$ & & & & & 0,102 \\
\hline Não & 51,5 & 27,1 & 10,0 & 11,0 & \\
\hline Sim & 55,8 & 25,8 & 11,1 & 7,3 & \\
\hline $\begin{array}{l}\text { Dificuldade no } \\
\text { acesso ao serviço de } \\
\text { saúde }\end{array}$ & & & & & 0,000 \\
\hline Não & 58,6 & 26,6 & 9,1 & 5,7 & \\
\hline Sim & 39,5 & 27,9 & 14,3 & 18,3 & \\
\hline Consulta médica & & & & & 0,084 \\
\hline Não & 59,5 & 24,5 & 6,8 & 9,2 & \\
\hline Sim & 52,0 & 27,3 & 11,3 & 9,4 & \\
\hline $\begin{array}{l}\text { Utilizou o serviço de } \\
\text { urgência/emergência }\end{array}$ & & & & & 0,000 \\
\hline Não & 55,6 & 26,5 & 9,3 & 8,6 & \\
\hline Sim & 40,5 & 28,4 & 17,4 & 13,7 & \\
\hline $\begin{array}{l}\text { Internação } \\
\text { hospitalar }\end{array}$ & & & & & 0,000 \\
\hline Não & 55,1 & 27,6 & 9,8 & 7,5 & \\
\hline Sim & 37,2 & 18,9 & 17,3 & 26,6 & \\
\hline Total & 53,4 & 26,7 & 10,5 & 9,4 & \\
\hline
\end{tabular}

Fonte: Estudo SABE, 2006.

Os fatores associados às necessidades mínima, moderada e máxima foram idade (mais longevos), sexo (feminino), dificuldade no acesso aos serviços de saúde, processo de fragilização e mobilidade física prejudicada. Engajamento social e sintomas depressivos foram associados às necessidades mínima e máxima; enquanto, doença cerebrovascular e multimorbidade estiveram associadas às necessidades moderada e máxima (Tabela 7).

Idosos que referiram queda no último ano tiveram uma chance de 1,53 vezes de apresentar necessidade mínima quando comparados aos não caidores. Já idosos com declínio cognitivo tiveram uma chance de aproximadamente seis vezes para apresentar necessidade moderada quando 
comparados aos sem declínio. Também foi associado à necessidade moderada, o uso de múltiplos medicamentos (Tabela 7).

Tabela 7 - Fatores associados à necessidade de cuidados de idosos. Município de São Paulo, 2006. (n=1413)

Fatores associados

\section{Necessidade mínima*}

Sexo feminino

$2,66[1,94-3,64]$

0,000

Idade ( $\geq 80$ anos)

$2,33[1,47-3,69]$

0,000

Engajamento social

$0,45[0,22-0,92]$

0,030

Dificuldade no acesso aos serviços de

$1,57[1,04-2,38]$

0,032

saúde

Processo de fragilização

$1,75[1,19-2,57] \quad 0,005$

Mobilidade física prejudicada

$2,43[1,32-4,47]$

0,005

Sintomas depressivos

$1,85[1,17-2,83]$

0,008

Queda no último ano

$1,53[1,04-2,25]$

0,030

\section{Necessidade moderada**}

Sexo feminino

$2,34[1,07-5,12] \quad 0,032$

Idade ( $\geq 80$ anos)

$2,82[1,37-5,80]$

0,005

Dificuldade no acesso aos serviços de

$2,61[1,38-4,94]$

0,004

saúde

Declínio cognitivo

$5,97[1,85-19,23] \quad 0,003$

Doença cerebrovascular

$4,25[1,66-10,89] \quad 0,003$

Multimorbidade

$2,52[1,14-5,53]$

0,022

Processo de fragilização

$2,77[1,41-5,45]$

0,004

Mobilidade física prejudicada

$2,92[1,49-5,74]$

0,002

Polifarmácia

$2,76[1,52-5,02]$

0,001

\section{Necessidade máxima***}

Sexo feminino

$5,78[2,58-12,92] \quad 0,000$

Idade ( $\geq 80$ anos)

$2,30[1,14-4,60] \quad 0,020$

Dificuldade no acesso aos serviços de

$4,00[1,88-8,58]$

0,000

saúde

Engajamento social

$0,19[0,08-0,45] \quad 0,000$

Multimorbidade

Doença cerebrovascular

$3,39[1,20-8,62]$

0,016

$7,65[2,75-21,27]$

0,000

Sintomas depressivos

$2,97[1,38-6,38] \quad 0,006$

Processo de fragilização

$6,32[2,67-14,92]$

0,000

Mobilidade física prejudicada

$5,96[2,86-12,42]$

0,000

\footnotetext{
*Ajustado por declínio cognitivo, acidente vascular encefálico, multimorbidade, doença osteoarticular, polifarmácia, utilização dos serviços de urgência e vulnerabilidade social.

**Ajustado por depressão, doença osteoarticular, queda, utilização dos serviços de urgência e vulnerabilidade social.

***Ajustado por declínio cognitivo, doença osteoarticular, polifarmácia, queda, utilização dos serviços de urgência e vulnerabilidade social.
} 


\subsubsection{Necessidade de cuidado e recebimento de ajuda}

Dos 798 idosos classificados com necessidade de cuidado, 73,0\% referiram ajuda de alguém para as suas demandas. As proporções de recebimento de ajuda foram estatisticamente significativas à idade e disfuncionalidade familiar, ou seja, idosos mais velhos e com boa funcionalidade familiar recebiam mais ajuda (Tabela 8 ).

Tabela 8 - Distribuição (\%) dos idosos com necessidade de cuidado segundo recebimento de ajuda de outra pessoa, características socioeconômicas, demográficas e multimorbidade. Município de São Paulo, 2006. (n=798)

\begin{tabular}{|c|c|c|c|}
\hline \multirow{2}{*}{ Características } & \multicolumn{2}{|c|}{ Recebe ajuda de outra pessoa } & \multirow{2}{*}{$\mathbf{p}$} \\
\hline & Não & Sim & \\
\hline Sexo & & & 0,223 \\
\hline Homem & 23,3 & 76,7 & \\
\hline Mulher & 28,4 & 71,6 & \\
\hline Idade & & & $\mathbf{0 , 0 0 0}$ \\
\hline 60 a 69 anos & 33,6 & 66,4 & \\
\hline 70 a 79 anos & 24,2 & 75,8 & \\
\hline 80 anos e mais & 15,7 & 84,3 & \\
\hline Estado marital & & & 0,687 \\
\hline Com companheiro & 27,7 & 72,3 & \\
\hline Sem companheiro & 26,2 & 73,8 & \\
\hline Mora sozinho & & & 0,331 \\
\hline Não & 26.3 & 73,7 & \\
\hline Sim & 31,3 & 68,7 & \\
\hline Vulnerabilidade social & & & 0,714 \\
\hline Sem vulnerabilidade & 23,0 & 77,0 & \\
\hline Muito baixa/baixa & 28,1 & 71,9 & \\
\hline Média/Alta/Muito alta & 26,1 & 73,9 & \\
\hline Funcionalidade familiar & & & $\mathbf{0 , 0 0 7}$ \\
\hline Funcional & 29,2 & 70,8 & \\
\hline Disfuncional & 45,8 & 54,2 & \\
\hline Multimorbidade & & & 0,988 \\
\hline Não & 26,9 & 73,1 & \\
\hline Sim & 27,0 & 73,0 & \\
\hline Total & 27,0 & 73,0 & \\
\hline
\end{tabular}

Fonte: Estudo SABE, 2006.

No Gráfico 4, observaram-se que entre os idosos classificados nas categorias necessidade mínima e moderada, 78,4\% e 78,7\% recebiam ajuda 
de alguma pessoa, respectivamente. Destaca-se para o auxílio recebido entre os idosos com necessidade máxima, no qual 48,7\% não recebiam auxílio nas atividades e 51,3\% recebiam ajuda de alguma pessoa.

Entre os idosos com necessidade mínima que utilizaram serviços de urgência e emergência $(76,7 \%)$ e naqueles com 60 a 69 anos $(26,5 \%)$ foi observado o não recebimento de ajuda. Quanto aos idosos com necessidade moderada, notou-se que as maiores proporções do não recebimento de ajuda estavam associadas à presença de engajamento social (26,5\%) e disfuncionalidade familiar $(70,6 \%)$.

Nos idosos com necessidade máxima observaram-se maiores proporções de não recebimento de ajuda entre as mulheres $(52,0 \%)$, a faixa etária de 60 a 69 anos (82,9\%), aqueles com engajamento social (62,5\%), naqueles que utilizaram a consulta médica e serviços de urgência/emergência $(58,6 \%)$.

Gráfico 4 - Distribuição (\%) dos idosos segundo necessidade de cuidado e recebimento de ajuda de alguma pessoa. Município de São Paulo, 2006. $(\mathrm{n}=798)$

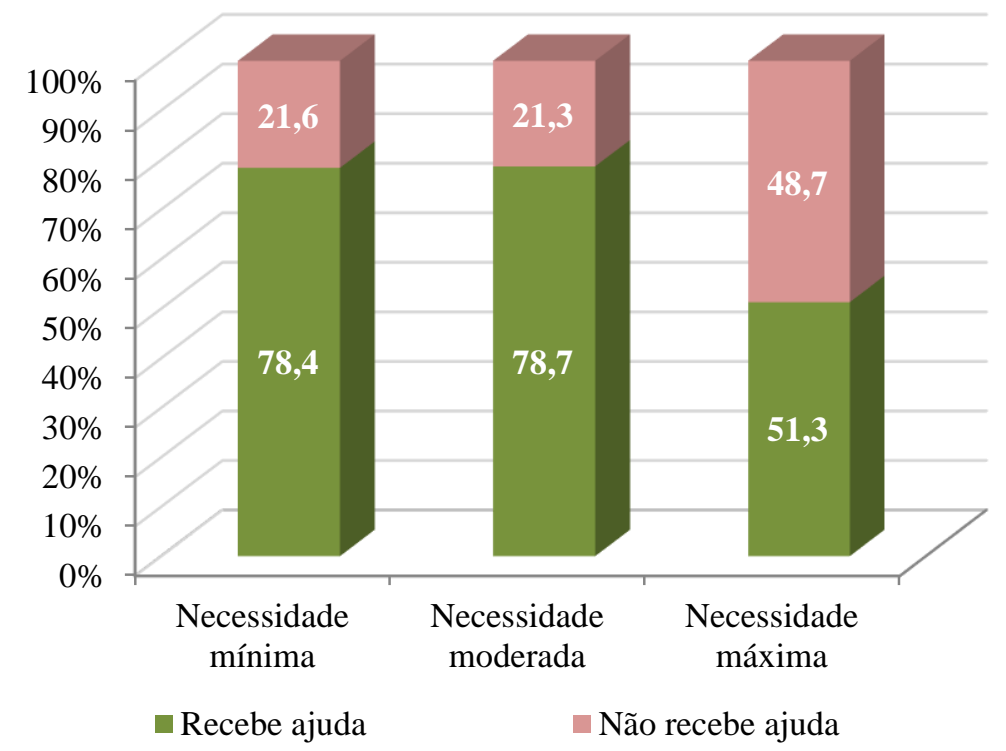

$\mathrm{p}=0,000$

Fonte: Estudo SABE, 2006. 
Do total de 615 cuidadores que auxiliavam os idosos em suas necessidades, 275 deles eram familiares e responderam à escala de sobrecarga de cuidados.

A pontuação média de sobrecarga para os cuidadores que prestavam cuidado aos idosos com necessidade mínima foi de 35,0 pontos (IC 95\%: 32,55-37,5; SE:1,24); para aqueles que auxiliavam os idosos com necessidade moderada, 43,7 pontos (IC 95\%: 40,20-47,23; SE:1,75); e, naqueles que cuidavam de idosos com necessidade máxima, 45,5 pontos (IC 95\%: 41,72-49,29; SE:1,89). A média de sobrecarga dos cuidadores de idosos com necessidade mínima apresentou diferença estatística com a média dos cuidadores de idosos com necessidades moderada e máxima $(\mathrm{p}<0,001)$, no entanto, não houve diferenças entre as médias dos cuidadores de idosos com necessidades moderada e máxima $(\mathrm{p}=0,484)$.

\subsubsection{Necessidade de cuidado e acesso e utilização dos serviços de saúde}

A dificuldade no acesso aos serviços de saúde foi relatada por $29,7 \%$ dos idosos. A prevalência dessa dificuldade de acesso entre os níveis de cuidado foi de $22,1 \%$ para idosos sem necessidade, $30,7 \%$ entre aqueles com necessidade mínima, 40,0\% dos idosos com necessidade moderada e 57,6\% daqueles com necessidade máxima (Gráfico 5). 
Gráfico 5 - Distribuição (\%) dos idosos segundo necessidade de cuidado e dificuldade no acesso aos serviços de saúde. Município de São Paulo, 2006. $(\mathrm{n}=1413)$

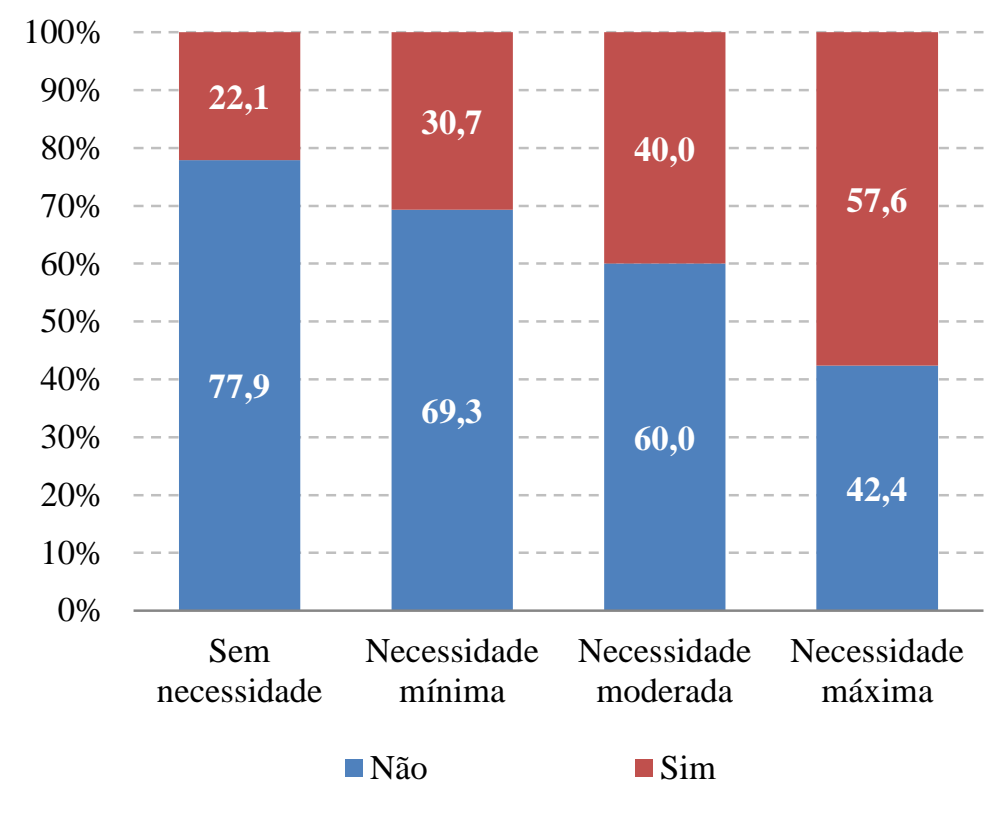

$\mathrm{p}=0,000$

Fonte: Estudo SABE, 2006.

Entre os idosos que referiram dificuldade no acesso aos serviços de saúde, os motivos como relato de serviços ruins e a presença de barreiras arquitetônicas foram mais citados pelos idosos sem necessidade; não ter companhia, distância dos serviços e falta de recursos financeiros foram apontados pelos idosos com necessidade mínima; falta de recursos financeiros, pelos idosos com necessidade moderada; e, falta de transporte e dificuldade de locomoção foram mais referidas pelos idosos com necessidade máxima (Gráfico 6). 
Gráfico 6 - Distribuição (\%) dos idosos com dificuldade de acesso aos serviços de saúde segundo os motivos da dificuldade e necessidade de cuidado. Município de São Paulo. Estudo SABE. 2006-2010 $(n=438 *)$

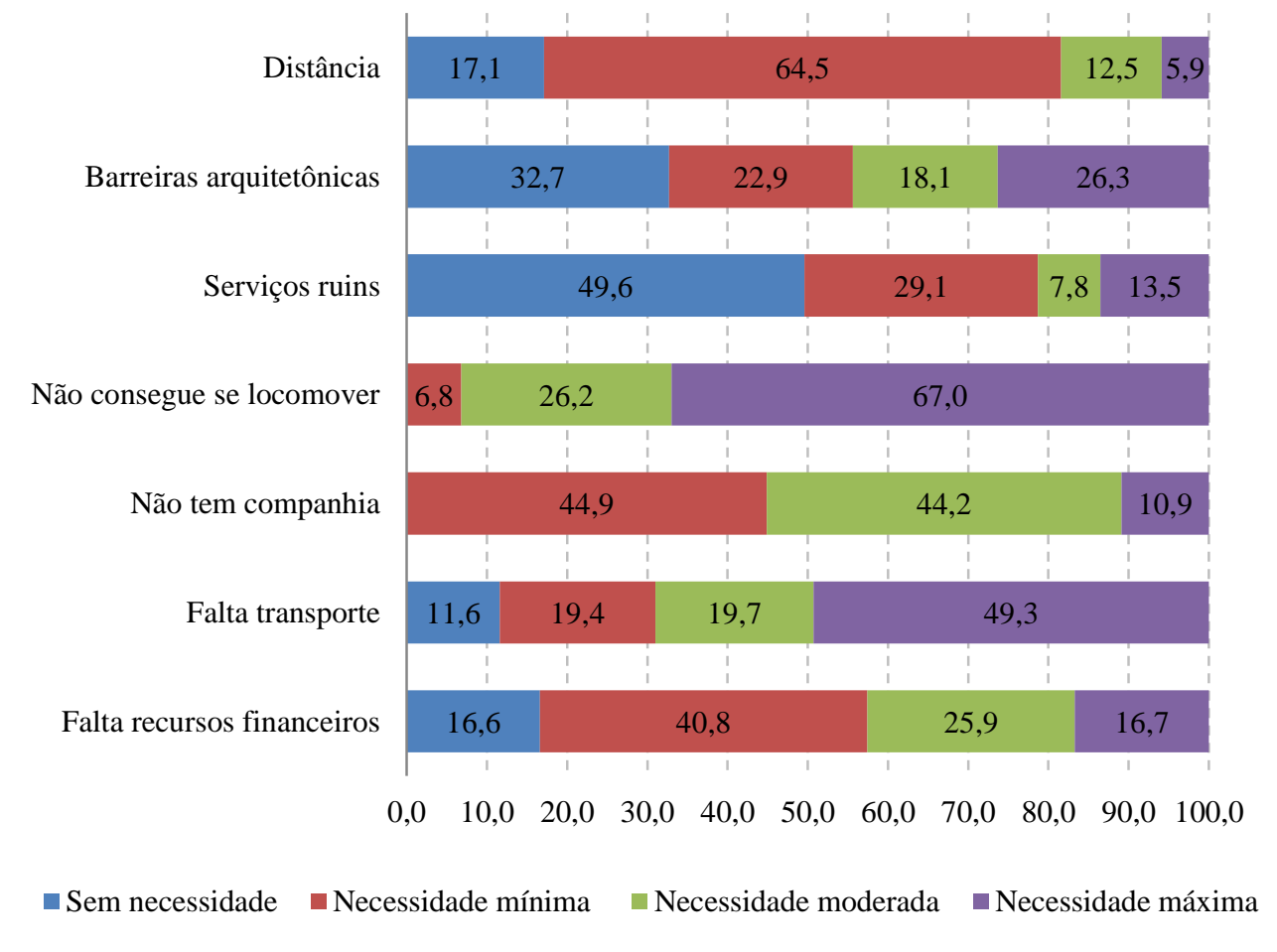

*Total de idosos que referiram dificuldade no acesso aos serviços $\quad \mathrm{p}=0,000$ Fonte: Estudo SABE, 2006.

Entre os idosos sem necessidade, 20,7\% não realizaram consulta, seguido de $17,0 \%$ dos idosos com necessidade mínima, 12,1\% entre aqueles com necessidade moderada e $18,1 \%$ naqueles com necessidade máxima (Gráfico 7). 
Gráfico 7 - Distribuição (\%) dos idosos segundo necessidade de cuidado e realização de consulta nos últimos 12 meses. Município de São Paulo, 2006. $(\mathrm{n}=1413)$

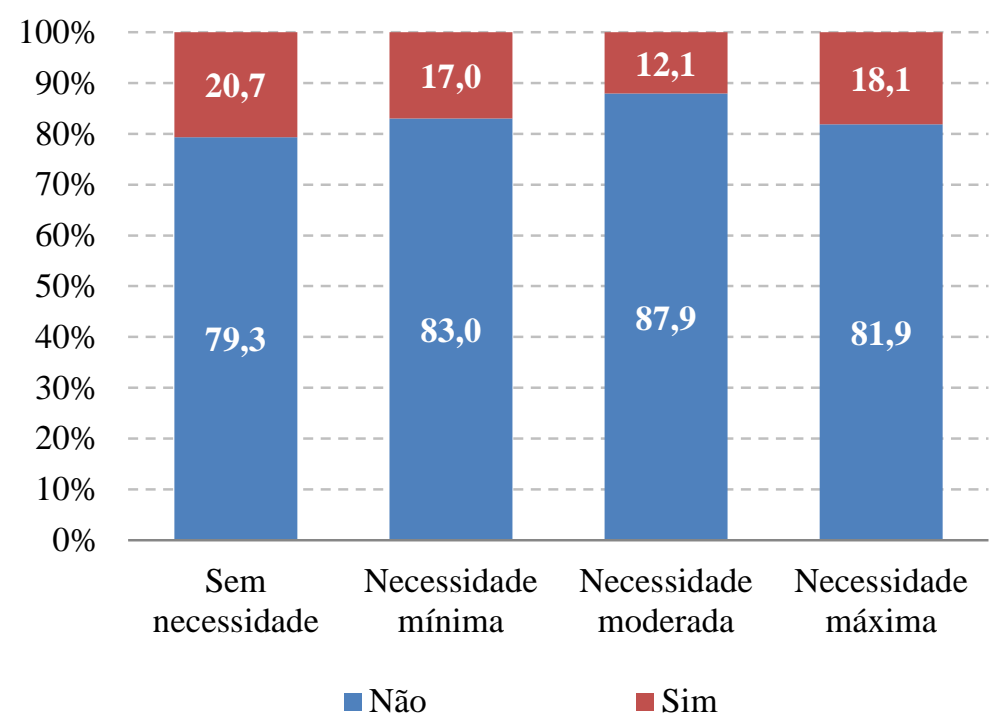

$\mathrm{p}=0,084$

Fonte: Estudo SABE, 2006.

A maioria dos idosos sem necessidade, naqueles com necessidade mínima e máxima não realizou a consulta no último ano por referir não necessitar desse serviço $(90,6 \%, 61,3 \%$ e $91,0 \%$, respectivamente). Já entre os idosos com necessidade moderada, 37,5\% não necessitaram do serviço, $43,2 \%$ precisou, mas não procurou o serviço e $18,9 \%$ procurou e não tinha vaga (Gráfico 8).

A utilização dos serviços de urgência foi de $11,1 \%$ entre os idosos independentes, 15,6\% com necessidade mínima, 24,2\% necessidade moderada e $21,5 \%$ com necessidade máxima. 
Gráfico 8 - Distribuição (\%) dos idosos segundo necessidade de cuidado e utilização dos serviços de urgência/emergência no último ano. Município de São Paulo, 2006. (n=1413)

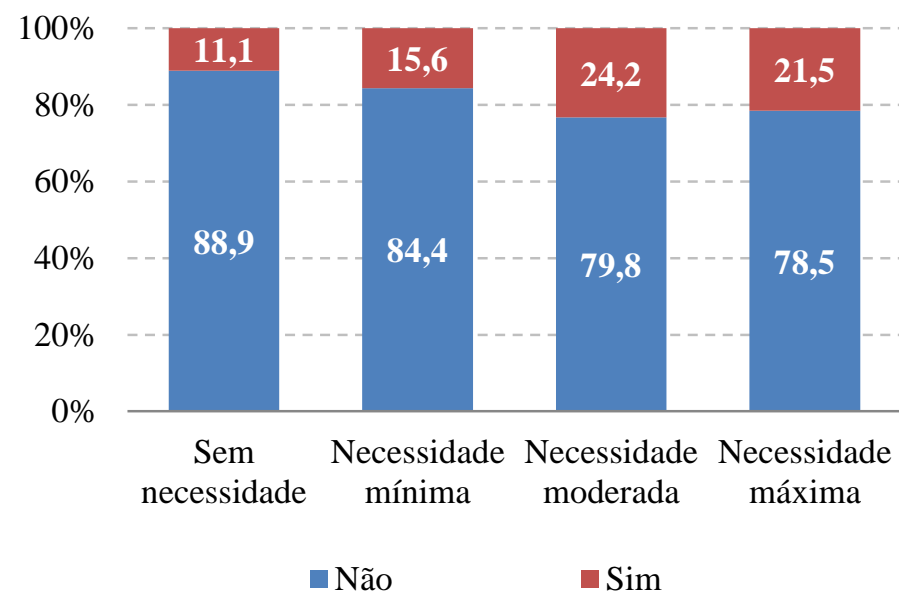

$\mathrm{p}=0,000$

Fonte: Estudo SABE, 2006.

Após a utilização dos serviços de urgência/emergência, a proporção de idosos que foram encaminhados para o domicílio segundo a necessidade de cuidado foi: $95,4 \%$ dos idosos sem necessidade, $97,1 \%$ dos idosos com necessidade mínima, $88,6 \%$ com necessidade moderada e 79,3\% com necessidade máxima (Gráfico 9).

Gráfico 9 - Distribuição (\%) dos idosos segundo necessidade de cuidado e procedência após a utilização do serviço de urgência/emergência. Município de São Paulo, 2006. ( $\left.\mathrm{n}=205^{*}\right)$

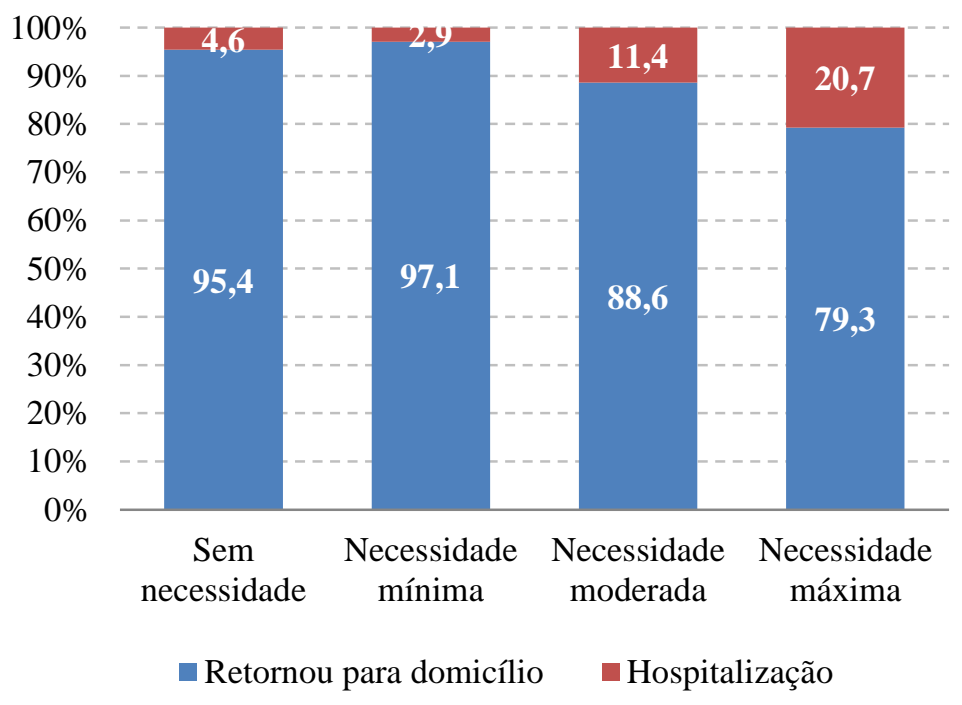

*Total de idosos que utilizaram o serviço de urgência/emergência $\quad \mathrm{p}=0,108$ Fonte: Estudo SABE, 2006. 
Quanto ao tempo da última utilização dos serviços de urgência/emergência, verifica-se que entre os períodos avaliados as maiores proporções foram de idosos sem necessidade de cuidado, exceto, para o período de 4 a 6 meses onde a maior proporção foi de idosos com necessidade mínima (Gráfico 10).

Gráfico 10 - Distribuição (\%) dos idosos segundo necessidade de cuidado e tempo de uso do serviço de acesso à urgência/emergência. Município de São Paulo, 2006. (n=205)

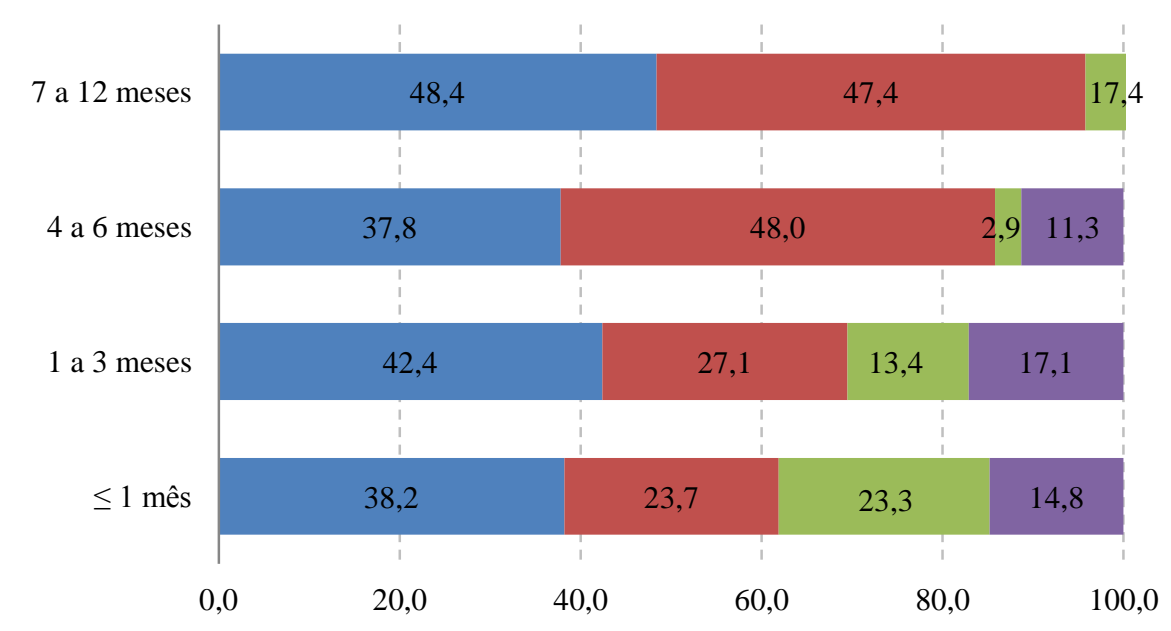

Sem necessidade $\square$ Necessidade mínima $\square$ Necessidade moderada $\square$ Necessidade máxima

*Total de idosos que utilizaram o serviço de urgência/emergência $\quad \mathrm{p}=0,169$

Fonte: Estudo SABE, 2006.

A prevalência de internação entre os idosos foi de 9,6\%. Entre os níveis de cuidado a proporção de internação foi de $6,7 \%$ para os idosos sem necessidade e naqueles com necessidade mínima, 15,8\% para aqueles com necessidade moderada e $27,2 \%$ dos idosos com necessidade máxima (Gráfico 11). 
Gráfico 11 - Distribuição (\%) dos idosos segundo necessidade de cuidado e internação no último ano. Município de São Paulo, 2006. $(\mathrm{n}=1413)$

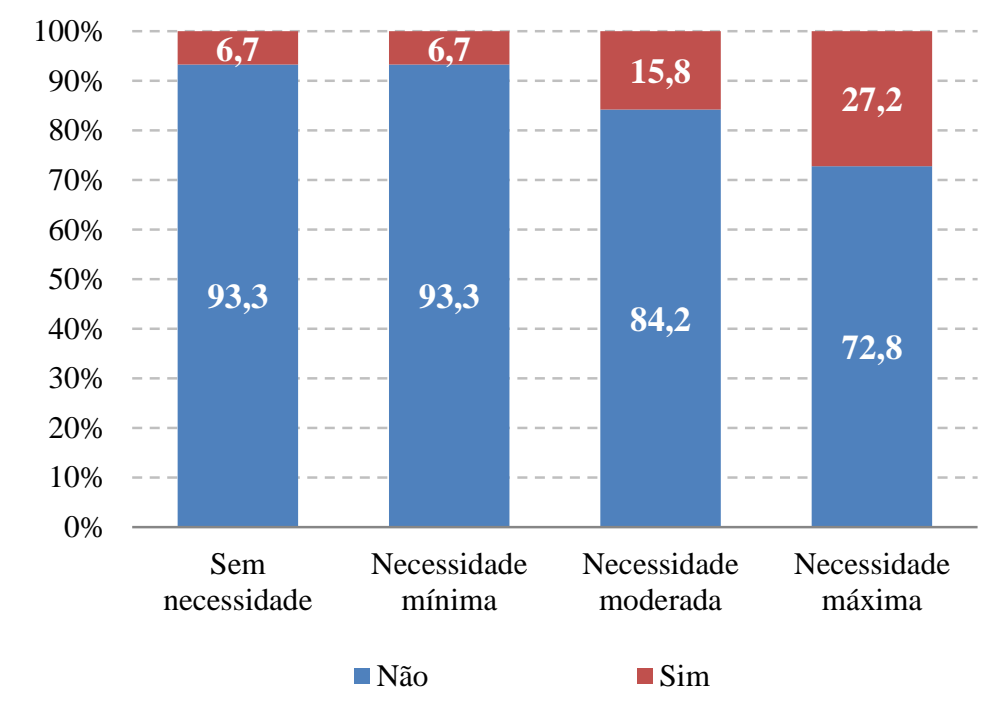

$\mathrm{p}=0,000$

Fonte: Estudo SABE, 2006.

Entre os idosos internados, $83 \%$ realizaram consultas médica no último, 71,9\% autorrelataram hipertensão arterial e 48,8\% referiram doença cardiovascular. Mais da metade dos idosos internados e com necessidade máxima relataram dificuldade no acesso aos serviços de saúde devido a dificuldades na locomoção $(\mathrm{p}<0,05)$. Ainda nesse grupo, ter duas ou mais doenças, disfuncionalidade familiar não foi associadas à necessidade de cuidados.

Durante o período de um ano os idosos poderiam ter utilizado mais de um dos serviços de saúde, por isso, identificou-se que 64,6\% dos idosos referiram ter realizado somente a consulta médica, 13,6\% não utilizou nenhum serviço, $8,9 \%$ realizaram consulta médica e utilizou serviço de urgência/emergência, 6,2\% consultaram e foram internados, 3,3\% foram ao serviço de urgência, $1,8 \%$ utilizou todos os serviços, $1,0 \%$ foram internados e $0,6 \%$ utilizaram serviço de urgência e urgência.

No Gráfico 12, as maiores proporções de idosos sem necessidade de cuidado foram encontradas entre o grupo que não utilizou os serviços de saúde e naqueles que somente consultaram. Entre as pessoas que somente utilizaram o serviço urgência/emergência prevaleceu os idosos com 
necessidade mínima. Já entre aqueles que somente internaram 29,1\% tinham necessidade moderada. Em relação aos grupos que utilizou todos os serviços (consulta, urgência e internação) e utilizaram o serviço de urgência/emergência e internação hospitalar, apresentaram mais idosos com necessidade máxima.

Gráfico 12 - Distribuição (\%) dos idosos segundo necessidade de cuidado e serviços de saúde utilizados no último ano. Município de São Paulo, 2006. $(n=1413)$

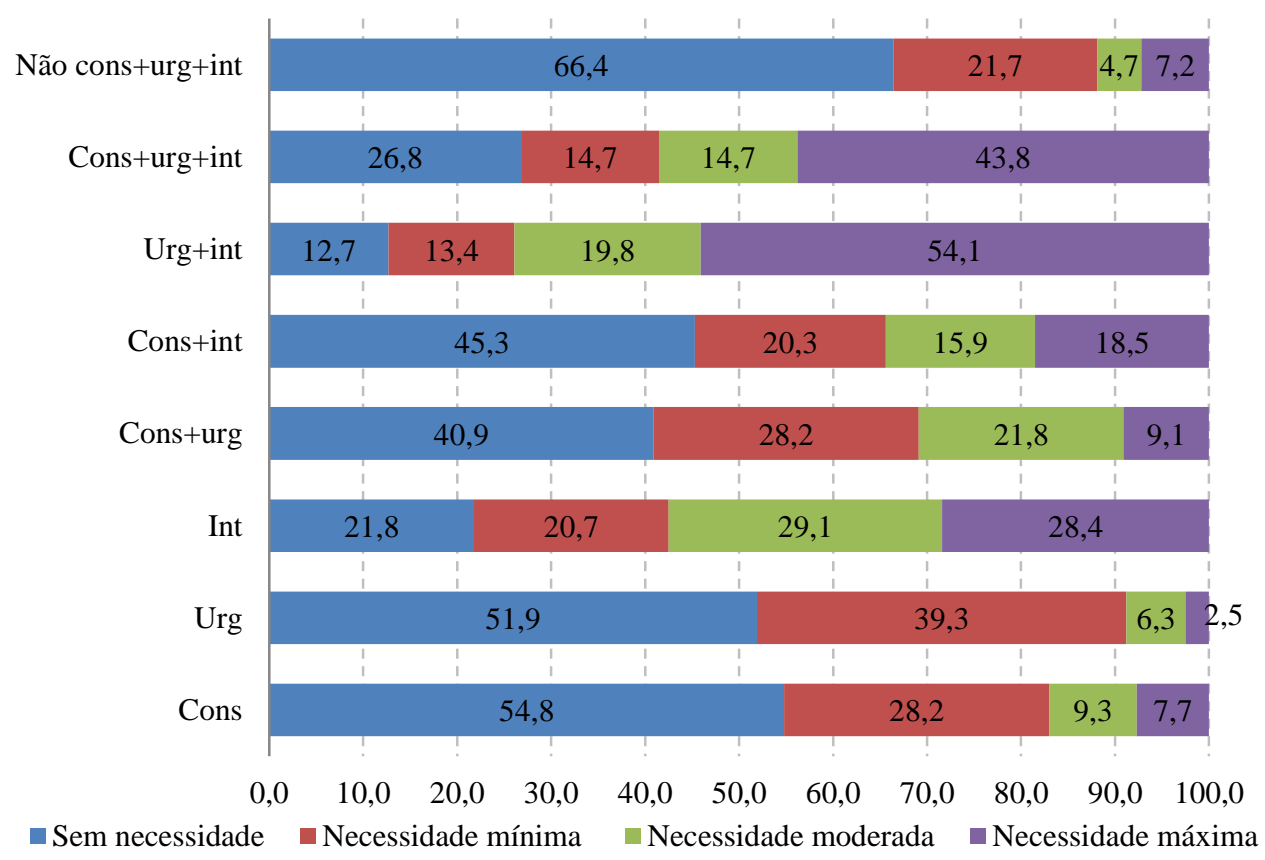

Cons: consulta; urg: urgência; int: internação $\mathrm{p}=0,000$

Fonte: Estudo SABE, 2006. 


\subsection{TRANSIÇÃO ENTRE OS NÍVEIS DE CUIDADO}

Nessa segunda etapa dos resultados foi avaliada a mudança entre os níveis de cuidado após o acompanhamento de quatro anos (2006 - 2010). Primeiramente, foram analisados os idosos classificados como "sem necessidade" no baseline identificando-se os fatores que determinaram a necessidade de cuidado. Em seguida, foram selecionados os idosos do baseline com alguma necessidade (mínima, moderada e máxima) com intuito de observar os fatores associados à piora dessa necessidade.

Dos 1413 idosos avaliados em 2006, 915 foram avaliados em 2010 (71,4\%). A diferença foi constituída por 268 óbitos (11,8\%), 220 idosos não localizados e recusas $(16,5 \%)$ e 10 institucionalizações $(0,3 \%)$ (Fluxograma $1)$.

Fluxograma 1. Idosos acompanhados no período de quatro anos. Município de São Paulo, 2006-2010. (n=1413)

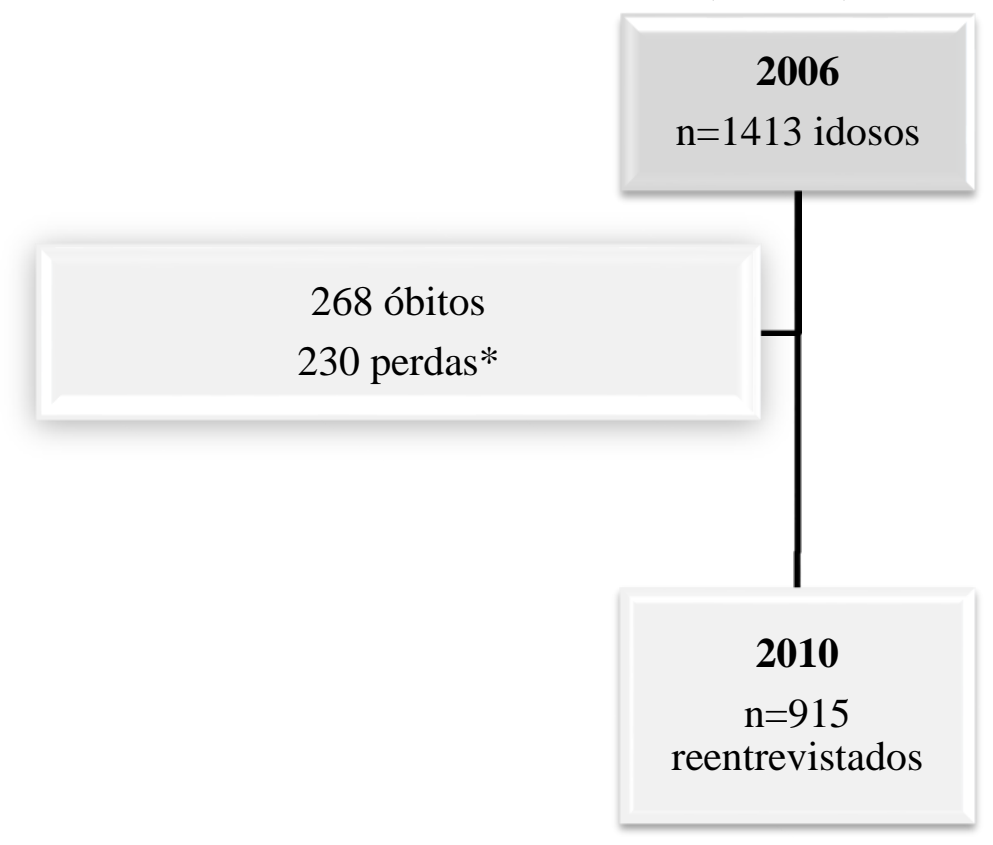

*Consideraram-se perdas, os idosos institucionalizados, recusas ou não localizados.

A proporção de óbitos para as categorias de necessidade de cuidado foram de 5,9\% para sem necessidade, 11,3\% para necessidade mínima, 
21,8\% para necessidade moderada e $35,4 \%$ para necessidade máxima (Gráfico 13).

Gráfico 13 - Distribuição (\%) dos idosos segundo óbito e necessidade de cuidado. Município de São Paulo. Estudo SABE. 2006-2010 $(n=1413)$

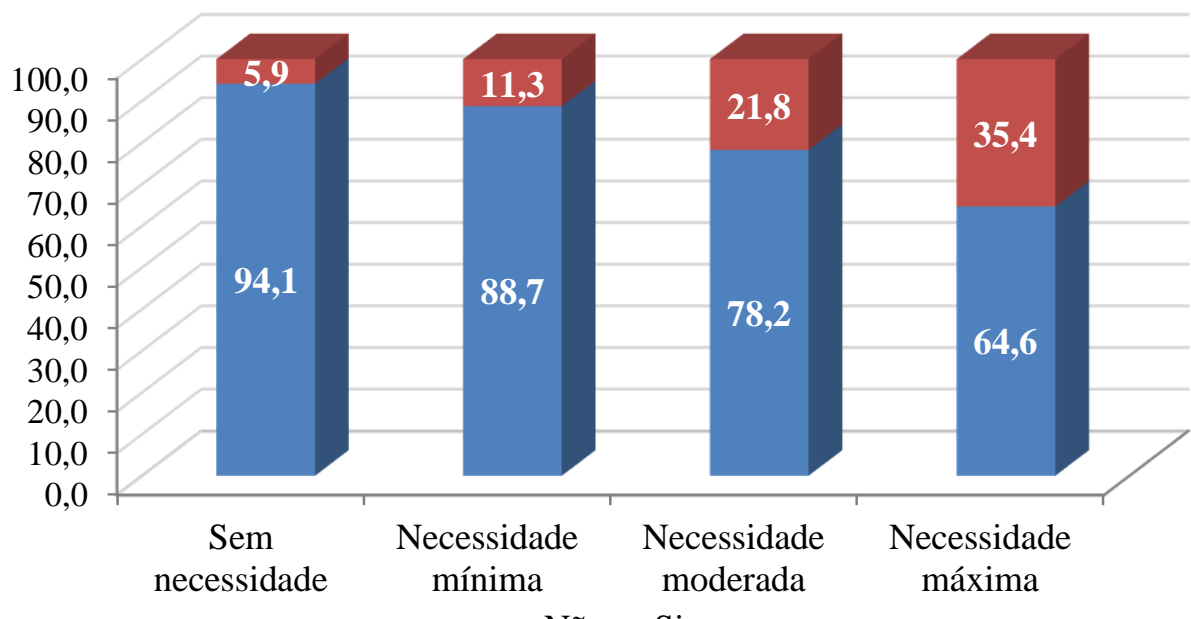

não $\quad$ Sim

$\mathrm{p}=0,000$

Fonte: Estudo SABE, 2006-2010.

\subsubsection{Fatores determinantes para a necessidade de cuidado}

$\mathrm{Na}$ coleta de 2006, 615 idosos foram classificados como sem necessidade, dos quais 459 foram reentrevistados, 51 óbitos, 105 perdas (Fluxograma 2).

Fluxograma 2. Idosos independentes acompanhados no período de quatro anos. Município de São Paulo, 2006-2010. (n=615)

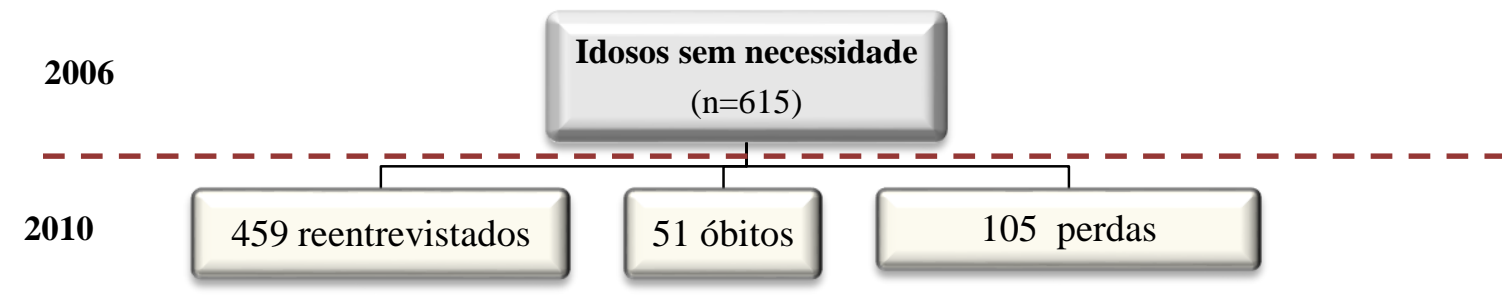


As diferenças entre as perdas, óbito e os idosos acompanhados foram encontradas no sexo e na idade, no qual idosos mais velhos e os homens tiveram maiores proporções de óbito (Tabela 9).

Tabela 9 - Distribuição (\%) dos idosos sem necessidade de cuidado no baseline segundo características sociodemográficas e condições de saúde. Município de São Paulo. Estudo SABE, 2006 (n=615)

\begin{tabular}{|c|c|c|c|c|}
\hline Características & $\begin{array}{c}\text { Total } \\
(n=615)\end{array}$ & $\begin{array}{l}\text { Acompanhados } \\
(n=459)\end{array}$ & $\begin{array}{l}\text { Óbito } \\
(n=51)\end{array}$ & $\begin{array}{l}\text { Perdas } \\
(\mathrm{n}=105)\end{array}$ \\
\hline \multicolumn{5}{|l|}{ Sociodemográficas } \\
\hline \multicolumn{5}{|l|}{ Sexo* } \\
\hline Homem & 50,6 & 48,1 & 71,5 & 55,1 \\
\hline Mulher & 49,4 & 51,9 & 28,5 & 44,9 \\
\hline \multicolumn{5}{|l|}{ Idade* } \\
\hline 60 a 69 anos & 69,3 & 72,2 & 36,2 & 67,7 \\
\hline 70 a 79 anos & 26,3 & 24,7 & 42,6 & 27,9 \\
\hline 80 anos e mais & 4,4 & 3,1 & 21,2 & 4,4 \\
\hline $\begin{array}{l}\text { Mora sozinho } \\
\text { Índice de vulnerabilidade } \\
\text { social }\end{array}$ & 12,5 & 11,9 & 11,3 & 15,4 \\
\hline Sem vulnerabilidade & 13,7 & 13,5 & 15,4 & 14,2 \\
\hline Muito baixa/baixa & 66,4 & 65,1 & 70,0 & 70,8 \\
\hline Média/alta/muito alta & 19,9 & 21,4 & 14,6 & 15,0 \\
\hline \multicolumn{5}{|l|}{ Condições de saúde } \\
\hline Hipertensão & 55,6 & 55,9 & 42,4 & 58,4 \\
\hline Diabetes & 17,7 & 16,8 & 24,1 & 19,4 \\
\hline $\begin{array}{l}\text { Doença pulmonar } \\
\text { obstrutiva crônica }\end{array}$ & 10,0 & 8,9 & 18,8 & 12,1 \\
\hline Doença cardiovascular & 17,8 & 17,7 & 29,9 & 14,0 \\
\hline Doença cerebrovascular & 3,6 & 3,4 & 0,0 & 5,5 \\
\hline Doença osteoarticular & 25,8 & 26,8 & 13,7 & 25,7 \\
\hline Osteoporose & 13,7 & 14,4 & 11,9 & 11,4 \\
\hline Declínio cognitivo & 3,1 & 3,0 & 1,1 & 4,1 \\
\hline Sintomas depressivos & 8,3 & 7,2 & 9,5 & 12,4 \\
\hline Internação & 6,7 & 5,9 & 17,2 & 6,4 \\
\hline Total & & 79,2 & $\mathbf{5 , 8}$ & 15,0 \\
\hline
\end{tabular}

$* \mathrm{p} \leq 0,005$

Fonte: Estudo SABE, 2006-2010.

Entre os idosos classificados como sem necessidade de cuidado na linha de base observou-se que, após quatro anos, 70,5\% permaneciam nesta categoria, 17,0\% apresentaram necessidade mínima, 5,4\% necessidade moderada e 7,1\% necessidade máxima (Gráfico 14). 
Gráfico 14 - Distribuição (\%) dos idosos sem necessidade de cuidado na linha de base segundo necessidade de cuidado após quatro anos. Município de São Paulo. Estudo SABE, 2006-2010. $(\mathrm{n}=459)$

2006

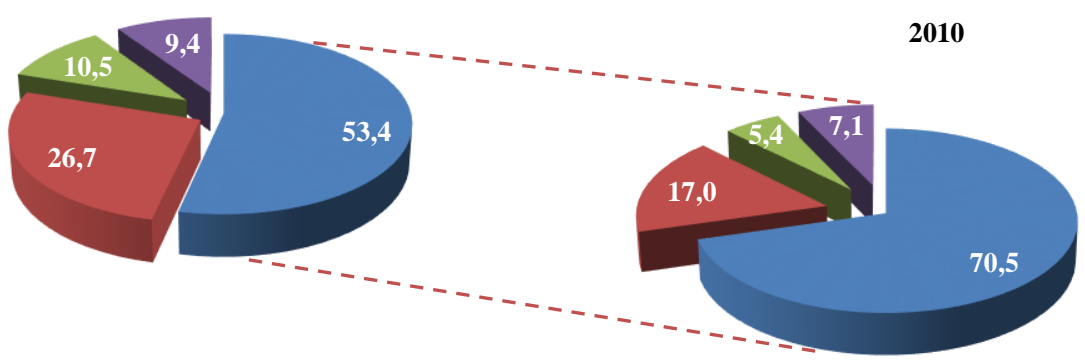

- Sem necessidade $\quad$ Necessidade mínima

$\square$ Necessidade moderada $\quad$ Necessidade máxima

Fonte: Estudo SABE, 2006-2010.

Em 2010, as maiores proporções de necessidade mínima, moderada e máxima foram encontradas entre os idosos mais velhos e com baixa escolaridade (Tabela 10).

Tabela 10 - Distribuição (\%) dos idosos sem necessidade de cuidado no baseline segundo necessidade de cuidado e características socioeconômicas e demográficas. Município de São Paulo, 2006-2010. $(n=459)$

\begin{tabular}{|c|c|c|c|c|c|}
\hline \multirow[t]{2}{*}{ Características } & \multicolumn{4}{|c|}{ Necessidade } & \multirow[t]{2}{*}{ p } \\
\hline & $\begin{array}{c}\text { Sem } \\
\text { necessidade }\end{array}$ & Mínima & Moderada & Máxima & \\
\hline Sexo & & & & & 0,134 \\
\hline Homem & 74,5 & 12,8 & 4,9 & 7,8 & \\
\hline Mulher & 66,8 & 20,9 & 5,9 & 6,4 & \\
\hline Idade & & & & & 0,006 \\
\hline 60 a 69 anos & 74,1 & 16,1 & 4,5 & 5,3 & \\
\hline 70 a 79 anos & 63,9 & 17,6 & 6,9 & 11,6 & \\
\hline 80 anos e mais & 40,5 & 30,8 & 15,7 & 13,0 & \\
\hline Estado marital & & & & & 0,609 \\
\hline $\begin{array}{c}\text { Com } \\
\text { companheiro }\end{array}$ & 70,6 & 16,2 & 7,0 & 6,2 & \\
\hline $\begin{array}{c}\text { Sem } \\
\text { companheiro }\end{array}$ & 70,4 & 17,5 & 4,5 & 7,6 & \\
\hline
\end{tabular}


(continuação)

\begin{tabular}{|c|c|c|c|c|c|}
\hline \multirow[t]{2}{*}{ Características } & \multicolumn{4}{|c|}{ Necessidade } & \multirow[t]{2}{*}{$\mathbf{p}$} \\
\hline & $\begin{array}{c}\text { Sem } \\
\text { necessidade }\end{array}$ & Mínima & Moderada & Máxima & \\
\hline Escolaridade & & & & & $\mathbf{0 , 0 3 5}$ \\
\hline Analfabeto & 54,8 & 22,1 & 13,1 & 10,0 & \\
\hline 1 a 3 anos & 66,5 & 22,3 & 5,0 & 6,2 & \\
\hline 4 a 7 anos & 69,7 & 14,8 & 6,3 & 9,2 & \\
\hline 8 anos e mais & 81,8 & 13,2 & 2,2 & 2,8 & \\
\hline Mora sozinho & & & & & 0,569 \\
\hline Não & 70,2 & 17,1 & 5,1 & 7,6 & \\
\hline Sim & 72,1 & 16,7 & 7,9 & 3,3 & \\
\hline $\begin{array}{l}\text { Insuficiência de } \\
\text { renda }\end{array}$ & & & & & 0,629 \\
\hline Não & 73,4 & 15,6 & 4,8 & 6,2 & \\
\hline Sim & 57,6 & 18,6 & 5,7 & 8,1 & \\
\hline $\begin{array}{l}\text { Vulnerabilidade } \\
\text { social }\end{array}$ & & & & & 0,126 \\
\hline $\begin{array}{l}\text { Sem } \\
\text { vulnerabilidade }\end{array}$ & 68,0 & 20,3 & 4,8 & 6,9 & \\
\hline $\begin{array}{c}\text { Muito } \\
\text { baixa/baixa }\end{array}$ & 69,1 & 20,0 & 5,5 & 5,4 & \\
\hline $\begin{array}{l}\text { Média/Alta/ } \\
\text { Muito alta }\end{array}$ & 76,3 & 6,5 & 5,9 & 11,3 & \\
\hline $\begin{array}{l}\text { Engajamento } \\
\text { social }\end{array}$ & & & & & 0,572 \\
\hline Não & 61,6 & 27,3 & 4,1 & 7,0 & \\
\hline Sim & 70,8 & 16,6 & 5,5 & 7,1 & \\
\hline $\begin{array}{l}\text { Funcionalidade } \\
\text { familiar }\end{array}$ & & & & & 0,259 \\
\hline Funcional & 70,5 & 17,6 & 5,4 & 6,5 & \\
\hline Disfuncional & 72,5 & 9,9 & 4,6 & 13,0 & \\
\hline Total & 70,5 & $\overline{17,0}$ & 5,4 & 7,1 & \\
\hline
\end{tabular}

As maiores proporção de necessidade de cuidado foram encontradas entre os idosos que autorreferiram diabetes e osteoporose, apresentaram declínio cognitivo, multimorbidade e polifarmácia (Tabela 11). 
Tabela 11 - Distribuição (\%) dos idosos sem necessidade de cuidado no baseline de acordo necessidade de cuidado e condições de saúde. Município de São Paulo, 2006-2010. (n=459)

\begin{tabular}{|c|c|c|c|c|c|}
\hline \multirow[t]{2}{*}{ Características } & \multicolumn{4}{|c|}{ Necessidade } & \multirow[t]{2}{*}{$\mathbf{P}$} \\
\hline & $\begin{array}{c}\text { Sem } \\
\text { necessidade }\end{array}$ & Mínima & Moderada & Máxima & \\
\hline $\begin{array}{l}\text { Hipertensão } \\
\text { arterial }\end{array}$ & & & & & 0,306 \\
\hline Não & 74,4 & 16,4 & 3,4 & 5,8 & \\
\hline Sim & 67,5 & 17,4 & 7,0 & 8,1 & \\
\hline Diabetes & & & & & 0,000 \\
\hline Não & 73,2 & 17,1 & 4,6 & 5,1 & \\
\hline Sim & 57,3 & 16,5 & 9,3 & 16,9 & \\
\hline $\begin{array}{l}\text { Doença pulmonar } \\
\text { obstrutiva crônica }\end{array}$ & & & & & 0,935 \\
\hline Não & 70,5 & 17,0 & 5,3 & 7,2 & \\
\hline Sim & 69,5 & 17,8 & 7,1 & 5,6 & \\
\hline $\begin{array}{l}\text { Doença } \\
\text { cardiovascular }\end{array}$ & & & & & 0,109 \\
\hline Não & 71,9 & 17,2 & 4,9 & 6,0 & \\
\hline Sim & 63,0 & 16,6 & 8,1 & 12,3 & \\
\hline $\begin{array}{l}\text { Doença } \\
\text { cerebrovascular }\end{array}$ & & & & & 0,558 \\
\hline Não & 71,2 & 16,7 & 5,2 & 6,9 & \\
\hline Sim & 52,1 & 24,1 & 12,4 & 11,4 & \\
\hline $\begin{array}{l}\text { Doença } \\
\text { osteoarticular }\end{array}$ & & & & & 0,459 \\
\hline Não & 72,4 & 16,2 & 4,9 & 6,5 & \\
\hline Sim & 64,7 & 19,9 & 7,2 & 8,2 & \\
\hline Osteoporose & & & & & 0,044 \\
\hline Não & 72,4 & 16,1 & 4,7 & 6,8 & \\
\hline Sim & 55,7 & 24,2 & 10,7 & 9,4 & \\
\hline Multimorbidade & & & & & 0,001 \\
\hline Não & 77,9 & 14,7 & 3,5 & 3,9 & \\
\hline Sim & 60,5 & 20,0 & 8,1 & 11,4 & \\
\hline Declínio cognitivo & & & & & $\mathbf{0 , 0 3 9}$ \\
\hline Não & 71,0 & 16,8 & 5,0 & 7,2 & \\
\hline Sim & 54,1 & 21,9 & 21,2 & 2,8 & \\
\hline $\begin{array}{l}\text { Sintomas } \\
\text { depressivos }\end{array}$ & & & & & 0,307 \\
\hline Não & 70,5 & 16,9 & 4,9 & 7,7 & \\
\hline Sim & 74,0 & 16,0 & 10,0 & 0,0 & \\
\hline
\end{tabular}


(continuação)

\begin{tabular}{|c|c|c|c|c|c|}
\hline \multirow[t]{2}{*}{ Características } & \multicolumn{4}{|c|}{ Necessidade } & \multirow[b]{2}{*}{$\mathbf{p}$} \\
\hline & $\begin{array}{c}\text { Sem } \\
\text { necessidade }\end{array}$ & Mínima & Moderada & Máxima & \\
\hline $\begin{array}{ll}\text { Processo } & \text { de } \\
\text { fragilização } & \end{array}$ & & & & & 0,130 \\
\hline Não & 73,4 & 16,0 & 5,4 & 5,2 & \\
\hline Sim & 65,0 & 18,6 & 5,3 & 11,1 & \\
\hline Polifarmácia & & & & & 0,004 \\
\hline Não & 76,4 & 14,8 & 3,8 & 5,0 & \\
\hline Sim & 59,8 & 21,0 & 8,4 & 10,8 & \\
\hline $\begin{array}{l}\text { Queda no último } \\
\text { ano }\end{array}$ & & & & & 0,720 \\
\hline Não & 71,8 & 16,4 & 5,1 & 6,7 & \\
\hline Sim & 65,5 & 19,2 & 6,6 & 8,7 & \\
\hline Total & 70,5 & 17,0 & 5,4 & 7,1 & \\
\hline
\end{tabular}

As variáveis relacionadas à utilização dos serviços de saúde não tiveram associação significativa com a necessidade de cuidado. No entanto, idosos que realizaram consulta no último ano apresentou maiores proporções de necessidade de cuidado (Tabela 12).

Tabela 12 - Distribuição (\%) dos idosos sem necessidade de cuidado no baseline de acordo segundo necessidade de cuidado e serviços de saúde. Município de São Paulo, 2006-2010. $(n=459)$ (continua)

\begin{tabular}{|c|c|c|c|c|c|}
\hline \multirow[t]{2}{*}{ Características } & \multicolumn{4}{|c|}{ Necessidade } & \multirow[t]{2}{*}{$\mathbf{p}$} \\
\hline & $\begin{array}{c}\text { Sem } \\
\text { necessidade }\end{array}$ & Mínima & Moderada & Máxima & \\
\hline Possui plano de saúde & & & & & 0,404 \\
\hline Não & 70,3 & 19,0 & 5,1 & 5,6 & \\
\hline $\operatorname{Sim}$ & 70,7 & 15,2 & 5,7 & 8,4 & \\
\hline $\begin{array}{l}\text { Dificuldade no acesso } \\
\text { ao serviço de saúde }\end{array}$ & & & & & 0,108 \\
\hline Não & 71,7 & 16,3 & 6,4 & 5,6 & \\
\hline Sim & 65,9 & 18,9 & 2,9 & 12,3 & \\
\hline $\begin{array}{l}\text { Realizou consulta } \\
\text { médica }\end{array}$ & & & & & 0,042 \\
\hline Não & 82,1 & 9,3 & 2,3 & 6,3 & \\
\hline Sim & 67,6 & 18,9 & 6,2 & 7,3 & \\
\hline
\end{tabular}


(continuação)

\begin{tabular}{|c|c|c|c|c|c|}
\hline \multirow[b]{2}{*}{ Características } & \multicolumn{3}{|c|}{ Necessidade } & \multirow[b]{2}{*}{ Máxima } & \multirow[b]{2}{*}{$\mathbf{p}$} \\
\hline & $\begin{array}{c}\text { Sem } \\
\text { necessidade }\end{array}$ & Mínima & Moderada & & \\
\hline $\begin{array}{l}\text { Utilizou o serviço de } \\
\text { urgência/emergência }\end{array}$ & & & & & 0,698 \\
\hline Não & 71,0 & 17,2 & 5,1 & 6,7 & \\
\hline Sim & 66,2 & 15,5 & 8,5 & 9,8 & \\
\hline Internação & & & & & 0,065 \\
\hline Não & 71,7 & 17,0 & 4,8 & 6,5 & \\
\hline Sim & 51,5 & 16,6 & 15,2 & 16,7 & \\
\hline Total & 70,5 & 17,0 & 5,4 & 7,1 & \\
\hline
\end{tabular}

Entre os idosos sem necessidade de cuidado no baseline, os fatores determinantes para desenvolvimento de necessidade foram: para mínima, sexo, idade, mobilidade física prejudicada; para necessidade moderada, idade e declínio cognitivo e, para necessidade máxima, idade e multimorbidade (Tabela 13).

Tabela 13 - Fatores determinantes para a necessidade de cuidado em idosos independentes. Município de São Paulo. Estudo SABE, 20062010. $(n=459)$

\begin{tabular}{lcc}
\hline Fatores & RRR $_{\text {aj }}[\mathrm{IC}$ 95\% $]$ & $\mathbf{p}$ \\
\hline Necessidade mínima* & $1,81[1,05-3,13]$ & 0,032 \\
Sexo (feminino) & $2,84[1,17-6,86]$ & 0,021 \\
Idade (80 anos e mais) & $2,94[1,02-8,43]$ & 0,045 \\
Mobilidade física prejudicada & & \\
Necessidade moderada** & $5,58[1,55-20,00]$ & 0,009 \\
Idade (80 anos e mais) & $7,83[1,60-38,24]$ & 0,012 \\
Declínio cognitivo & & \\
Necessidade máxima*** & $2,60[1,13-5,96]$ & 0,026 \\
Idade (70 anos a 79 anos) & $5,59[1,87-16,62]$ & 0,002 \\
Idade ( $\geq 80$ anos) & $3,50[1,32-9,30]$ & 0,012 \\
Multimorbidade &
\end{tabular}

\footnotetext{
*Ajustado por vulnerabilidade social, dificuldade no acesso aos serviços de saúde, declínio cognitivo, multimorbidade, queda e fragilidade.

** Ajustado por vulnerabilidade social, dificuldade no acesso aos serviços de saúde, sexo, multimorbidade, queda e fragilidade.

*** Ajustado por vulnerabilidade social, dificuldade no acesso aos serviços de saúde, sexo, queda e fragilidade.
} 


\subsubsection{Fatores determinantes para a piora entre os níveis de necessidade de cuidado}

Dos 798 idosos, no baseline, com alguma necessidade de cuidado somente 456 foram reentrevistados em 2010 (Fluxograma 3).

Fluxograma 3 - Fluxograma dos idosos com necessidade de cuidado (mínima, moderada e máxima) acompanhados no período de quatro anos. Município de São Paulo, 20062010. $(n=798)$

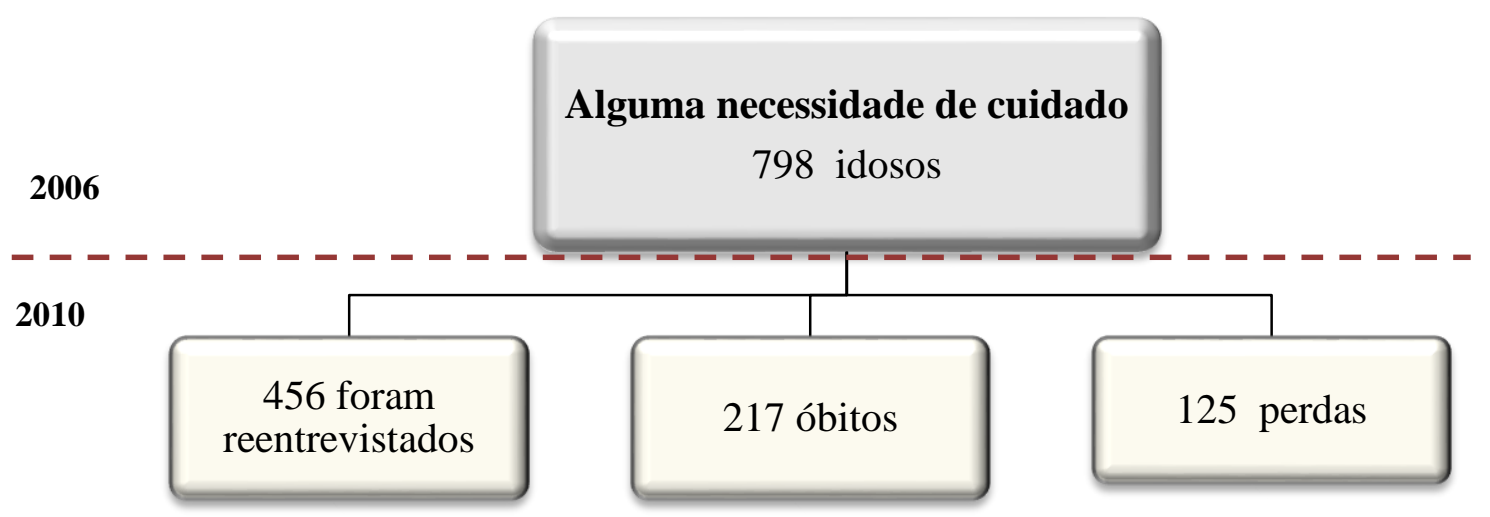

No início do acompanhamento, 64,6\% dos idosos foram classificados como necessidade mínima, 21,5\% necessidade moderada e 13,9\% necessidade máxima. Entre os idosos com necessidade mínima, 30,2\% mantiveram-se neste mesmo nível; 41,4\% evoluíram positivamente para a categoria sem necessidade de cuidado; e, pioraram 14,3\% e 14,0\% para necessidade moderada e máxima, respectivamente (Tabela 14).

Em relação aos idosos com necessidade moderada, 17,1\% melhoraram e foram classificados como sem necessidade, 21,2\% para necessidade mínima, 31,5\% necessidade moderada e 30,2\% pioraram para necessidade máxima. Quanto aos idosos com necessidade máxima, 52,2\% mantiveram nessa mesma condição, 21,6\% retornaram para necessidade moderada, $17,4 \%$ evoluíram para necessidade mínima e 8,7\% foram classificados como sem necessidade (Tabela 14). 
Tabela 14 - Distribuição (\%) dos idosos segundo classificação de necessidade de cuidado no baseline e no acompanhamento. Município de São Paulo, 2006-2010. (n=456)

\begin{tabular}{|c|c|c|c|c|c|}
\hline \multirow{2}{*}{$\begin{array}{c}\text { Necessidade } \\
\text { de cuidado } \\
2006\end{array}$} & \multicolumn{4}{|c|}{$\begin{array}{l}\text { Necessidade de cuidado } \\
2010\end{array}$} & \multirow[t]{2}{*}{ Total } \\
\hline & $\begin{array}{c}\text { Sem } \\
\text { necessidade }\end{array}$ & Mínima & Moderada & Máxima & \\
\hline Mínima & 41,4 & 30,2 & 14,3 & 14,0 & 64,6 \\
\hline Moderada & 17,1 & 21,2 & 31,5 & 30,2 & 21,5 \\
\hline Máxima & 8,7 & 17,4 & 21,6 & 52,2 & 13,9 \\
\hline Total & 31,6 & 26,5 & 19,0 & 22,8 & 100,0 \\
\hline
\end{tabular}

Fonte: Estudo SABE, 2006-2010.

A partir da evolução da necessidade de cuidados, 33,6\% mantiveram-se na mesma categoria, 24,8\% pioraram e 41,6\% melhoraram. As características socioeconômicas e demográficas dos idosos que pioraram a necessidade de cuidado não diferiram daqueles que mantiveram ou melhoram a condição. A proporção de piora da necessidade de cuidado aumentou quando aumentava a idade, diminuía os níveis de escolaridade e não havia engajamento social (Tabela 15).

Tabela 15 - Distribuição (\%) dos idosos de acordo com a piora da necessidade de cuidado e características socioeconômicas e demográficas. Município de São Paulo, 2006-2010. (n=456) 
(continuação)

\begin{tabular}{|c|c|c|c|}
\hline \multirow[t]{2}{*}{ Características } & \multicolumn{2}{|c|}{ Piora da necessidade de cuidado } & \multirow[t]{2}{*}{$\mathbf{p}$} \\
\hline & Não & Sim & \\
\hline Escolaridade & & & 0,475 \\
\hline Analfabeto & 70,0 & 30,0 & \\
\hline 1 a 3 anos & 74,3 & 25,7 & \\
\hline 4 a 7 anos & 77,4 & 22,6 & \\
\hline 8 anos e mais & 80,2 & 19,8 & \\
\hline Mora sozinho & & & 0,797 \\
\hline Não & 75,4 & 24,6 & \\
\hline Sim & 73,7 & 26,3 & \\
\hline Insuficiência de renda & & & 0,485 \\
\hline Não & 73,3 & 26,7 & \\
\hline Sim & 76,6 & 23,4 & \\
\hline Vulnerabilidade social & & & 0,616 \\
\hline Sem vulnerabilidade & 81,8 & 18,2 & \\
\hline Muito baixa/baixa & 73,8 & 26,2 & \\
\hline Média/Alta/ Muito alta & 75,6 & 24,4 & \\
\hline Engajamento social & & & 0,334 \\
\hline Não & 68,7 & 31,3 & \\
\hline Sim & 75,9 & 24,1 & \\
\hline Funcionalidade familiar & & & 0,940 \\
\hline Funcional & 76,5 & 23,5 & \\
\hline Disfuncional & 76,0 & 24,0 & \\
\hline Total & 75,2 & 24,8 & \\
\hline
\end{tabular}

Em relação às condições de saúde, idosos fragilizados e com mobilidade física prejudicada apresentaram maiores proporções de piora de necessidade de cuidado (Tabela 16).

Tabela 16 - Distribuição (\%) dos idosos de acordo com a piora da necessidade de cuidado e condições de saúde. Município de São Paulo, 2006-2010. ( $\mathrm{n}=456)$

\begin{tabular}{lccc}
\hline Condições de saúde & \multicolumn{2}{c}{ Piora da necessidade de cuidado } & p \\
\cline { 2 - 3 } & Não & Sim & \\
\hline Hipertensão arterial & & & 0,041 \\
Não & 82,6 & 17,4 & \\
Sim & 72,5 & 27,5 & \\
\end{tabular}


(continuação)

\begin{tabular}{|c|c|c|c|}
\hline \multirow[t]{2}{*}{ Características } & \multicolumn{2}{|c|}{ Piora da necessidade de cuidado } & \multirow[t]{2}{*}{$\mathbf{p}$} \\
\hline & Não & Sim & \\
\hline Sexo & & & 0,818 \\
\hline Diabetes & & & 0,913 \\
\hline Não & 75,2 & 24,8 & \\
\hline Sim & 74,7 & 25,3 & \\
\hline $\begin{array}{l}\text { Doença pulmonar obstrutiva } \\
\text { crônica }\end{array}$ & & & 0,268 \\
\hline Não & 74,0 & 26,0 & \\
\hline Sim & 82,4 & 17,6 & \\
\hline Doença cardiovascular & & & 0,382 \\
\hline Não & 76,3 & 23,7 & \\
\hline Sim & 72,7 & 27,3 & \\
\hline Doença cerebrovascular & & & 0,109 \\
\hline Não & 76,5 & 23,5 & \\
\hline Sim & 63,7 & 36,3 & \\
\hline Doença osteoarticular & & & 0,242 \\
\hline Não & 72,2 & 27,8 & \\
\hline Sim & 77,7 & 22,3 & \\
\hline Osteoporose & & & 0,520 \\
\hline Não & 74,0 & 26,0 & \\
\hline Sim & 77,2 & 22,8 & \\
\hline Multimorbidade & & & 0,097 \\
\hline Não & 80,6 & 19,4 & \\
\hline Sim & 72,9 & 27,1 & \\
\hline Declínio cognitivo & & & 0,063 \\
\hline Não & 76,8 & 23,2 & \\
\hline Sim & 66,0 & 34,0 & \\
\hline Sintomas depressivos & & & 0,340 \\
\hline Não & 77,6 & 22,4 & \\
\hline Sim & 72,7 & 27,3 & \\
\hline Processo de fragilização & & & 0,000 \\
\hline Não & 86,5 & 13,5 & \\
\hline Sim & 68,9 & 31,1 & \\
\hline Polifarmácia & & & 0,149 \\
\hline Não & 77,9 & 22,1 & \\
\hline Sim & 72,0 & 28,0 & \\
\hline Queda no último ano & & & 0,994 \\
\hline Não & 75,2 & 24,8 & \\
\hline Sim & 75,2 & 24,8 & \\
\hline Mobilidade física prejudicada & & & $\mathbf{0 , 0 0 0}$ \\
\hline Não & 79,3 & 20,7 & \\
\hline Sim & 62,5 & 37,5 & \\
\hline Total & 75,2 & 24,8 & \\
\hline
\end{tabular}


As variáveis relacionadas à utilização dos serviços de saúde não tiveram associação significativa com a piora da necessidade de cuidado. No entanto, é válido destacar que um terço dos idosos que utilizaram somente a internação apresentaram maiores proporções de piora da necessidade de cuidado (Tabela 17).

Tabela 17 - Distribuição (\%) dos idosos de acordo com a piora da necessidade de cuidado e utilização dos serviços de saúde. Município de São Paulo, 2006-2010. (n=456)

\begin{tabular}{|c|c|c|c|}
\hline \multirow[t]{2}{*}{ Utilização dos serviços de saúde } & \multicolumn{2}{|c|}{$\begin{array}{c}\text { Piora da necessidade de } \\
\text { cuidado }\end{array}$} & \multirow[t]{2}{*}{$\mathbf{p}$} \\
\hline & Não & Sim & \\
\hline Possui plano de saúde & & & 0,876 \\
\hline Não & 74,9 & 25,1 & \\
\hline Sim & 75,6 & 24,4 & \\
\hline $\begin{array}{l}\text { Dificuldade no acesso ao serviço de } \\
\text { saúde }\end{array}$ & & & 0,339 \\
\hline Não & 73,4 & 26,6 & \\
\hline Sim & 78,5 & 21,5 & \\
\hline Realizou consulta médica & & & 0,795 \\
\hline Não & 74,0 & 26,0 & \\
\hline Sim & 75,4 & 24,6 & \\
\hline $\begin{array}{l}\text { Utilizou o serviço de } \\
\text { urgência/emergência }\end{array}$ & & & 0,103 \\
\hline Não & 73,5 & 26,5 & \\
\hline Sim & 81,1 & 18,2 & \\
\hline Internação & & & 0,528 \\
\hline Não & 74,7 & 25,3 & \\
\hline Sim & 79,0 & 21,0 & \\
\hline $\begin{array}{l}\text { Serviços de saúde utilizados os } \\
\text { últimos } 12 \text { meses }\end{array}$ & & & 0,662 \\
\hline Somente consulta médica & 74,2 & 25,8 & \\
\hline Somente serviços & 78,3 & 21,7 & \\
\hline urgência/emergência & & & \\
\hline Somente internação hospitalar & 68,0 & 32,0 & \\
\hline Utilizou consulta+urgência & 79,6 & 20,1 & \\
\hline Utilizou consulta+internação & 71,9 & 28,1 & \\
\hline $\begin{array}{l}\text { Utilizou consulta+urgência+ } \\
\text { internação }\end{array}$ & 92,9 & 25,8 & \\
\hline Utilizou urgência+internação & 100,0 & 0,0 & \\
\hline Não utilizou nenhum dos serviços & 70,1 & 29,9 & \\
\hline Total & 75,2 & 24,8 & \\
\hline
\end{tabular}

Fonte: Estudo SABE, 2006-2010. 
Idosos em processo de fragilização tiveram uma chance de 2,12 vezes de piora da necessidade quando comparados aos não frágeis. Idosos com mobilidade física prejudicada apresentaram chance de 1,77 vezes de piora quando comparados àqueles com mobilidade preservada (Tabela 18).

Tabela 18 - Fatores determinantes para a piora da necessidade de cuidado entre os idosos. Município de São Paulo. Estudo SABE, 20062010. $(n=456)$

\begin{tabular}{lcc} 
Fatores & OR $_{\text {aj }}[\mathrm{IC} \mathrm{95 \% ]}$ & $\mathbf{p}$ \\
\hline Processo de fragilização & $2,12[1,05-4,27]$ & 0,037 \\
Mobilidade física prejudicada & $1,77[1,01-3,12]$ & 0,049
\end{tabular}

**Ajustado por idade, sexo, funcionalidade familiar, vulnerabilidade social, multimorbidade, declínio cognitivo. 
DISCUSS ÃO

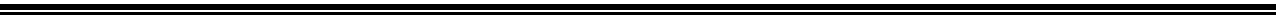




\section{DISCUSSÃO}

Com os resultados foi possível observar uma hierarquização nas dificuldades referidas para o desempenho das atividades de vida diária. Inicialmente observou-se o comprometimento nas AIVDs e em seguida nas ABVDs, corroborando com outros estudos (Ramos et al., 1993; Finlaysona, Mallinsonb, Barbosac, 2005; Torres, 2009). Durante o processo de envelhecimento, as perdas das habilidades para o desenvolvimento dessas atividades acontecem primeiramente naquelas que são consideradas mais complexas evoluindo para as atividades mais simples. Diferente de alguns estudos, não incluiu-se a "continência", pois não implica isoladamente em um maior comprometimento funcional (Guralnik, Simonsick, 1993; Moraes, 2012).

Em relação aos resultados obtidos a partir da escala de Guttman, observaram-se coeficientes satisfatórios o que demonstra que há uma hierarquia nas dificuldades das atividades de vida diária. Os dados encontrados podem ser corroborados com estudo que avaliou três grupos de idosos. Um deles refere-se a uma amostra de idosos de base populacional e os outros de amostras idosos avaliados a partir dos serviços de saúde (MedCaid e Medicare) Os autores observaram uma alta intercorrelação (alpha de Cronbach acima de 0,70) entre as variáveis de medidas funcionais, apontando a unidimensionalidade em todos os três estudos. Em cada estudo, obtiveram-se coeficiente de reprodutibilidade maior que 0,90 e coeficientes de escalabilidade superiores a 0,70 (Spector et al., 1987). Tais resultados apontam índices satisfatórios que representam a hierarquia das dificuldades no desempenho das atividades cotidianas. Podendo assim, inferir a unidimensionalidade do comprometimento funcional.

Também o estudo de Ramos et al. (1993) apontou um coeficiente de reprodutibilidade de 0,94 e escalabilidade de 0,65. Esses autores ainda sugeriram uma escada de declínio funcional de acordo com as seguintes atividades: fazer compras (49\%), utilizar transporte (42\%), cuidar das finanças $(33 \%)$, manusear os medicamentos (21\%), incontinência (10\%), caminhar $(9 \%)$, vestir $(8 \%)$, tomar banho $(6 \%)$, comer $(5 \%)$, ir ao banheiro 
(6\%), realizar higiene pessoal (6\%) e levantar da cama para a cadeira (4\%). Torres (2009) avaliou 2143 idosos do município de São Paulo e também encontrou coeficientes satisfatórios (coeficiente de reprodutibilidade de 0,90 e de escalabilidade de 0,89).

Assumindo os pressupostos da existência de uma hierarquia das dificuldades dos idosos em realizar as atividades cotidianas, estabeleceu-se a classificação de necessidade de cuidados. Necessidade de cuidado, nesse estudo, refere-se às dificuldades apresentadas pelos idosos para o desempenho das atividades cotidianas que requeriam auxílio de outra pessoa para desempenhá-las.

Idosos com algum grau de dependência apresentam maiores proporções de internação quando comparados àqueles independentes. Notase que a assistência a envolve serviços de reabilitação, educação em saúde, múltiplos tratamentos e terapias, próteses, bem como o cuidado informal e formal na comunidade (Ramos et al., 1993).

O reconhecimento dos níveis de dependência e a oferta de cuidados específicos são importantes para garantir a promoção do bem estar na velhice, ou seja, a função de preservação do bom estado funcional.

Assim, a estratificação da necessidade de cuidado em níveis possibilita identificar os grupos mais dependentes e que requerem mais atenção assim como aqueles independentes e promoverem ações que mantenham a funcionalidade.

A frequência do manuseio do telefone é diária dependendo da demanda do idoso. O uso do telefone envolve o ato de ligar e receber ligações e para a sua execução está relacionada com a capacidade cognitiva, aspectos culturais, escolaridade, boa acuidade auditiva e visual e habilidades motoras finas.

Nunes et al. (2010) identificaram entre os idosos com dependência moderada que $21,4 \%$ apresentam dificuldade para o manuseio do telefone. Os autores também afirmam que essa atividade esteve associada com declínio cognitivo, sintomas depressivos, mobilidade prejudicada, além de baixa escolaridade. 
O idoso pode apresentar dificuldades, em especial no ato de ligar, devido às tecnologias existentes nos aparelhos. Alguma pessoa pode ensinar o idoso a manusear o aparelho, assim como, a adoção de aparelhos adaptados para garantir a realização dessa atividade (Goodman, Brewster, Gray, 2004). Optou-se por incluir essa atividade na classificação da necessidade mínima pelo fato de o idoso demandar de auxílio quando houver a atividade em momentos esporádicos durante o dia.

Tal classificação não subestima o cuidado para com essa atividade, uma vez que, trata-se de um meio de comunicação para o idoso e favorece o convívio social. Além disso, o uso do telefone possibilita o acesso do idoso a diversos serviços dentre eles os de saúde, como marcação de consultas e solicitação de atendimento de emergência (Hassan, Nasir, 2008; Torres, 2009).

A atividade "uso de transporte" refere-se ao deslocamento do idoso por meio da utilização de um transporte (automóvel, taxi, ônibus e outros) para se deslocar (OMS, 2004), permitindo a socialização dos idosos com amigos e parentes e o acesso a bens e aos serviços de saúde. Algumas alterações fisiológicas podem influenciar na utilização do transporte como o tempo de reação, visão, audição, a força muscular e amplitude de movimento (Coughlin, 2001; Ragland; Satariano; MacLeod, 2004; MacLeod et al., 2014).

Essa atividade é importante para a manutenção da autonomia e autoestima no idoso. No entanto, não é incomum para os idosos a fazer mudanças graduais ao longo dos anos para os seus hábitos de transporte e padrões em resposta às mudanças de suas necessidades e capacidades. Estudo com grupo focal de idosos que cessaram a atividade dirigir apontou que todos os participantes recebiam ajuda de amigos, família e / ou vizinhos para satisfazer as necessidades de transporte. No entanto, muitos participantes estavam com medo de tornar-se um fardo. Além disso, relataram não usar o transporte público por ser inseguro, inadequado e, geralmente, não responder às suas necessidades (Adler, Rottunda, 2006).

A família é a principal fonte de apoio aos idosos com comprometimento na utilização do transporte. Taylor e Tripodes (2001) 
avaliaram 315 idosos com demência na Califórnia e apontaram que cônjuges e filhos adultos fornecem regularmente o transporte para o idoso, prestando auxílio no deslocamento às compras, ao consultório médico e às atividades sociais/lazer. Ainda observou que metade dos cuidadores não faltou ao trabalho para auxílio transporte, $33 \%$ faltaram ao trabalho, pelo menos ocasionalmente e $13 \%$ deixaram de trabalhar.

A independência para preparar refeição e situação alimentar, foi muito valorizado entre mulheres mais velhas (Sidenvall, Nydahl, Fjellström, 2001; Gustafsson et al., 2003). Entre idosos com mobilidade física comprometida observou a influência importante sobre a realização de compras e preparação de refeições, que por sua vez, resultaram no baixo consumo de refeições quentes levando a ingesta alimentar insuficiente (Wylie, Copeman, Kirk, 1999).

Preparar refeições está relacionado com os papéis sociais e questões saúde. As mulheres independentes para o preparo das refeições temia se tornar um fardo para a sociedade ou parentes. No entanto, quando foi necessária ajuda, parentes ou amigos eram os provedores de ajuda preferenciais. Familiares ajudavam em pequenas atividades, facilitando, assim, independência, enquanto, as amigas, auxiliavam nas compras (Andersson et al., 2003; Gustafsson et al., 2003).

Gustafsson et al. (2003) apontam que as mulheres dependentes para o preparo da refeições apresentaram estratégias de adaptação à realidade dentre elas citam-se a reabilitação e uso do serviço de transporte para realizar as compras, o que permitiu maior independência.

A atividade manejo da própria medicação requer o planejamento, organização e execução da atividade, exigindo habilidades cognitivas complexas. Quanto ao planejamento, o idoso deve programar os horários e quais medicamentos tomarão em cada momento. Em seguida, a organização dos próprios medicamentos exige boa acuidade visual e algum nível de instrução para a identificação dos medicamentos e, por fim a execução da atividade. Essa última por sua vez requer, muitas vezes, habilidade motora fina preservada para manuseio dos comprimidos. Doenças articulares com rigidez das articulações associada à redução da força muscular dos membros 
superiores também dificultam a execução. A não execução dessa atividade pode comprometer o controle de doenças crônicas. Portanto, reconhece-se a necessidade de um cuidado diário para auxiliar o idoso nessa atividade para garantir uma estabilidade no quadro clínico.

Os dados do estudo apontam maior proporção de dificuldade no desempenho de atividades como vestir e transferir-se. Alguns autores contradizem essa ordem reafirmando que o idoso apresenta dificuldade, primeiramente, em atividades como transferir-se, tomar banho e caminhar em decorrência da redução da força nos membros inferiores (Dunlop, Hughes, Manheim, 1997).

No entanto, Alexandre et al (2012) afirmam que o ato de vestir requer força de membros superiores, flexibilidade, coordenação motora fina, força de membros inferiores e equilíbrio. Esta mudança sutil tem limitado a consequência num curto período de tempo, transformar o estado funcional do idoso a partir de independente sobre dependente.

Higiene pessoal e tomar banho afetam o conforto, a segurança e o bem-estar dos idosos. Os cuidados de higiene incluem atividades que mantém a limpeza pessoal e a aparência do corpo. Atividades de higiene pessoal como tomar banho, escovar os dentes e usar fio dental, lavar e pentear os cabelos e realizar os cuidados com as unhas - promovem conforto, relaxamento, uma autoimagem positiva uma pele saudável e, ajudam a prevenir infecções e doenças (Potter et al., 2103).

A ausência de boa higiene pode ser indício de declínio cognitivo, dificuldades motoras ou por presença de maus tratos por parte das pessoas responsáveis pelo cuidado do idoso. Quando o idoso não consegue se higienizar pode não se sentir confortável para o convívio, podendo ser marginalizado pelas pessoas com quem convive (Torres, 2009; Souza et al., 2007).

Fatores pessoais, sociais e culturais que influenciam o desempenho dessa atividade. Quanto aos fatores pessoais, estimular que o idoso verbalize as preferências e os desejos sobre a realização da higiene, promover a individualização do cuidado. Em relação aos aspectos pessoais, o cuidador deve reconhecer a frequência e os produtos utilizados para a higiene. Além 
disso, no ambiente doméstico, orientar o idoso e à família quanto às adaptações, técnicas e abordagens de higiene, a fim de promoção uma relação de cuidado terapêutico (Potter et al., 2103).

É importante destacar aos profissionais que prestarão cuidados non domicílio do idoso que o ambiente contém uma história própria e significados inerentes àquela família. A assistência desenvolvida no domicílio deverá levar em consideração as características e rotinas próprias da família (Duarte, Diogo, 2013). Assim, durante os cuidados de higiene deve-se preservar o máximo possível a independência do idoso, garantir a privacidade, transmitir respeito e propiciar bem-estar físico e segurança.

Em relação à higiene oral, nota-se que idosos paulistanos têm alta prevalência de edentulismo (69,4\% das mulheres e 30\% dos homens) comparados às outras faixas etárias (Teixeira, 2007). Vários motivos podem desencadear uma saúde bucal ruim, um deles é a higiene bucal deficiente durante toda a vida do indivíduo, uso de alguns medicamentos (iatrogênicos para a saúde bucal), falta de orientação e de interesse em saúde bucal e ao não acesso aos serviços de assistência odontológica (Dini, Castellanos, 1993; Pucca Jr., 1996).

Ramos et al (2013) apontam que "deitar/levantar da cama", "pentear os cabelos", "tomar banho" e "vestir a roupa" são necessidade essenciais e que, quando necessitam de ajuda para serem realizadas, requerem o auxílio de outra pessoa para realizar tais atividades com alguma segurança e regularidade. Uma parcela da população requer auxílio para essas atividades, o que em última estância, o idoso não tem condições adequadas ou dignas para viver só, e deve ser foco de vigilância e prevenção de agravos.

O comprometimento dessas atividades requer uma mudança na reorganização dos serviços a fim de promover uma qualidade de vida dos idosos, espera-se que essas pessoas envelheçam com dignidade e segurança, desfrutando da vida através da plena realização de todos os direitos humanos e liberdades fundamentais. 
Quanto à classificação da necessidade de cuidados, mais da metade dos idosos entrevistados foram considerados independentes e não necessitando de um cuidador de forma esporádica ou integral.

Entre esse grupo é importante preservar a independência e autonomia por meio da participação social de acordo com seus desejos e capacidades; e ao mesmo tempo, propiciar proteção, segurança e cuidados de saúde adequados, quando necessários (Brasil, 2005).

Uma das estratégias que promove e mantem o bem-estar pessoal por meio da participação em atividades sociais, destacam-se os grupos de convivência que constituem um meio importante para facilitar a participação mediante a realização de atividades de promoção e o fomento da interação entre as gerações (ONU, 2003).

Em relação aos níveis de cuidado, 26,7\% necessitavam de um cuidador em períodos intermitentes (quando necessitava) para auxílio em algumas AIVD, 10,5\% dos idosos apresentavam necessidade moderada, os quais requerem um cuidador de forma rotineira para o auxílio das atividades já comprometidas e 9,4\% apresentaram necessidade máxima, ou seja, necessitam de cuidador em tempo integral. Esses achados demonstram que cerca de $20 \%$ dos nossos idosos necessitam de um cuidador, o que exige da família uma reorganização para o cuidado a ser ofertado a esse idoso.

Giacomin et al. (2005) avaliaram a necessidade do cuidador por meio da presença da dificuldade nas atividades como comer, vestir-se, ir ao banheiro, banhar-se, levantar-se de uma cadeira sem apoio; e/ou presença de incapacidade cognitiva; e encontraram uma prevalência de $23 \%$ de idosos que necessitavam de cuidador. Esse grupo era constituído por idoso com baixa escolaridade e renda domiciliar, não dispunha de recursos assistenciais comunitários, sendo a família a principal provedora de cuidado.

Entre os idosos, os fatores associados aos níveis de cuidado mínimo, moderado e máximo foram idade, ser do sexo feminino, processo de fragilização, mobilidade física prejudicada e dificuldade no acesso aos serviços de saúde.

Com o processo fisiológico do envelhecimento, a capacidade funcional de cada sistema do organismo humano diminui. Até 
aproximadamente os 20 ou 30 anos, quando se atinge um ápice, as pessoas vão desenvolvendo suas capacidades e, a partir daí, o desempenho funcional vai declinando pouco a pouco, ao longo dos anos, ocorrendo o denominado envelhecimento funcional (Paschoal, 2002).

O comprometimento funcional está relacionado à idade e é geralmente considerado como um ponto de extremidade comum, através de comprometimento nos domínios físico, cognitivo ou sensorial, das doenças crônicas e condições que afetam pessoas de envelhecimento (Fried, Guralnik, 1997).

Um fenômeno importante encontrado na população idosa é o aumento dos idosos longevos, ou seja, indivíduos com idade igual ou superior a 80 anos. Esse grupo apresenta peculiaridades comuns devido às alterações nessa faixa etária (Camarano, Kanso, Mello, 2004). Observaramse nesse grupo maiores chances de apresentar necessidade de cuidados e, consequentemente, e quase $90 \%$ deles recebiam mais ajuda de um cuidador para atender as suas demandas. Isso reflete um quadro de sobrevivência de idosos na dependência de pessoas para suprirem suas dificuldades nas atividades cotidianas.

Ademais, entre os idosos sem necessidade de cuidado no baseline encontraram-se naqueles que eram longevos maiores risco de apresentar necessidade de cuidado (mínima, moderada e máxima) em um período de quatro anos. O envelhecimento é inevitável, no entanto, urge a necessidade de conhecer as peculiaridades do envelhecimento a fim de atender esse grupo etário com maior especificidade. Esse grupo apresenta maiores demandas de cuidado e, consequentemente, exige mudança na estrutura da família para ofertar o cuidado. Os serviços de saúde também deverão ser reorganizados a fim de disponibilizar recursos para atender as demandas específicas desse grupo etário.

Entre a população idosa, as mulheres apresentam maior proporção devido à maior expectativa de vida quando comparada aos homens. Embora as mulheres vivam mais, a proporção de anos vividos livre de incapacidade é menor nesse grupo (Camargos, Perpetuo, Machado, 2005). 
Vários estudos apontam que as mulheres idosas apresentam maior prevalência e incidência de dificuldade para ABVD e AIVD do que nos homens (Stuck et al., 1999; Zunzunegui et al., 2009; Nunes et al., 2010; Alexandre et al., 2012; Alexandre et al., 2014).

As diferenças entre homens e mulheres decorrem em função da exposição a fatores biológicos e sociais ao longo da vida. Dentre as biológicas, devem-se considerar o tipo e severidade de condições crônicas, os marcadores neuroendócrinos e imunológicos. Além disso, as mulheres utilizam com mais frequência os serviços de saúde e estão mais atentas às anormalidades (Artazcoz et al, 2004; Varadhan et al., 2008; Sen, Östlin, 2008).

Destaca-se que embora as mulheres vivam mais apresentam maiores chances de requerer um cuidador por apresentarem um comprometimento na funcionalidade. Entre as mulheres que necessitavam de cuidado observou-se a maioria referiu ter suas demandas atendidas $(71,6 \%)$ semelhantes à proporção entre os homens $(76,7 \%)$. Nesse estudo, entre os idosos sem necessidade de cuidado no baseline identificou que as mulheres tinham um risco de $80 \%$ de desenvolverem necessidade mínima em um período de quatro anos.

Notou-se após o acompanhamento, que as mulheres pioraram o declínio das atividades com funções mais complexas como, por exemplo, utilizar transporte, fazer compras e tarefas domésticas. Segundo, OMS (2005) a saúde das mulheres idosas geralmente é negligenciada ou ignorada. Associado a essa condição possuem pouca ou nenhuma renda por não terem trabalho remunerado, o que pode aumentar o comprometimento funcional. Em detrimento da funcionalidade e da segurança econômica, o cuidado será suprido pelos familiares.

Caso o idoso requeira uma necessidade mínima e não há um suporte familiar suficiente, uma possibilidade de serviço seria o Programa de Acompanhante de Idosos (PAI). Esse programa é uma estratégia exitosa proposta pela Secretaria Municipal de Saúde do município de São Paulo atende idosos com comprometimento funcional, mobilidade reduzida, dificuldade de acesso aos serviços de saúde, insuficiência no suporte 
familiar e social. Tal programa tem como diretrizes incentivar a autonomia e independência, propiciar a inserção e participação social da pessoa idosa e oferecer suporte técnico às famílias (São Paulo, 2012).

A síndrome da fragilidade emerge como um dos desafios do século 21 na área gerontogeriátrica por ser preditora de eventos como declínio funcional e outros eventos adversos à saúde (Fried; Guralnik, 1997; Newman et al., 2001; Fried et al., 2004; Fabrício, Rodrigues, 2008; Duarte, Lebrão, 2013). O processo de fragilização esteve associado à necessidade de cuidados, em consequência da vulnerabilidade apresentada pelos idosos, que exigem cuidados contínuos, progressivos e complexos serviços sociais e de saúde.

A fragilidade é definida como um processo fisiopatológico único, resultante de alterações em uma série de mecanismos biológicos e que leva a modificações de múltiplos sistemas e, eventualmente, ao desequilíbrio homeostático. A diminuição de reservas fisiológicas e aumento da vulnerabilidade dos indivíduos resultam em um processo interno e progressivo exteriorizado por um fenótipo composto por cinco componentes mensuráveis: perda de peso não intencional, fadiga, redução da força e da velocidade de caminhada e baixa atividade física (Fried et al., 2001; Duarte, Lebrão, 2013).

O fenótipo de fragilidade foi proposto e validado por Fried et al. (2001) tem sido utilizado em diversos estudos em diferentes regiões do mundo e encontrada uma prevalência variando de $5 \%$ a $20 \%$ de idosos frágeis e uma incidência anual de 7\% (Avila-Funes et al., 2008; VarelaPinedo, Ortiz-Saavedra, Chávez-Jimeno, 2008; Santos-Eggimann et al., 2009). No Brasil, Duarte et al. (2010) avaliaram 1.115 idosos ( $\geq 65$ anos) residentes no município de São Paulo - identificaram uma prevalência de fragilidade de 8,6\% no ano de 2006. Estudos pertencentes à Rede Fibra nos municípios de São Paulo (Distrito Hermelino Matarazzo) e de Santa Cruz (Rio Grande do Norte) encontraram uma proporção de idosos frágeis de 7,0\% e 17,1\%, respectivamente (Sousa et al., 2012; Yassuda et al., 2012). 
Idosos com necessidade de cuidado e em processo de fragilização apresentaram uma chance de duas vezes de apresentar piora na necessidade de cuidado após quatro anos de acompanhamento.

Sabe-se que a síndrome é silenciosa e envolve um processo contínuo, resultante do impacto de déficits em múltiplos sistemas, principalmente, nos sistemas neuroendócrino, imunológico e musculoesquelético, desencadeando o declínio funcional. No entanto, pode ser reversível ou postergável, a partir de sua identificação precoce quando seus sinais são, ainda, pouco perceptíveis.

Recentemente, Nunes et al. (2015) propuseram a avaliação de fragilidade por questões autorreferidas de seus componentes, cuja aplicação é simples, rápida e de baixo custo que possibilita o rastreamento dos indivíduos em processo de fragilização, e estabelecimento de intervenções precoces apropriadas e individualizadas.

Para prevenir a fragilidade e seus agravos é necessário formar profissionais capacitados e em número adequado e a existência de recursos suficientes a fim de reconhecer que o cuidado ofertado a esse grupo requer habilidade específicas (Duarte, Lebrão, 2013).

Associação entre a necessidade de cuidado (mínima, moderada e máxima) e mobilidade física prejudicada foi identificada entre os idosos avaliados. Define-se mobilidade física como a capacidade de um indivíduo para mover-se em seu próprio ambiente. Envolve os movimentos coordenados dos sistemas musculoesqueléticos e nervoso, manutenção do equilíbrio, postura e o alinhamento corporal ao levantar-se, movimentar-se e realizar as atividades de vida diária e participar de atividades sociais. A avaliação da mobilidade engloba a amplitude de movimento marcha (equilíbrio, postura, capacidade de andar sem assistência) (Potter et al., 2013).

Alguns estudos apontam que a mobilidade física prejudicada precede a dependência (Verbrugge, Jette, 1994; Rosso et al., 2013). Tendo em vista, as alterações que ocorrem durante o envelhecimento que diminuem a mobilidade física do idoso, tornam-se necessárias ações que promovam a reabilitação e previnam os agravos, como atividades e exercícios físicos 
para ajudar o paciente nas AVD, assim, como o uso de dispositivos assistivos para caminhada.

O comprometimento na mobilidade física requer auxílio de um cuidador desde atividades relacionadas ao seu entorno social quanto naquelas relacionadas ao autocuidado. Ademais, a mobilidade física prejudicada foi determinante para a piora entre os níveis de cuidado durante o acompanhamento. Medidas preventivas como a prática de atividade física regular pode apresentar benefícios na mobilidade, por melhorar o fortalecimento muscular, o equilíbrio, além de promover um estilo de vida ativo parte fundamental para um envelhecer com saúde de qualidade (Matsudo, 2009).

Neste estudo, a polifarmácia foi associada à necessidade de cuidados moderada. Mais de $70 \%$ dos idosos com necessidade moderada fazem uso de mais de quatro medicamentos. A maior prevalência de doenças crônicas faz dos idosos grandes consumidores de serviços de saúde e possivelmente o grupo mais medicalizado da sociedade.

Segundo Santos et al. (2013) os principais motivos que levam a pratica da polifarmácia são a não adesão do idoso ao tratamento farmacológico, as reações adversas, as interações medicamentosas, o alto custo com a medicação e hospitalizações.

Santos et al. (2013) encontraram 26,4\% de idosos goianienses faziam uso da polifarmácia e estavam associados às mulheres, viúvas, idosos longevos e pior autopercepção de saúde. Pérès et al. (2005) encontraram associação positiva entre a progressão da incapacidade funcional e o número de medicamentos (quatro ou mais) em uma coorte com idosos (65 anos e mais). Hanlon et al.(2002) encontraram associação significativa entre o uso inadequado de medicamentos e o declínio da capacidade funcional em uma coorte de idosos americanos (65 a 105 anos) da comunidade.

Esse fato alerta para o importante papel que os medicamentos desempenham na manutenção da saúde e da capacidade funcional dos idosos, sendo fundamentais ações que promovam sua adequada prescrição no processo de atenção à saúde dessa população (Nogueira et al., 2010). 
Segundo a OMS, os problemas relacionados à terapia medicamentosa no idoso devem ser abordados sobre três pontos de vista: paciente, o prescritor e o medicamento. Em relação ao paciente deve-se considerar a perda da memória, diminuição da capacidade visual e habilidade manual, falta de esclarecimento e pratica de automedicação. O idoso apresenta múltiplas doenças e, quando não controladas o médico, tende a aumentar o número de fármacos, que podem gerar reações adversas. No idoso, há alterações na farmacocinética e farmacodinâmica devido à perda da reserva funcional de alguns órgãos e deterioração do controle homeostático. Quanto à prescrição, o prescritor pode ter tido um ensino inadequado sobre a gerontologia e geriatria e a prescrição de medicamentos inapropriados para o idoso (Offerhaus, 1997).

Em relação ao engajamento social, observou-se que os idosos participativos socialmente apresentam menores chances de apresentar necessidade mínima e máxima.

$\mathrm{O}$ engajamento social aponta o envolvimento das pessoas no seu ambiente social e pode proporcionar uma sensação de controle sobre a própria vida e eficácia em suas habilidades. O engajamento social pode promover ou reforçar os recursos pessoais que aumentam resistência em face de processos de doenças que se tornam mais grave ao longo do tempo (Mendes de Leon, Glass, Berkman, 2003).

As perdas da função física podem levar à redução do engajamento social, que por sua vez acelera declínio funcional. (também conhecido como "use-o ou perca-o"). Manter relacionamentos sociais e participação ativa na família e na comunidade pode fomentar um sentimento de cumprir papéis sociais importantes e aumentar a sensação de controle pessoal e competência (Baltes, Wahl, Schmid-Furstoss, 1990). Outra pesquisa mostrou que o envolvimento social e controle pessoal contribuem para uma adaptação mais bem-sucedida para as limitações relacionadas à idade e está associada à redução da incapacidade (Mendes de Leon et al., 1996). A execução das tarefas para promover o autocuidado constitui uma resposta adaptativa para equilibrar os efeitos incapacitantes da doença física e 
comprometimento com condições psicossociais e ambientais que moldam os comportamentos (Glass, 1998).

A presença de sintomas depressivos foi associada aos idosos com necessidade mínima e máxima. Penninx et al. (1998) apontaram que a presença de sintomas depressivos gera um impacto no desempenho físico (comprometimento na mobilidade física), desencadeando a incapacidade. Idosos deprimidos apresentam sofrimento psicológico favorecendo a alterações neurais, hormonais e imunológicas, que aumentam o tônus simpático e diminui o tônus vagal, causando imunossupressão e humor deprimido. Essa resposta aumenta a susceptibilidade a doenças e diminuição do desempenho físico. Os sintomas depressivos são potencialmente modificáveis e evitáveis. Portanto, a prevenção e tratamento de sintomas depressivos pode ser um dos alvos mais eficazes para intervenções destinadas a reduzir a necessidade de cuidados dos idosos.

A prevalência de quedas nesse estudo foi de $28,5 \%$ semelhante aos estudos nacionais (Perracini, Ramos, 2002; Lebrão, 2003; Ribeiro et al., 2008; Brito et al., 2013a) e internacionais (Tinetti, Speechley, 1989; Ambrose et al., 2013 ). Define-se queda como "vir a inadvertidamente ficar no solo ou em outro nível inferior, excluindo mudanças de posição intencionais para se apoiar em móveis, paredes ou outros objetos" (SES, 2010). A maioria das quedas ocorre durante a caminhada ou prática de exercícios físicos, sendo os idosos mais velhos mais propensos às quedas do que os idosos jovens (Mertz et al., 2010). Ribeiro et al. (2008) apontam como fatores de risco extrínsecos às quedas o piso escorregadio na casa e no banheiro, calçados inadequados e degraus na soleira da porta. Tais condições chamam a atenção para a precariedade das moradias que não oferecem segurança às pessoas idosas.

Nesse estudo, os idosos que caíram nos doze meses anteriores à entrevista tiveram chances maiores de apresentar necessidade mínima. Esses idosos apresentam uma dependência leve, no entanto, necessitam de um cuidador ocasionalmente para auxiliá-lo. Esse evento sinaliza a necessidade de uma reorganização da familiar para auxiliar o idoso em atividades relacionadas ao seu entorno social. 
As quedas podem desencadear a limitações funcionais. Uma das explicações pode ser a limitação na mobilidade devido às dores das contusões. Outro fator está relacionado à síndrome pós-queda, caracterizada pelo medo de cair novamente, que implica em uma série de mudanças comportamentais que resulta em uma diminuição da atividade física habitual e social. Além disso, a família pode apresentar uma superproteção negativa, aceitando a limitação mobilidade como algo inerente ao envelhecimento. Isso se traduz em uma diminuição marcha, limitação para atividades de vida diária, aumentando a probabilidade de dependência (Pío et al., 2006; Wijlhuizen, Chorus, Hopman-Rock, 2008).

A OMS aponta como pilares para prevenção das quedas o aumento da conscientização do idoso, familiares, profissionais de saúde e gestores sobre a importância da prevenção das quedas, assim como a melhoria da identificação e avaliação dos fatores de risco e dos determinantes das quedas com intuito de identificar e implementar as intervenções à população idosa de acordo com a sua realidade (SES, 2010).

Idosos que apresentaram declínio cognitivo tiveram uma chance de cinco vezes maior de apresentar necessidade de cuidado moderada em relação aos idosos independentes. Durante o processo do envelhecimento, pode ocorrer o declínio de diferentes funções cognitivas como memória de longo e curto prazo, habilidade para cálculo, função executiva e o conhecimento semântico, essenciais para o desempenho das atividades (Pérès et al, 2008; Ribeiro et al., 2010).

A presença de declínio cognitivo pode tornam-se esquecidos, apresentar dificuldades de orientação (confusão sobre o tempo, o lugar e as pessoas), e têm dificuldades na tomada de decisões e na realização de tarefas domésticas (como preparar refeições). Além disso, o humor e comportamento podem ser afetados, com uma perda de motivação e interesse, os sintomas de depressão.

Idosos sem necessidade e que apresentaram declínio cognitivo no baseline tiveram um risco de aproximadamente sete vezes maior para apresentar necessidade moderada após quatro anos de acompanhamento. 
Notam-se o quão idosos cognitivamente prejudicados podem requer a necessidade de um cuidador presencial intermitente.

Tal condição mostra a importância dos profissionais de saúde que atuam na atenção básica em realizar a avaliação cognitiva e funcional do idoso precocemente com intuito de planejar um cuidado direcionado às limitações e peculiaridades apresentadas no declínio cognitivo, garantindo a segurança à pessoa idosa e suporte à família (OMS, 2013).

Etxeberria et al. (2006) avaliaram a eficiência de um programa cuja função era estimular as habilidades cognitivas residuais de pacientes com demência em estágio avançado, por meio de atividades de estimulação controlada para reduzir seus distúrbios comportamentais, maximizar a sua interação com o ambiente, funcionando nas atividades da vida diária e, assim, melhorar a sua qualidade de vida e as pessoas ao seu redor. Também envolveram a família no cuidado com intuito de melhorar a interação entre eles. Os autores concluíram que a intervenção paciente-família conjunta melhora a qualidade de vida de ambos, bem como uma maior e melhor comunicação.

Em relação às múltiplas doenças, os dados são semelhantes aos de estudos populacionais realizados no país. Observa-se a maioria dos idosos apresenta duas ou mais doenças, sendo mais prevalente a hipertensão arterial e as doenças articulares (Lima-Costa; Barreto; Giatti, 2003; Louvison, 2006; Nunes et al., 2010; Pinto; Neri, 2013). As condições crônicas podem ser prevenidas ou adiadas durante o processo do envelhecimento a partir de adoções de mudanças no estilo de vida e adesão ao tratamento farmacológico. Quando não há o controle das doenças, estas podem gerar limitações funcionais e, desencadear a dependência.

Tendo em vista que algumas doenças são incapacitantes alguns pesquisadores tem avaliado compressão das morbidades, ou seja, avaliam o impacto da eliminação dessas doenças sobre a expectativa de vida livre de incapacidade. Campolina et al (2013) identificaram as doenças eliminadas que geraram o maior aumento de expectativa de vida livre de incapacidade, para o sexo feminino, foram a doença cardíaca, o diabetes e a hipertensão arterial. Já para o sexo masculino, as doenças eliminadas que geraram maior 
aumento de expectativa de vida livre de incapacidade foram a doença cardíaca, a hipertensão arterial e a doença pulmonar crônica. Essa avaliação permite atuar nos fatores de risco dessas doenças assim como no controle das mesmas com intuito de prevenir os agravos e promover a saúde.

Idosos considerados sem necessidade no baseline e com multimorbidade apresentaram maior risco de desenvolver necessidade de cuidado máxima. Justifica-se esse achado devido à presença de duas ou mais doenças apresentarem uma interação sinérgica significativa, por meio de, pelo menos, dois efeitos de interação biologicamente plausíveis e importantes. No primeiro, ambas as doenças associadas apresentam um risco substancial de maior incapacidade do que a esperada pelo efeito das doenças individuais; e, em segundo lugar, somente uma das doenças está associada com uma incapacidade na presença da outra doença (Fried et al., 1999).

Um exemplo observado neste estudo foi associação das doenças cerebrovasculares e necessidade de cuidado. A doença cerebrovascular é uma doença incapacitante que compromete a qualidade de vida do idoso. Dunlop et al. (2002) encontraram um risco de 15,8\% entre os idosos com declínio funcional (uma ou duas atividades) atribuída ao acidente vascular cerebral e um risco de $7,1 \%$ em relação a três ou mais atividades. Alexandre et al (2012) apontaram que para os idoso homens a doença cerebrovascular foi determinante para a dependência nas ABVD. Idosos que apresentaram tal doença tinha pior declínio funcional, aumentando a demanda de cuidados de outra pessoa e dependendo da gravidade das sequelas da doença aumenta a sobrecarga do cuidador.

Modelos de gerenciamento clínico de doenças crônicas foram propostos pela OMS com intuito auxiliar na tomada de decisão, com foco na população, na prevenção, na qualidade, integração entre os níveis de atenção, flexibilidade e adaptabilidade com vigilância permanente. No Brasil, estratégias de saúde que levem em conta esses princípios são de grande importância para a atenção à saúde do idoso e para o manejo das doenças crônicas (OMS, 2003). 
Nota-se que entre os idosos avaliados alta proporção de idosos que utilizam os serviços de saúde corroborando com outras pesquisas realizadas no país (Guerra et al., 2001; Won, Díaz, 2007; Carret et al., 2011 ). Somente $13,6 \%$ dos idosos não realizaram consulta médica, não utilizaram serviços de urgência/emergência e não foram hospitalizados nos últimos doze meses anteriores à entrevista. Esse grupo foi composto por idosos independentes e mais jovens, uma parcela deles não tinha doenças crônicas $(6,7 \%)$ e um quarto deles não utilizava medicamentos.

Entre os idosos que não utilizaram nenhum serviço de saúde observa-se que mais de $90 \%$ deles apresentaram uma ou mais doenças crônicas. As doenças crônicas requerem um cuidado contínuo, com consultas trimestrais regulares. Além das consultas, a oferta atividades de promoção da saúde e a prevenção das doenças são necessárias para manter a independência, prevenir e retardar o aparecimento de doenças (UNFPA, 2012).

Malta e Merhy (2010) apontam que as linhas de cuidado das doenças crônicas se justificam pela magnitude destas doenças, pelos custos que estas agregam por gerar eventos contínuos/crônicos e que, com frequência se agudizam, especialmente quando não bem cuidados.

A linha de cuidados seria uma ferramenta que organizaria a rede estabelecendo os fluxos assistenciais e garantidos ao usuário, a fim de atender às suas necessidades de cuidado. Pessôa, Santos e Torres (2012) afirma que o cuidado integral é pleno, feito com base no acolhimento do profissional de saúde, no estabelecimento de vínculo e na responsabilização diante do problema de saúde trazido pelo usuário. Ela funciona com base nos Projetos Terapêuticos, ou seja, conjunto de atos assistenciais para resolver determinado problema de saúde do usuário, com base em uma avaliação de risco (físico, emocional, econômico, entre outros).

Ainda observa-se que o modelo de atenção está voltado para ações curativistas e não para ações de promoção da saúde (Veras et al., 2013). Os dados apontam maior proporção consulta entre os idosos independentes. Já entre os idosos que não consultaram os principais motivos do não acesso aos serviços foram autorrelato de serviço ruim e barreiras arquitetônicas. 
A OMS apontou que idosos enfrentam muitas barreiras de acesso aos serviços de saúde como: longas distâncias ou transportes inacessíveis, centros de saúde não são planejados para idosos com deficiência ou limitação física, tempo de atendimento muito curto; fragmentação dos serviços e alto custo dos medicamentos. Com intuito de aumentar a conscientização e capacitar os provedores de cuidados aos idosos, algumas ações foram propostas com intuito de melhorar as atitudes, educação e formação dos prestadores de cuidados de saúde para que possam avaliar e tratar condições dos idosos; adaptar os sistemas de gestão às necessidades das pessoas idosas, tornando o acesso físico mais fácil para as pessoas idosas com mobilidade física comprometida ou deficiência visual ou auditiva (OMS, 2004).

Estudo realizado com a amostra da Pesquisa Nacional de Amostra de Domicílio (PNAD) avaliou a utilização dos serviços de saúde em indivíduos com 15 anos e mais de idade e encontrou como motivos para não procurar serviços de saúde: a falta de dinheiro, a possível demora no atendimento e o horário inadequado de funcionamento dos serviços. Embora tenha sido mencionada com menor frequência, a ausência de um acompanhante foi mais importante como motivo de não procura entre os portadores de doenças crônicas, reforçando, assim, a necessidade de atendimento domiciliar para uma parte, ainda que pequena, desses indivíduos (Almeida et al., 2002).

Louvison et al (2008) apontou como motivos citados para a não utilização dos serviços, mesmo precisando, às questões da gravidade da doença, à automedicação e, ainda, à qualidade, distância e custo dos serviços.

Destaca-se para os idosos com necessidade máxima que não procuraram os serviços de saúde, sendo os principais motivos dificuldade de locomoção e falta de transporte. Isso realmente é um problema, tanto para o idoso quanto para a família em desloca-lo aos serviços de saúde com toda essa dependência. Um das alternativas para a assistência a esse grupo etário seria o Serviço de Atenção Domiciliar uma vez que é regido pelos 
princípios de ampliação do acesso, acolhimento, equidade, humanização e integralidade da assistência (Brasil, 2012).

Outro tipo de serviço a ser disponibilizado a esse grupo seria o Serviço de Atendimento Especial - Atende - que é uma modalidade de transporte gratuito oferecido pela Prefeitura do Município de São Paulo e se destina às pessoas com alto grau de severidade e dependência, que estejam impossibilitadas de utilizar outros meios de transporte público (São Paulo, 1996).

Em relação à hospitalização e utilização dos serviços de urgência/emergência as maiores proporções foram encontradas entre os idosos com necessidade moderada e máxima. Chama a atenção para o grupo de idosos classificados com necessidade máxima. Entre esse grupo observou-se maiores proporções de dificuldade no acesso ao serviço de saúde devido ao prejuízo na locomoção e falta de transporte. Tal fato pode ser corroborado por Rittner; Kirk (1995) que identificaram em idosos frágeis de baixa renda como dificuldade ao acesso aos serviços de saúde, o uso do transporte. A maioria dos avaliados autoavaliou seu estado de saúde como ruim ou muito ruim, e mais da metade não tinha cuidados médicos durante os seis meses anteriores, apesar da presença de vários sintomas físicos, isolamento social e pouco apoio comunitário.

Os possíveis motivos para a maior utilização dos serviços de alta complexidade (urgência/emergência e internação) esta relacionado a multimorbidade e polifarmácia. Pela dificuldade no acesso ao serviço de saúde, o que gera o não acompanhamento de sua saúde levando a uma descompensação da doença e recorre primeiramente aos serviços de urgência/emergência e pela gravidade da doença, precisam ser hospitalizados.

Além disso, pode ser apontada a menor continência familiar às doenças de maior gravidade (Louvison et al., 2008). Tal afirmação pode ser observada entre os idosos com maior dependência com necessidade máxima. São pessoas com uma dependência grave requerem um cuidador em tempo integral e, no entanto, quase metade dos idosos (48,7\%) não recebe o auxílio em suas atividades cotidianas. 
Esse grupo de idosos que não recebem auxílio, a maioria reside com outras pessoas $(85,7 \%)$, com multimorbidade $(70,6 \%)$ e, uma parcela referiu disfunção familiar $(17,7 \%)$ e não utilizou nenhum serviço de saúde $(9,3 \%)$. A partir desses resultados, notou-se que tanto a família, comunidade, sociedade e poder público não asseguraram ao idoso a efetivação do direito à vida e à saúde, conforme previsto no Estatuto do Idoso (Brasil, 2003). Pavarini e Neri (2000) afirmam que a prestação de cuidado a um familiar deveria ser um dever moral e ético, no entanto, na prática tem-se mostrado controvérsias ao exercer essa solidariedade por parte do cuidador devido aos conflitos com sua individualidade.

As atividades relacionadas à necessidade máxima englobam atividades como auxílio para ir ao banheiro, tomar banho, alimentar-se, realizar higiene pessoal. Tais atividades são consideradas mais difíceis, tanto na habilidade em executá-las quanto pelo constrangimento em realizálas. Assim, muitas vezes, as demandas do cuidado ultrapassam os limites do esforço físico e psicossocial. Quando não há alternativas viáveis para auxiliar o idoso, ou quando as habilidades e recursos pessoais são insuficientes para o manejo da situação, poderá ocorrer uma desorganização do cuidado, o que traz implicações negativas para o idoso, cuidador e família (Neri, 1993; Sousa et al., 2004). Infelizmente, nos idosos avaliados não foi possível identificar os motivos do não auxílio nas atividades que demandavam o cuidador em tempo integral.

Sugerem-se pesquisas futuras para investigar os motivos do não atendimento a essa demanda. Cabe ressaltar que há um desequilíbrio entre a demanda e oferta dos cuidados básicos. Não se observa, nessas condições, a presença de um envelhecimento saudável e em condições de dignidade.

Mulheres idosas são as principais cuidadoras de seus cônjuges, mas são menos propensas a receber cuidados familiares (Oliveira, Neri, D’Elboux, 2013).

Observa-se que a população já vivencia a 'crise global de cuidados', que gera impactos negativos para a qualidade de vida idosos, aumenta os custos dos serviços de saúde e medidas devem ser repensadas para garantir um envelhecimento digno (OMS, 2005). 
A crise de cuidados ocorre devido às tendências demográficas em diversos países, em que há o aumento na proporção de mulheres sem filhos, mudanças nos padrões de divórcio e casamento, e o número, de maneira geral, muito menor de filhos de futuros idosos; tudo isso contribui para uma diminuição da rede de apoio da família (Wolf, 2001).

A família, especialmente esposas e filhas, é a principal provedora de cuidados (Boff, 2002). A prestação de cuidados a um idoso, pode muitas vezes, exigir uma reestruturação na vida de seu cuidador, alterando costumes, rotinas, hábitos e até mesmo a natureza sua relação com o idoso (Giraldo et al., 2005). Com a inserção progressiva da mulher no mercado de trabalho, os homens tem assumido essa função devido às alterações nos arranjos familiares (Brito et al., 2013b).

Tais modificações impactaram na dinâmica interna da própria família que atualmente conta com menos recursos para assistir seus membros mais dependentes, ou seja, há um menor potencial de ajuda domiciliar aos idosos necessitados.

Entre os idosos com boa funcionalidade familiar observa-se mais auxílio no desempenho de suas atividades. Duarte e Cianciarullo (2002) apontam que a família apresenta uma estrutura funcional de acordo com sua capacidade de adaptação harmônica frente às situações adversas. As famílias funcionais são aquelas que proporcionam um encontro harmonioso entre as pessoas, vivenciam o diálogo, respeito e aceitação de todos. Por outro lado, famílias disfuncionais tendem a ser severas e rígidas, inflexíveis e com vínculos unidirecionais e imutáveis. Qualquer mudança no papel ou na expectativa do papel de algum de seus membros ocasiona desestruturação do sistema familiar, uma vez que seus membros não estão prontos a se adaptar às novas situações.

Frente a isso, observa-se que a dinâmica familiar pode contribuir ou ser um fator estressor na assistência ao idoso, sendo observada no estudo uma maior proporção de idosos sem ajuda naqueles que relataram disfunção familiar. As famílias disfuncionais não se adaptam às situações de dependência e reestruturação para o cuidado do idoso, negligenciando assim o cuidado com o idoso. 
Além disso, o cuidador ao longo da prestação de cuidados pode apresentar sentimentos de tensão, angústia e sobrecarga, o que pode levar o cuidador, por um lado, a ignorar suas próprias necessidades e, por outro, levar à negligência assistencial daqueles que cuidam (Neri, Carvalho, 2002; Duarte et al (2013).

Duarte et al (2013) avaliaram 329 cuidadores de idosos residentes no município de São Paulo e encontraram que 91,3\% eram cuidadores familiares e $8,7 \%$ cuidadores não familiares. Entre os cuidadores familiares, a maioria era mulher, casado, residia com os idosos, prestava o cuidado a maior parte do tempo e estava nessa função a mais de cinco anos.

O suporte existente ao idoso pode ou não sobrecarregar o cuidador. Capilla-Diàz (2005) aponta que a sobrecarga é um conceito multidimensional onde se identifica estresse, sentimentos negativos e dificuldades relacionadas ao cuidado do idoso. Famílias disfuncionais tendem a ser menos suportiva e apresentar mais sobrecarga, o que compromete a prestação de cuidado com o idoso.

Estudo realizado na Colômbia com 39 cuidadores familiares de idosos com dependência identificaram que a maioria era mulheres, filhas, residiam com os idosos e tinham filhos, compartilham o papel de cuidador com outro e não possuem atividade remunerada. Em relação ao cuidado prestado, 76,9\% dedicam mais de oito horas por dia, 30,8\% cuidam do idoso entre 3 a 6 anos, 56\% recebem apoio dos familiares e 7,7\% do sistema formal (Giraldo et al., 2005).

Entre os cuidadores familiares observaram maiores pontuações de sobrecarga entre os cuidadores de idosos com necessidade moderada e máxima, no entanto, não houve diferenças entre esses grupos. Isso aponta que idosos com necessidade moderada e máxima requerem o cuidado diário e essa demanda tende a aumentar a tensão e a frequência de cuidado, sobrecarregando o cuidador.

Diante do exposto, urge a necessidade de reformular os serviços de saúde, assim como o suporte aos cuidadores, para que possam responder às demandas emergentes dos idosos. Intervenções em diferentes níveis de 
atenção e espaços institucionais, incluindo unidades de internamento, hospital-dia e centros para cuidado prolongado (Coelho Filho, 2000).

Condições sociais e econômicas desfavoráveis afetam a saúde ao longo da vida, o que ocasiona a ocorrência de doenças crônicas e dificulta o acesso e utilização dos serviços de saúde e, consequentemente, refletirá na funcionalidade do idoso, gerando maior demanda de cuidado. No presente estudo, a vulnerabilidade social considerada um indicador de pobreza e sinalizador de desigualdades entre os idosos não foi associada à necessidade de cuidado. Tal resultado contradiz aos encontrados na literatura cujas afirmações apontam que piores condições sociais afetam o estilo de vida, gera danos fisiológicos e doenças, aumentando o risco de dependência (Braithwaite, Mont, 2009; Brunner et al., 2009). Embora os dados sejam divergentes, acredita-se que neste estudo, por se tratar de demanda de necessidade de cuidados, refletem que independente da classificação de vulnerabilidade social, a proporção de idosos demandantes de cuidado é semelhante.

Por outro lado, encontrou-se associação da necessidade de cuidado ente escolaridade e suficiência de renda as quais são consideradas proxi de inserção social. Idosos com mais anos de escolaridade e que relataram suficiência de renda apresentaram menores proporção de necessidade de cuidado. Tal fato pode ser justificado pela compreensão das orientações médicas e de saúde.

Quanto às limitações do estudo, apontam-se as informações autorreferidas, referente às doenças crônicas e ao desempenho das atividades de vida diária, que podem trazer vieses aos resultados. No entanto, estudos brasileiros têm apontado boa validade desse tipo de informação para detectar condições de saúde (Lima-Costa et al., 2007; Selem et al., 2013). Outro aspecto a ser considerado diz respeito à classificação do IPVS versão 2000. Não houve nova versão do índice, no período de 2006 e, com o crescimento do município novos setores censitários foram criados, mas não atualizaram a sua classificação do índice. 
CONCLUSÃO 


\section{CONCLUSÃO}

A necessidade de cuidado foi elaborada a partir da hierarquização das atividades de vida diária e, em seguida, a classificou-se a dependência apresentada pelo idoso de acordo a necessidade de requer um cuidador para auxiliá-lo nas suas demandas. Os níveis de cuidado foram estabelecidos de acordo com a frequência de cuidado a ser demandado pelo idoso quando às atividades comprometidas. Assim, os níveis de cuidado foram sem necessidade (idosos independentes), necessidade mínima (idoso apresenta dependência leve e requer um cuidador ocasionalmente para auxiliá-lo nas atividades relacionadas ao seu entorno), necessidade moderada (idoso com dependência moderada e requer a presença de um cuidador presencial e não há necessidade de um tempo integral), necessidade máxima (idosos com grande dependência e necessita de um cuidador presencial em tempo integral).

Metade dos idosos avaliados é independente e não necessita de um cuidador presencial. No entanto, cerca de $20 \%$ desses idosos apresentaram necessidade moderada e máxima, e demandam auxílio em atividades diárias e a presença diária de um cuidador é necessária. Os fatores associados à necessidade de cuidado foram idade, sexo, engajamento social, declínio cognitivo, sintomas depressivos, mobilidade física prejudicada, processo de fragilização, multimorbidade, doenças cerebrovasculares, polifarmácia, queda e dificuldade no acesso aos serviços de saúde.

A maioria dos idosos com necessidade de cuidado recebia auxílio nas atividades comprometidas, no qual as maiores proporções de ajuda foram encontradas entre os idosos mais velhos e com boa funcionalidade familiar. Ao avaliar o auxílio de acordo com a necessidade de cuidado, quase metade dos idosos com necessidade máxima não recebiam ajuda. Esse grupo é o mais demandante de serviços de saúde como serviços de urgência/emergência e internações hospitalares. Ademais, entre aqueles que referiram dificuldade para acessar os serviços apresentam dificuldade para locomoção e falta transporte. 
Essa parcela de idosos devem ser foco de gestores, comunidade e família devido a complexidade de cuidado e de serviços a serem otimizados a essa população, uma vez que, estão propensos a um envelhecimento sem dignidade.

Entre os idosos que não utilizaram os serviços de saúde no último ano, a maioria era independente e apresentava doenças crônicas. Esse grupo requer um acompanhamento das doenças crônicas, ações de promoção da saúde e prevenção de agravos como a redução no desempenho funcional.

Em relação à transição de cuidados, no período de quatro anos observaram-se entre os idosos independentes uma piora de aproximadamente $30 \%$; enquanto naqueles que possuíam necessidade de cuidados, foi de $24,8 \%$. Nos primeiros, os fatores determinantes para a piora da necessidade de cuidados foram idade, sexo, declínio cognitivo, mobilidade física prejudicada e multimorbidade; enquanto, nos outros, mobilidade física prejudicada e processo de fragilização.

Esse trabalho permitiu identificar algumas contribuições para a melhoria das condições de saúde do idoso, atuação da família e dos serviços de saúde. Primeiramente, cita-se o construto de necessidade de cuidado que foi avaliado pelo autorrelato dos idosos para as AIVD e ABVD. Isso permite que o profissional de saúde tenha o conhecimento do grau de dependência e qual o nível de cuidado o idoso requererá. Ao planejar as intervenções e estabelecerá estratégias para mobilizar o acesso ao cuidado.

A necessidade de cuidado é um evento sinalizador do idoso em requerer cuidadores. Com isso, aponta uma visão macro das necessidades e direciona as ações de enfermagem como todos os membros da equipe.

Esse trabalho sinalizou que o cuidado está envolvido com as necessidades básicas do indivíduo. Embora os avanços em tecnológicos tenham auxiliado no diagnóstico das condições clínicas, percebe-se que os profissionais não valorizam o cuidado básico. Torna-se primordial o reconhecimento dos profissionais de saúde das demandas de cuidados dos idosos exigindo assim, conhecimentos técnicos e científicos sobre a geriatria e gerontologia. Sabe-se que os cuidados básicos são inerentes à rotina das famílias, assim profissional deverá reconhecer o potencial cuidador do idoso 
em sua família e investir em investir em práticas adequadas, trazendo benefícios para quem cuida e quem é cuidado.

Outra contribuição apontada, nesse estudo, foi o acesso e utilização dos serviços saúde de acordo a necessidade de cuidado da pessoa idosa. Os dados demonstram que o serviço de saúde precisa se reestruturar para atender as demandas específicas dessa clientela. Além disso, requer oferecimento de suporte aos profissionais que nele está inserido e às famílias.

Uma das possibilidades seria o estabelecimento de uma linha de cuidados, a partir das demandas dos idosos, levando em consideração a família e recursos presentes identificados com vistas à adaptação e adequação das circunstâncias individuais visando a melhor qualidade de vida do idoso e de seu entorno. 
REFERÊNCIAS BIBLIOGRÁFICAS 


\section{REFERÊNCIAS BIBLIOGRÁFICAS}

Adler G, Rottunda S. Older adults' perspectives on driving cessation. J Aging Stud. 2006; 20(3):227-235.

Alemanha. Ministério da Saúde da Alemanha. Report by the advisory board to review the definition of the need for long-term care [internet]. Alemanha; 2009. [atualizado 2015; citado 2015 jan 05]. Disponível em: http://www.bmg.bund.de/fileadmin/redaktion/pdf_english/Report_by_the_a dvisory_board_to_review_the_definition_of_the_need_for_longterm_care.pdf

Alexandre TS, Corona LP, Nunes DP, Santos JL, Duarte YA, Lebrão ML. Gender differences in incidence and determinants of disability in activities of daily living among elderly individuals: SABE study. Arch Gerontol Geriatr. 2012;55(2):431-7. DOI: 10.1016/j.archger.2012.04.001

Alexandre TS, Corona LP, Nunes DP, Santos JL, Duarte YA, Lebrão ML. Disability in instrumental activities of daily living among older adults: gender differences. Rev Saude Publica. 2014; 48(3):379-89.

Almeida OP, Almeida SA. Confiabilidade da versão brasileira da Escala de Depressão Geriátrica (GDS) versão reduzida. Arq Neuropsiquiatr. 1999; 57:421-426.

Almeida MF, Barata RB, Montero CV, Silva ZP. Prevalência de doenças crônicas auto-referidas e utilização de serviços de saúde, PNAD/1998, Brasil. Ciência \& Saúde Coletiva. 2002; 7(4):743-756.

Andersson J, Nydahl M, Gustafsson K, Sidenvall B, Fjellströ, C. Meals and snacks among elderly self-managing and disabled women. Appetite. 2003; 41(2):149-160.

Anvisa. Agência Nacional de Vigilância Sanitária. Resolução RDC no 283, de 26 de setembro de 2005. Aprova o Regulamento Técnico que define normas de funcionamento para as Instituições de Longa Permanência para Idosos. Diário Oficial da União, Brasília, 2005.

Artazcoz L, Artieda L, Borrell C, Cortes I, Benach J, Garcia V. Combining job and family demands and being healthy: what are the differences between men and women? Eur J Public Health. 2004;14(1):43-48.

Avila-Funes JA, Helmer C, Amieva H, Barberger-Gateau P, Le Goff M, Ritchie K, et al. Frailty among community-dwelling elderly people in France: the three-city study. J Gerontol A Biol Sci Med Sci. 2008; 63A(10):1089-1096. 
Baltes M, Wahl H, Schmid-Furstoss U. The daily life of elderly Germans: activity patterns, personal control, and functional health. J Gerontol B Psychol Sci Soc Sci 1990;45:P173-9.

Batistoni SST, Neri AL, Cupertino APFB. Validade da escala de depressão do Center for Epidemiological Studies entre idosos brasileiros. Rev Saude Publica. 2007; 41(4):598-605.

Batista AS, Jaccoud LB, Aquino L, El-Moor PD. Envelhecimento e dependência: desafios para a organização da proteção social. Brasília: Coleção Previdência Social, Ministério da Previdência Social; 2008. v.28.

Benedetti TRB, Mazo GZ, Barros MV. Aplicação do Questionário Internacional de Atividade Física para avaliação do nível de atividades físicas de mulheres idosas: validade concorrente e reprodutibilidade teste/reteste. Rev Bras Cienc Mov. 2004;12(1):25-33.

Benedetti TRB, Antunes PC, Rodriguez-Añez CR, Mazo GZ, Petroski EL. Reprodutibilidade e validade do Questionário Internacional de Atividade Física (IPAQ) em homens idosos. Rev Bras Med Esporte. 2007;13(1):11-6.

Boff L. Saber cuidar: ética do humano. 8.ed. São Paulo: Vozes; 2002.

Braithwaite J, Mont D. Disability and poverty: A survey of World Bank Poverty Assessments and implications. Eur J of Disabil Res. 2009; 3:219232

Brasil. Constituição, 1988. Constituição da República Federativa do Brasil. Brasília: Senado; 1988.

Brasil. Lei no 8.080 de 19 de Setembro de 1990. Dispõe sobre as condições para a promoção, proteção e recuperação da saúde, a organização e o funcionamento dos serviços correspondentes e dá outras providências. Diário Oficial da União, Brasília 19 set. 1990.

Brasil. Lei $\mathrm{n}^{\circ} 8.842$ de 04 de janeiro de 1994. Dispõe sobre a Política Nacional do Idoso, cria o Conselho Nacional do Idoso e dá outras providências. Diário Oficial da União, Brasília 4 jan. 1994.

Brasil. Decreto $n^{\circ} 1.948$ de 04 de julho de 1996. Regulamenta a Lei 8.842, de 4 de janeiro de 1994, que dispõe sobre a Política Nacional do Idoso, e dá outras providências. Diário Oficial da República Federativa do Brasil, Brasília 4 jul. 1996.

Brasil. Ministério da Saúde. Portaria n ${ }^{\circ}$ 1.395/GM, de 10 de dezembro de 1999. Dispõe sobre a Política Nacional de Saúde do Idoso e dá outras providências. Diário Oficial da União, Brasília 13 dez. 1999. Seção1.

Brasil. Lei $n^{\circ}$. 10.741 de outubro de 2003. Dispõe sobre o Estatuto do Idoso e dá outras providências. Diário Oficial da União, Brasília 1 out. 2003. 
Brasil. Ministério da Saúde. Portaria no 2.528 de 19 de outubro de 2006. Dispõe atualização da Política Nacional de Saúde do Idoso e dá outras providências. Diário Oficial da União, Brasília; 2006.

Brasil. Portaria $\mathrm{n}^{\circ} 2.528$ de 19 de outubro de 2006. Dispõe atualização da Política Nacional de Saúde do Idoso do Ministério da Saúde. Diário Oficial da União; 2006.

Brasil. Ministério da Saúde. Atenção à saúde da pessoa idosa e envelhecimento. Área Técnica Saúde do Idoso. Brasília (Brasil): Ministério da Saúde; 2010.

Brasil. Ministério da Saúde. Portaria MS/GM no 2.527 de 27 de outubro de 2011. Redefine a atenção domiciliar no âmbito do Sistema Único de Saúde (SUS). Diário Oficial da União, Brasília 28 jan. 2011.

Brasil. Ministério da Saúde. Caderno de atenção domiciliar. Brasília: Ministério da Saúde; 2012.

Brito TA, Fernandes MH, Coqueiro RS, Jesus CS. Quedas e capacidade funcional em idosos longevos residentes em comunidade. Texto Contexto Enferm. 2013a; 22(1): 43-51.

Brito TRP, Nunes DP, Duarte YAO, Lebrão ML. Diferenças de Gênero Entre cuidadores de idosos: Evidências do Estudo Sabe. In: Souza DN, Rua MS (coordenadores). Cuidadores informais de Pessoas idosas: caminhos de Mudança. Aveiro : UA Editora, 2013b. p.93-98.

Brunner E, Shipley M, Spencer V, Kivimaki M, Chandola T et al. Social inequality in walking speed in early old age in the Whitehall II Study. Gerontol A Biol Sci Med Sci. 2009; 64A(10):1082-1089.

Buñuales MTJ, Diego PG, Moreno JMM. La Clasificación Internacional del Funcionamento de la Discapacidad y de la Salud (CIF) 2001. Rev Esp Salud Publica. 2002; 76:271-9.

Caldas CP. Envelhecimento com dependência: responsabilidades e demandas da família. Cad Saude Publica. .2003; 19(3):773-781.

Camarano AA, Kanso S, Mello JL. Como vive o idoso brasileiro? In: Camarano AA, organizadora. Os novos idosos brasileiros: muito além dos 60? Rio de Janeiro (RJ): IPEA; 2004. p.25-73.

Camarano AA, Mello JL. Introdução. In: Camarano AA (org). Cuidados de longa duração para a população idosa: um novo risco social a ser assumido? Rio de Janeiro: Ipea; 2010. p.13-37.

Camargos MCS, Perpetuo IHO, Machado CJ. Expectativa de vida com incapacidade funcional em idosos em São Paulo, Brasil. Rev Panam Salud Publica. 2005;17(5/6):379-86. 
Campolina AG, Adami F, Santos JLF, Lebrão ML. A transição de saúde e as mudanças na expectativa de vida saudável da população idosa: possíveis impactos da prevenção de doenças crônicas. Cad Saude Publica. 2013;29(6):1217-1229.

Carret MLV, Fassa AG, Paniz VMV, Soares PC. Características da demanda do serviço de saúde de emergência no Sul do Brasil. Cienc Saude Colet 2011; 16(Supl.1):1069-1079.

Carvalho MFC, Romano-Lieber NS, Bergsten-Mendes G, Secoli SR, Ribeiro E, Lebrão ML, et al. Polifarmácia entre idosos do Município de São Paulo - Estudo SABE. Rev Bras Epidemiol. 2012; 15(4): 817-27.

Coelho Filho JM. Modelos de serviços hospitalares para casos agudos em idosos. Rev. Saude Publica. 2000; 34(6):666-671.

Conceição LFS. Saúde do idoso: orientações ao cuidador do idoso acamado. Rev Med Minas Gerais. 2010; 20(1): 81-91.

Coughlin JF. Beyond health and retirement: placing transportation on the aging policy agenda. The Public Policy and Aging Report. 2001; 11(4):20 23.

Crepeau BE, Neistadt E. M. Terapia ocupacional. Rio de Janeiro: Guanabara; 2002.

Dini EL, Castellanos RA. Doenças periodontais em idosos: Prevalência e prevenção para populações de terceira idade. Rev Bras Odontol. 1993; 50(2):3-9.

Dodge $\mathrm{HH}$, Du Y, Saxton JA, Ganguli M. Cognitive domains and trajectories of functional independence in non-demented elderly. J Gerontol A Biol Sci Med Sci. 2006; 61(12): 1330-1337.

Duarte, Y.A.O. Família: rede de suporte ou fator estressor. A ótica de idosos e cuidadores familiares [tese de doutorado]. São Paulo: Escola de Enfermagem, Universidade de São Paulo; 2001.

Duarte, Y.A.O.; Cianciarullo, T.I. Idoso, família e saúde na família. In: Cianciarullo TI. Saúde na família e na comunidade. São Paulo: Robe, 2002.

Duarte YAO, Andrade CL, Lebrão ML. O Índex de Katz na avaliação da funcionalidade dos idosos. Rev Esc Enferm USP. 2007; 41(2):317-25.

Duarte YAO. Manual de formadores de cuidadores de pessoas idosas. Secretaria Estadual de Assistência e Desenvolvimento social: Fundação Padre Anchieta; 2009.

Duarte YAO, Nunes DP, Corona LP, Lebrão ML. Como estão sendo cuidados os idosos frágeis de São Paulo? A visão mostrada pelo Estudo SABE (Saúde, bem estar e envelhecimento). In: Camarano AA (org). 
Cuidados de longa duração para a população idosa: um novo risco social a ser assumido? Rio de Janeiro: Ipea; 2010. p.123-144.

Duarte YAO, Diogo MJD. Cuidados em domicílio: conceito e práticas. In: Freitas EV et al. Tratado de Geriatria e gerontologia. 3.ed. Rio de Janeiro: Guanabara Koogan, 2011. p.1276-1284, cap.113

Duarte YAO, Costa PR, Nunes DP, Lebrão ML. Quem são, como se sentem e com que suporte contam os cuidadores de idosos dependentes no Brasil: evidências do Estudo SABE. In: Souza DN, Rua MS (coordenadores). Cuidadores informais de Pessoas idosas: caminhos de Mudança. Aveiro : UA Editora, 2013. p.70-75.

Duarte YA, Diogo MJD. Cuidados em domicílio: conceitos e práticas. In: Freitas EV, Py L, Cançado FAX, Doll J, Gorzoni ML. Tratado de Geriatria e Gerontologia. Rio de Janeiro: Guanabara Koogan; 2013. p.1276-1284.

Duarte YA, Lebrão ML. Fragilidade e envelhecimento. In: Freitas EV, Py L, Cançado FAX, Doll J, Gorzoni ML. Tratado de Geriatria e Gerontologia. Rio de Janeiro: Guanabara Koogan; 2013. p.1285-1298.

Dunlop DD, Hughes LS, Manheim LM. Disability in activities of daily living: patterns of change and a hierarchy of disability. Am J Public Health. 1997;87(3):378-383.

Dunlop DD, Manheim LM, Sohn MW, Liu X, Chang RW. Incidence of functional limitation in older adults: the impact of gender, race, and chronic conditions. Arch Phys Med Rehabil. 2002;83(7): 964-971.

Etxeberria I, Yanguas JJ, Buiza C, Zulaica A, Galdona N, González MF. Programa de intervención conjunto familiar-paciente con deterioro cognitivo grave basado en las actividades del método Montessori. Revista Española de Geriatría y Gerontología. 2006;41: 8-53.

Fabrício SCC, Rodrigues RAP. Revisão da literatura sobre fragilidade e sua relação com o envelhecimento. Rev Rene. 2008; 9(2):112-119.

Ferrucci L, Guralnik JM, Cecchi F, Marchionni N, Salani B, Kasper J, et al. Constant hierarchic patterns of physical functioning across seven populations in five countries. Gerontologist. 1998;38(3):286-294.

Finlaysona M, Mallinsonb T, Barbosac VM. Activities of daily living (ADL) and instrumental activities of daily living (IADL) items were stable over time in a longitudinal study on aging. J Clin Epidemiol. 2005;58:338349.

Freitas JOF, Aguiar CRRA. Avaliação das funções cognitivas de atenção, memória e percepção em pacientes com esclerose múltipla. Psicologia: Reflexão e Crítica. 2011; 25(3):457-466. 
Fried LP, Guralnik JM. Disability in older adults: evidence regarding significance, etiology and risk. J Am Geriatr Soc. 1997; 45(1):92-100.

Fried LP, Bandeen-Roche K, Kasper JD, Guralnik JM. Association of Comorbidity with Disability in Older Women: The Women's Health and Aging Study. J Clin Epidemiol. 1999; 52(1):27-37.

Fried LP, Tangen CM, Walston J, Newman AB, Hirsch C, Gottdiener J, et al. Frailty in older adults: evidence for a phenotype. J Gerontol A Biol Sci Med Sci. 2001; 56A(3): M146-M156.

Fried LP, Ferrucci L, Darer J, Williamson JD, Anderson G. Untangling the concepts of disability, frailty and comorbidity: implications for improved targeting and a care. J Gerontol A Biol Sci Med Sci. 2004; 59(3):255-263.

Fundação Seade. Índice Paulista de Vulnerabilidade Social (IPVS) [internet]. São Paulo, 2000. [citado 2014 nov. 14]. Disponível em: http://www.seade.gov.br/projetos/ipvs/

Giacomin KC, Uchôa E, Firmo JOA, Lima-Costa MF. Projeto Bambuí: um estudo de base populacional da prevalência e dos fatores associados à necessidade de cuidador entre idosos. Cad Saude Publica. 2005;21(1):80-91.

Gill TM, Kurland B. The burden and patterns of ADL disability among community-living older persons. J Gerontol A Biol Sci Med Sci. 2003; 58(1):70-5.

Giovanella L, Stegmüller K. Crise financeira europeia e sistemas de saúde: universalidade ameaçada? Tendências das reformas de saúde na Alemanha, Reino Unido e Espanha. Cad. Saúde Pública. 2014; 30(11):1-19.

Giraldo CI, Franco GM, Correa LS, Salazar MO, Tamayo AM. Cuidadores familiares de ancianos: quiénes son y cómo asumen este rol. Rev Salud Publica (Bogota). 2005;23(2):7-15

Glass TA. Conjugating the "tenses" of function: Discordance among hypothetical, experimental, and enacted function in older adults. Gerontologist. 1998; 38(1):101-12.

Goodman J, Brewster S, Gray P. Older people, mobile devices and navigation. In: HCI and the Older Population; 2004; Leeds, UK. Disponível em: http://www.dcs.gla.ac.uk/utopia/workshop/goodman.pdf

Gonçalves LHT, Silva YF, Pfeiffer S. O cuidado do idoso fragilizado e de seus cuidadores no contexto domiciliar. Cogitare Enferm. 1996; 1(2): 39-47.

Guerra HL, Firmo JOA, Uchoa E, Lima-Costa MFF. The Bambuí Health and Aging Study (BHAS): factors associated with hospitalization of the elderly. Cad. Saude Publica. 2001; 17(6):1345-1356. 
Guralnik JM1, Simonsick EM. Physical disability in older Americans. J Gerontol. 1993; 48:3-10.

Guralnik JM, Simonsick EM, Ferrucci L, Glynn RJ, Berkman LF, Blazer DG et al. A Short Physical Performance Battery Assessing Lower-Extremity Function - Association With Self-Reported Disability And Prediction Of Mortality And Nursing-Home Admission. J Gerontol. 1994; 49(2): M85M94.

Guralnik JM, Fried LP, Salive ME. Disability as a public health outcome in the aging population. Annu Rev Public Health 1996; 17:25-46.

Gustafsson K, Andersson I, Andersson J, Fjellström C, Sidenvall B. Older women's perceptions of independence versus dependence in food-related work. Public Health Nurs. 2003;20(3):237-247.

Guttman L. The basis of scalogram analisy: In Stouffer SA. Measurement and prediction. New York: Princeton Universtiy Press; 1950. p.60-90.

Hanlon JT, Fillenbaum GG, Kuchibhatla M, Artz MB, Boult C, Gross CR, et al. Impact of inappropriate drug use on mortality and functional status in representative community dwelling elders. Med Care. 2002;40(2):166-76.

Hassan H, Nasir MHNM. The use of mobile phones by older adults: a Malaysian study. Accessibility and Computing archive. 2008; 92:Pages 1116. DOI: $10.1145 / 1452562.1452564$

Icaza MC, Albala C. Minimental State Examination (MMSE) del Studio de dementia en Chile: Análisis estadístico. OPAS; 1999. p.1-18.

Instituto Brasileiro de Geografia e Estatística (IBGE). Pesquisa de Informações Básicas Municipais: perfil dos municípios brasileiros. Rio de Janeiro; 2006.

Instituto Brasileiro de Geografia e Estatística (IBGE) [Internet]. Primeiros resultados definitivos do Censo 2010 [atualizado 2014; acesso em $08 \mathrm{Jul}$ 2014]. 2010a. Disponível em: http:www.ibge.gov.br.

Instituto Brasileiro de Geografia e Estatística (IBGE). Pesquisa de Informações Básicas Municipais: perfil dos municípios brasileiros. Rio de Janeiro; 2010b.

Instituto de Mayores y Servicios Sociales (IMSERSO). Atención a las personas em situación de dependencia em España: Libro Blanco. Madrid; Observatorio de Personas Mayores: Madrid; 2004.

Kail BL, Taylor MG. Cumulative inequality and racial disparities in health: private insurance coverage and black/white differences in functional limitations. J Gerontol B Psychol Sci Soc Sci. 2014; 69(5):798-808. DOI:10.1093/geronb/gbu005. 
Karsch UM. Idosos dependentes: famílias e cuidadores. Cad Saude Publica 2003; 19(3):861-866.

Katz S, Ford AB, Moskowitz RW, Jackson BA, Jaffe MW. Studies of illness in the aged. The index of ADL: a standardized measure of biological and psychosocial function. JAMA. 1963; 185(21):914-919.

Kempen GILM, Suumeijer TPBM. The development of hierarchical polychotomous ADL-IADL scale for noninstitucionalized elders. Gerontologist .1990; 30(4):497-502.

Landia F, Liperotia R, Russoa A, Capoluongob E, Barillaroa C, Pahorc M, et al. Disability, more than multimorbidity, was predictive of mortality among older persons aged 80 years and older. J Clin Epidemiol. 2010; 63:752-759.

Lebrão ML. O projeto SABE em São Paulo: uma visão panorâmica. In: Lebrão ML, Duarte YAO. O projeto SABE no Brasil: uma abordagem inicial. Brasília: Organização Pan-Americana da Saúde; 2003.

Lima FD. Elaboração do banco de dados. In: Lebrão ML, Duarte YAO. O projeto SABE no Brasil: uma abordagem inicial. Brasília: Organização PanAmericana da Saúde; 2003.

Lima AP, Mantovani MF, Ulbrich EM, Zavadil ETC. Produção científica sobre a hospitalização de idosos: uma pesquisa bibliográfica. Cogitare Enferm. 2009;14(4):740-747.

Lima-Costa MF, Barreto SM, Giatti L. Condições de saúde, capacidade funcional, uso de serviços de saúde e gastos com medicamentos da população idosa brasileira: um estudo descritivo baseado na Pesquisa Nacional por Amostra de Domicílios. Cad Saude Publica. 2003; 19(3):735743.

Lima-Costa MF, Peixoto SV, Firmo JOA, Uchoa E. Validade do diabetes auto-referido e seus determinantes: evidências do projeto Bambuí. Rev. Saude Publica. 2007; 41(6): 947-953.

Louvison MCP. Desigualdades no uso e acesso aos serviços de saúde entre a população idosa do município de São Paulo [dissertação]. São Paulo: Faculdade de Saúde Pública, Universidade de São Paulo; 2006.

Louvison MCP et al . Desigualdades no uso e acesso aos serviços de saúde entre idosos do município de São Paulo. Rev. Saúde Pública. 2008; 42(4): 733-740.

Louvison MCP, Rosa TEC. Envelhecimento e políticas de saúde da pessoa idosa. In: Berzins MB, Borges MC (organizadoras). Políticas públicas para um país que envelhece. São Paulo: Martinari, 2012. p.155-179. 
MacLeod KE, Ragland DR, Prohaska TR, Smith ML, Irmiter C, Satariano WA. Missed or delayed medical care appointments by older users of nonemergency medical transportation. Gerontologist. 2014; 1-12. DOI:10.1093/geront/gnu002.

Maia FOM. Vulnerabilidade e envelhecimento: panorama dos idosos residentes no município de São Paulo - Estudo SABE [tese de doutorado]. São Paulo: Escola de Enfermagem, Universidade de São Paulo; 2011.

Malta DC, Merhy EE. The path of the line of care from the perspective of non-transmissible chronic diseases. Interface- Comunic., Saude, Educ. 2010; 14(34):593-605.

Matsudo SMM. Envelhecimento, atividade física e saúde. Envelhecimento \& Saúde. 2009; 47:76-79.

Mendes EV. Redes de atenção à saúde. Rev Med Minas Gerais. 2008; 18(Supl 4): S3-S11.

Mendes EV. As redes de atenção à saúde. Brasília: Organização PanAmericana da Saúde; 2011.

Mendes de Leon C. F., Seeman T. E., Baker D. I., Richardson E. D., Tinetti M. E., 1996. Self-efficacy, physical decline and change in functioning in community-living elders: A prospective study. J Gerontol B Psychol Sci Soc Sci. 1996; 51(4):S183-90.

Mendes de Leon CF, Gold DT, Glass TA, Kaplan L, George KL. Disability as a Function of Social Networks and Support in Elderly African Americans and Whites: The Duke EPESE 1986-1992. J Gerontol B Psychol Sci Soc Sci. 2001; 56(3): S179-S190. DOI:10.1093/geronb/56.3.S179.

Mendes de Leon CF, Glass TA, Berkman LF. Social Engagement and Disability in a Community Population of Older Adults The New Haven EPESE. Am J Epidemiol 2003; 157:633-642.

Mertz KJ, Lee DC, Sui X, Powell KE, Blair SN. Falls among adults: the association of cardiorespiratory fitness and physical activity with walkingrelated falls. Am J Prev Med. 2010;39:15-24. DOI:10.1016/j.amepre.2010.03.013.

Moraes EM, Lanna FM. Incapacidade cognitiva: abordagem diagnóstica e terapêutica das demências no idoso. Belo Horizonte: Folium; 2010.

Moraes EM. Atenção à saúde do Idoso: aspectos Conceituais. Brasília: Organização Pan-Americana da Saúde; 2012.

Moraes EM, Caldas CP. Cuidados de longa duração. In: Borges APA, Coimbra AMC, organizadoras. Envelhecimento e Saúde da Pessoa Idosa. Rio de Janeiro: EAD/Ensp; 2014. p.251-260. 
Moreira MD, Caldas CP. A importância do cuidador no contexto da saúde do idoso. Esc Anna Nery R Enferm. 2007; 11(3):520-5.

National Institute on Aging (NIA) [internet]. Estados Unidado [atualizado 2014; citado 2014 nov. 26] Disponível em: http://www.niapublications.org/agepages/longtermsp.

Neri AL. Bem-estar e estresse em familiares que cuidam de idosos fragilizados e de alta dependência. In: Neri AL (Org.). Qualidade de vida e idade madura. Campinas, SP: Papirus; 1993.

Neri AL, Sommerhalder C. As várias faces do cuidado e do bem-estar do cuidador. In: Neri AL, Pinto MEB, Sommerhalder C, Perracini MR, Yuaso DR. Cuidar de idosos no contexto da família: questões psicológicas e sociais. São Paulo: Alínea; 2002. p.9-63.

Neri AL, Carvalho VAML. O bem-estar do cuidador: aspectos psicossociais. In: Freitas, EV, Py L, Neri AL, Cançado FAX, Gorzoni ML, Rocha SM. Tratado de Geriatria e Gerontologia. Rio de Janeiro: Guanabara Koogan; 2011. p.778-779.

Newman AB, Gottdiener JS, Mcburnie MA, Hirsch CH, Kop WJ, Tracy R, et al. Associations of subclinical cardiovascular disease with frailty. J Gerontol A Biol Sci Med Sci. 2001; 56A(3):M158-M166.

Nogueira SL, Ribeiro RCL, Rosado LEFPL, Franceschini SCC, Ribeiro AQ, Pereira ET. Fatores determinantes da capacidade funcional em idosos longevos. Rev Bras Fisioter. 2010; 14(4):322-9.

Nunes DP, Nakatani AYK, Silveira EA, Bachion MM, Souza MR. Capacidade funcional, condições socioeconômicas e de saúde de idosos atendidos por equipes de Saúde da Família de Goiânia (GO, Brasil). Ciênc. saúde coletiva. 2010; 5(6): 2887-2898. DOI: http://dx.doi.org/10.1590/S1413-81232010000600026

Nunes DP, Duarte YAO, Santos JLF, Lebrão ML. Rastreamento de fragilidade em idosos por instrumento autorreferido. Rev Saude Publica. 2015 (49). No prelo.

Offerhaus L (editor). Drugs for the elderly. 2.ed. Copenhagen: WHO Regional Office for Europe; 1997.

Oliveira DC, Neri AL, D'Elboux MJ. Variáveis relacionadas à expectativa de suporte para o cuidado de idosos residentes na comunidade. Rev LatinoAm Enfermagem [Internet]. 2013 [citado 2014 Set 25];21(3). Disponível em: http://www.scielo.br/pdf/rlae/v21n3/pt_0104-1169-rlae-21-03-0742.pdf

Organização Mundial de Saúde. CIF - Classificação Internacional de funcionalidade, incapacidade e saúde. Lisboa; 2004. Disponível em: http://www.crefito10.org.br/cmslite/userfiles/file/artigos/cif/CIF_port_200 4.pdf 
Organização Mundial da Saúde (OMS). Towards age-friendly primary health care. Geneva: Organização Mundial de Saúde; 2004.

Organização Mundial de Saúde (OMS). Envelhecimento ativo: uma política de saúde. Brasília: Organização Pan-Americana da Saúde; 2005.

Organização das Nações Unidas (ONU). Plano de ação internacional contra o envelhecimento. Brasília: Secretaria Especial dos Direitos Humanos; 2003.

Paixão Jr CM, Reichenheim ME. Uma revisão sobre instrumentos de avaliação do estado funcional do idoso. Cad. Saude Publica. 2005;21(1):719.

Palloni A, Peláez M. Histórico e natureza do estudo. In: Lebrão ML, Duarte YAO. O projeto SABE no Brasil: uma abordagem inicial. Brasília: Organização Pan-Americana da Saúde; 2003. p.33-44.

Parahyba MI, Veras R, Melzer D. Incapacidade funcional entre as mulheres idosas no Brasil. Rev Saude Publica. 2005; 39:383-91.

Paschoal SMP. Autonomia e independência. In: Papaléo-Netto M, organizador. Gerontologia: a velhice e o envelhecimento em visão globalizada. São Paulo: Atheneu; 2002. p.311-323

Paula JJ, Bertola L, Ávila RT, Assis Lde O, Albuquerque M, Bicalho MA, et al. Development, validity, and reliability of the general activities of daily living scale: a multidimensional measure of activities of daily living for older people. Rev Bras Psiquiatr. 2014;36(2):143-52. DOI: 10.1590/15164446-2012-1003.

Pavarini SCI, Neri AL. Compreendendo dependência, independência e autonomia no contex to domiciliar: conceitos, atitudes e comportamentos. In: Duarte YAO, Diogo MJD (Orgs.). Atendimento domiciliar: um enfoque gerontológico. São Paulo: Atheneu; 2000.

Paz AA, Santos BRL, Eidt OR. Vulnerabilidade e envelhecimento no contexto da saúde. Acta Paul Enferm. 2006;19(3):338-42.

Penninx BWJH, Guralnik JM, Ferrucci L, Simonsick EM, Deeg DJH, Wallace RB. Depressive symptoms and physical decline in communitydwelling older persons. JAMA. 1998; 279(21):1720-6.

Pérèz K, Verret C, Alioum A, Barberger-Gateau P. The disablement process: Factors associated with progression of disability and recovery in French elderly people. Disabil Rehabil. 2005;27(5):263-76.

Perneczky R, Pohl C, Sorg C, Hartmann J, Komossa K, Alexopoulos P, et al. Complex activities of daily living in mild cognitive impairment: conceptual and diagnostic issues. Age Ageing. 2006; 35:240-245. 
Perracini MR, Ramos LR. Fatores associados a quedas em uma coorte de idosos residentes na comunidade. Rev. Saude Publica. 2002;36(6):709-716.

Pessôa LR, Santos EHA, Torres KRBO. Manual do Gerente: desafios da média gerência na saúde. Rio de Janeiro, Ensp; 2011.

Pinheiro R. Cuidado em saúde. In: Pereira IB, Lima JCF. Dicionário da Educação profissional em saúde. $2^{\mathrm{a}} \mathrm{ed}$. Fundação Oswaldo Cruz. Escola Politécnica de Saúde Joaquim Venâncio; 2009. Disponível em: http://www.epsjv.fiocruz.br/dicionario/verbetes/cuisau.html

Pinto JM, Neri AL. Doenças crônicas, capacidade funcional, envolvimento social e satisfação em idosos comunitários: Estudo Fibra. Cien Saude Colet. 2013; 18(12):3449-3460.

Pío TVS, Lampré MPM, Gimeno ABE, Romero ACS, Arín EF. Alteraciones de la marcha, inestabilidad y caídas. In: Sociedad Española de Geriatría y Gerontología (SEGG). Tratado de geriatría para residentes. Madrid: $\quad$ SEGG; $2006 . \quad$ Disponível em: file://C:/Users/Daniela/Downloads/S35-05\%2019_II.pdf

Potter PA, Perry AG, Stockert PA, Hall AM. Fundamentos de enfermagem. 8 a ed. Rio de Janeiro: Elsevier; 2013.

Pucca Jr. GA. Saúde bucal do idoso: Aspectos sociais e preventivos. In: Papaléo Neto M, organizador. Gerontologia. São Paulo: Editora Atheneu; 1996. p.297-310

Ragland DR, Satariano WA, MacLeod KR. Reasons given by older people for limitation or avoidance of driving. Gerontologist. 2004;44(2):237-244. DOI: 10.1093/geront/44.2.237.

Ramos LR, Perracini M, Rosa TE, Kalache A. Significance and management of disability among urban elderly residents in Brazil. J Cross Cult Gerontol. 1993;8(4):313-23. DOI: 10.1007/BF00972560.

Ramos LR, Andreoni S, Coelho-Filho JM, Lima-Costa MF, Matos DL, Rebouças M, et al. Perguntas mínimas para rastrear dependência em atividades da vida diária em idosos. Rev Saude Publica. 2013; 47(3):506-13.

Rao JNK, Scott AJ. On chi-squared tests for multiway contingency-tables with cell proportions estimated from survey data. Ann Stat. 1984; 12:46-60.

Ribeiro AP, Souza ER, Atie S, Souza AC, Schilithz AO. A influência das quedas na qualidade de vida de idosos. Cien Saude Colet. 2008;13(4):12651273.

Ribeiro PCC, Oliveira BHD, Cupertino APFB, Neri AL, Yassuda MS. Desempenho de idosos na bateria cognitiva CERAD: relações com variáveis sociodemográficas e saúde percebida. Psicol Reflex Crit. 2010; 23(1):102109. 
Rittner B, Kirk AB. Health care and public transportation use by poor and frail elderly people. Soc Work. 1995;40(3):365-373. DOI:10.1093/sw/40.3.365.

Rodrigues MAP, Facchini LA, Thumé E, Maia F. Gender and incidence of functional disability in the elderly: a systematic review. Cad Saude Publica. 2009; 25(Sup 3):S464-S476.

Rosa TEC, Benicio MHD, Latorre MRDO, Ramos LR. Fatores determinantes da capacidade funcional entre idosos. Rev Saude Publica. 2003; 37:40-8.

Rosow I, Breslau NA. Guttman Health Scale for aged. J Gerontol. 1966; 21(4):556-9.

Rosso AL, Taylor JA, Tabb LP, Michael YL. Mobility, disability, and social engagement in older adults. J Aging Health. 2013; 25(4):617-637. DOI: $10.1177 / 0898264313482489$

Rubin GS, Bandeen-Roche K, Prasada-Rao P, Fried LP. Visual Impairment and Disability in Older Adults. Optom Vis Sci. 1994; 71(12):750-760.

São Paulo (SP). Atende - Transporte Especial. Lei Municipal no 11.602, de 12 de julho de 1994, regulamentada pelo Decreto Municipal no 36.071; 09 de maio 1996.

São Paulo (SP). Secretaria Municipal da Saúde Coordenação de Atenção Básica. Área Técnica de Saúde da Pessoa Idosa. Documento Norteador do Programa Acompanhante de Idosos do Município de São Paulo; 2012.

Santos TRA, Lima DM, Nakatani AYK, Pereira LV, Leal GS, Amaral RG. Consumo de medicamentos por idosos, Goiânia, Brasil. Rev Saude Publica. 2013;47(1): 94-103.

Santos-Eggimann B, Cuénoud P, Spagnoli J, Junod J. Prevalence of frailty in middle-aged and older community-dwelling Europeans living in 10 countries. J Gerontol A Biol Sci Med Sci. 2009; 64A(6):675-681.

Secoli SR. Polifarmácia: interações e reações adversas no uso de medicamentos por idosos. Rev bras enferm. 2010; 63(1):136-140.

Secretaria de Estado de Saúde (SES). Relatório global da OMS sobre prevenção de quedas na velhice. São Paulo; 2010.

Selem SSC, Castro MA, César CLG, Marchioni DML, Fisberg RM. Validade da hipertensão autorreferida associa-se inversamente com escolaridade em brasileiros. Arq. Bras. Cardiol. 2013; 100(1):52-59.

Sen G, Ostlin P. Gender inequity in health: why it exists and how we can change it. Glob Public Health. 2008; 3:1-12 
Sheikh JI, Yesavage JA. Geriatric Depression Scale (GDS): Recent evidence and development of a shorter version. Clinical Gerontology: A Guide to Assessment and Intervention. New York: The Haworth Press; 1986.

Silva NN. Processo de amostragem. In: Lebrão ML, Duarte YAO. O projeto SABE no Brasil: uma abordagem inicial. Brasília: Organização PanAmericana da Saúde; 2003.

Sidenvall B, Nydahl M, Fjellström C. Managing food shopping and cooking: the experiences of older Swedish women. Ageing Soc. 2001; 21(2):151-168. DOI:10.1017/S0144686X01008121

Simões JR, Murijo MG, Pereira K. Perfil psicomotor na praxia global e fina de crianças de três a cinco anos pertencentes à escola privada. ConScientiae Saude. 2008;7(2):151-157.

Siu AL, Reuben DB, Hays RD. Hierarchical measures of physical function in ambulatory geriatrics. J Am Geriatr Soc. 1990; 38(10):1113-9.

Scazufca M. Brazilian version of the Burden Interview scale for the assessment of burden of care in carers of people with mental illnesses. Rev Bras Psiquiatr. 2002;24(1), p. 12-7.

Souza AS, Meira EC, Neri IG, Silva JA, Gonçalves LHT. Fatores de risco de maus-tratos ao idoso na relação idoso/cuidador em convivência intrafamiliar. Textos Envelhecimento. 2004; 7(2). Disponível Rio de Janeiro 2004

Sousa ACPA, Dias RC, Maciel ACC, Guerra RO. Frailty syndrome and associated factors in community-dwelling elderly in Northeast Brazil. Arch Gerontol Geriatr. 2012; 54(2):e95-e101.

Spector WD, Katz S, Murphy JB, Fulton JP. The hierarchical relationship between activities of daily living and instrumental activities of daily living. J Chron Disease. 1987; 40(6):481-489.

Stein AT. Acesso a atendimento médico continuado: uma estratégia para reduzir a utilização de consultas não urgentes em serviço de emergência. Porto Alegre: Universidade Federal do Rio Grande do Sul; 1998.

Streiner DL, Norman GR. Health measurement scales. 3rd ed. Oxford: Oxford University Press; 2003.

Stuck AE, Walthert JM, Nikolaus T, Bula CJ, Hohmann C, Beck JC. Risk factors for functional status decline in community-living elderly people: a systematic literature review. Soc Sci Med. 1999;48(4):445-69. 
Taylor BD, Tripodes S. The effects of driving cessation on the elderly with dementia and their caregivers. Accid Anal Prev. 2001;33(4):519-528. DOI:10.1016/S0001-4575(00)00065-8.

Teixeira DSC. Condições de saúde bucal dos idosos moradores no município de São Paulo em 2006 [dissertação de mestrado]. São Paulo. Faculdade de Saúde Pública da USP; 2007.

Thomas VS, Rockwood K, McDowell I. Multidimensionality in instrumental and basic activities of daily living. Clin Epidemiol. 1998; 51(4):315-321.

Tinetti ME, Speechley M. Prevention of falls among the elderly. N Engl J Med 1989; 320(16):1055-9..

Torres MV. Hierarquização de incapacidade funcional de idosos no município de São Paulo: uma análise longitudinal [dissertação]. São Paulo: Faculdade de Saúde Pública, Universidade de São Paulo; 2009.

Torres GV, Reis LA, Fernandes MH, Xavier TT. Relação entre funcionalidade familiar e capacidade funcional de idosos dependentes no município de Jequié (BA). Rev Baiana Saude Publica. 2010; 34(1):19-30.

Tsutsui T, Muramatsu N. Care-needs certification in the long-term care insurance system of Japan. J Am Geriatr Soc. 2005; 53:522-527.

UNFPA. Fundo de População das Nações Unidas. Envelhecimento no Século XXI: Celebração e Desafio. Disponível em: http://www.unfpa.org/sites/default/files/pub-pdf/Portuguese-Exec-

Summary_0.pdf. Fundo de População das Nações Unidas (UNFPA) e HelpAge International, 2012

Van Den Akker M, Buntinx F, Knottnerus JA. Comorbidity or multimorbidity: what's in a name. A review of literature. Eur J Gen Pract. 1996; 2:65-70.

Vale EG, Pagliuca LMF. Construção de um conceito de cuidado de enfermagem: contribuição para o ensino de graduação. Rev Bras Enferm 2011; 64(1): 106-13.

Varadhan R, Walston J, Cappola AR, Carlson MC, Wand GS, Fried LP. Higher levels and blunted diurnal variation of cortisol in frail older women. J Gerontol A Biol Sci Med Sci. 2008:63(2):190-195.

Varela-Pinedo L, Ortiz-Saavedra PJ, Chávez-Jimeno H. Síndrome de fragilidad en adultos mayores de la comunidad de Lima Metropolitana. Rev Soc Peru Med Interna. 2008; 21(1):11-15.

Verbrugge LM, Jette AM. The disablement process. Soc Sci Med. 1994;38(1):1-14. 
Veras RP, Caldas CP, Cordeiro HA, Motta LB, Lima KC. Desenvolvimento de uma linha de cuidados para o idoso: hierarquização da atenção baseada na capacidade funcional. Rev. Bras. Geriatr. Gerontol. 2013; 16(2):385-392.

Zunzunegui MV, Alvarado BE, Beland F, Vissandjee B. Explaining health differences between men and women in later life: A cross-city comparison in Latin America and the Caribbean. Soc Sci Med.. 2009;68 (2) 235-242.

Waldow VR. Cuidado humano: o resgate necessário. 3.ed. Porto Alegre: Sagra Luzzatto; 2001.

Wijlhuizen GJ, Chorus AMJ, Hopman-Rock M. Fragility, fear of falling, physical activity and falls among older persons: Some theoretical considerations to interpret mediation. Prev Med. 2008; 46(6):612-4. DOI: 10.1016/j.ypmed.2008.01.016.

Wolf DA. Population change: friend or foe of the chronic care system. Health Aff. 2001; 20(6):28-42.

Wong R, Díaz JJ. Health care utilization among older Mexicans: health and socioeconomic inequalities. Salud Pública de México. 2007; 49(4): S505S514.

Wylie C, Copeman C, Kirk SFL. Health and social factors affecting the food choice and nutritional intake of elderly people with restricted mobility $\mathrm{J}$ Hum Nutr Diet. 1999; 12(5):375-380.

Yassuda MS, Lopes A, Cachioni1 M, Falcao DVS, Batistoni SST, Guimarães VV, et al. Frailty criteria and cognitive performance are related: data from the Fibra Study in Ermelino Matarazzo, São Paulo, Brazil. J Nutr Health Aging. 2012; 16(1):55-61.

Young HM. Challenges and solutions for care of frail older adults. Online J Iss Nurs [Internet]. 2003 [cited 2013 Jan 08]; 8(2). Disponível em: www.nursingworld.org/MainMenuCategories/ANAMarketplace/ANAPerio dicals/OJIN/TableofContents/Volume82003/No2May2003/OlderAdultsCare Solutions.aspx 
ANEXOS

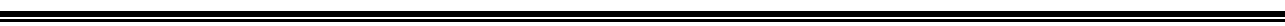


ANEXO I. Aprovação do Comitê de Ética do Estudo SABE 2000

MINISTERIO DA SAÚDE

Conselho Nacional de Saude

Comissấo Nacional de Etica em Pesquisa - CONEP

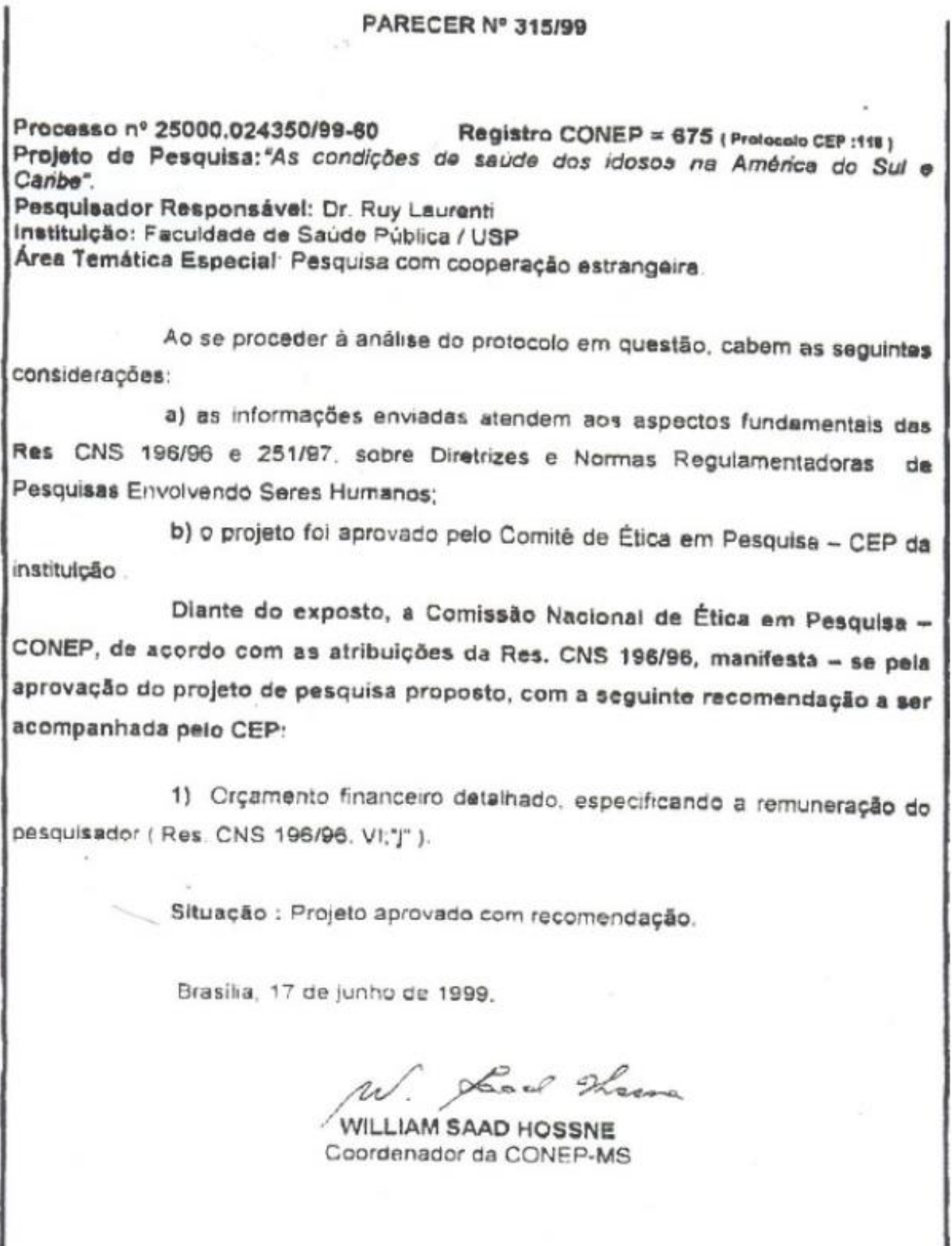


ANEXO II. Aprovação do Comitê de Ética do Estudo SABE 2006

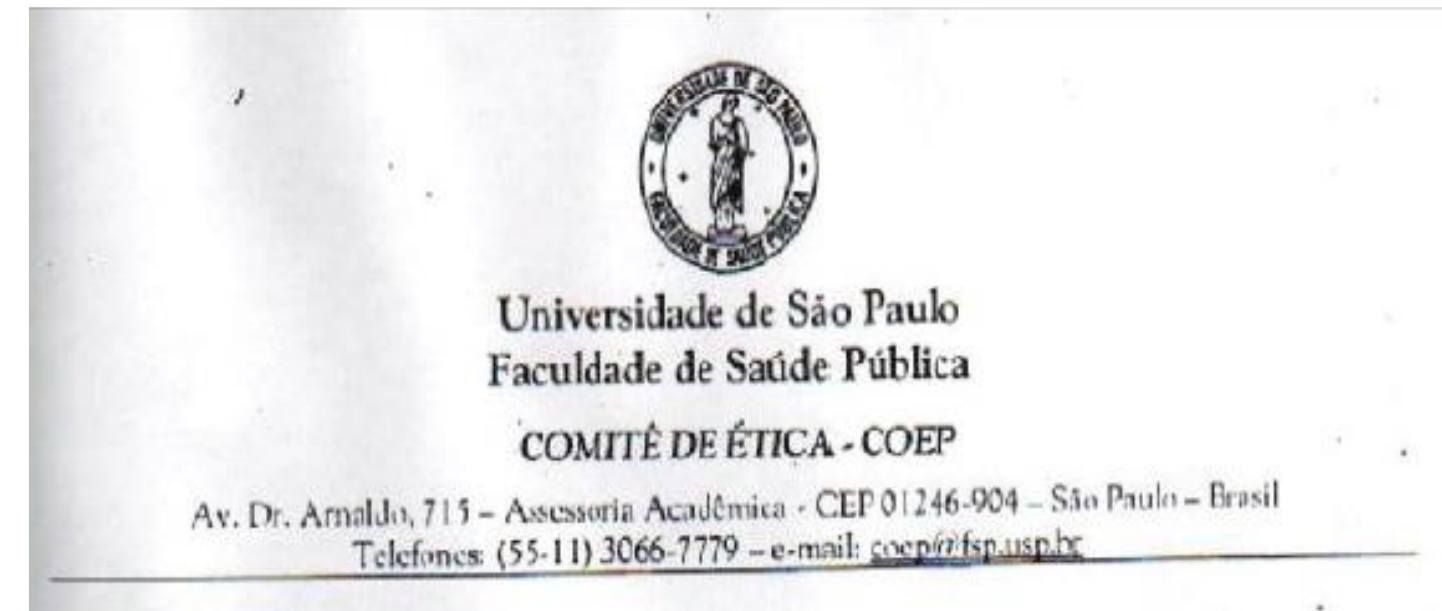

\section{Of.COEP/83/06}

14 de março de 2006

Pelo presente, informo que o Comitè de Ética em Pesquisa da Faculdade de Saúde Pública da Universidade de São Paulo-COEP, aprovou o Protocolo de Pesquisa n. ${ }^{\circ}$ 1345, intifulado: "PROJETO SABE-2005 - SAÚDE, BEM-ESTAR E ENVELHECIMENTO. AS CONDIÇÕES DE SAÚDE E DE VIDA DOS IDOSOS NO MUNICÍPIO DE SÄO PAULO", apresentado pela pesquisadora Maria Lúcia Lebrăo.

Atenciosamente,

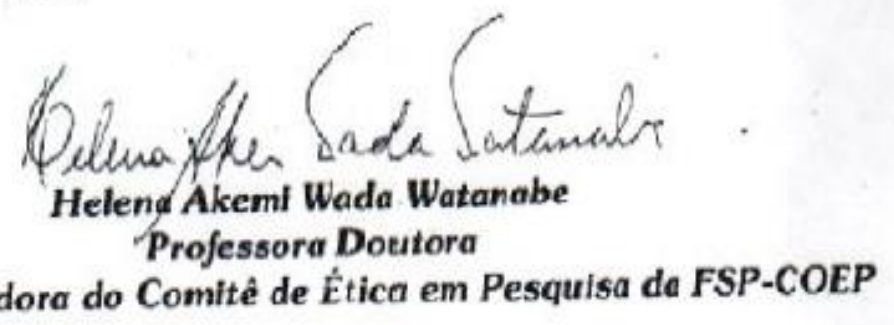


ANEXO III. Aprovação do Comitê de Ética do Estudo SABE 2010

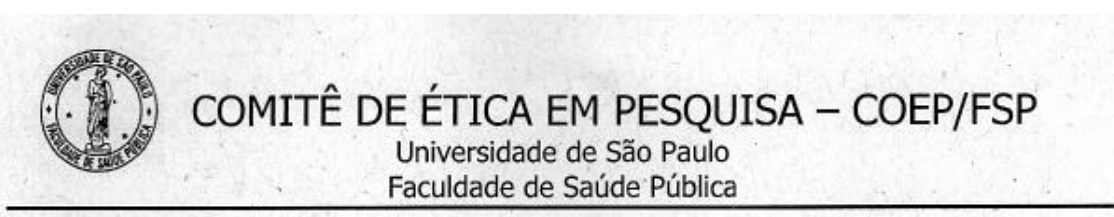

OF.COEP/23/10

5 de março de 2010

Prezado(a) Pesquisador(a) e Orientador(a),

o Comitê de Ética em Pesquisa da Faculdade de Saúde Pública da Universidade de São Paulo - COEP/FSP, anạlisou, de acordo com a Resolução N.0 196/96 do Conselho Nacional de Saúde - CNS e suas complementares, o protocolo de pesquisa n.o 2044, intitulado "ESTUDO SABE 2010: SAÚDE, BEM-ESTAR E ENVELHECIMENTO - ESTUDO LONGITUDINAL SOBRE AS CONDIÇÕES DE VIDA E SAÚdE DOS IDOSOS NO MUNICÍPIO DE SÃO PAULO", área temática GRUPO III, sob responsabilidade do(a) pesquisador(a) Maria Lucia Lebrao, e considerou que a pendência anteriormente apresentada por este COEP foi atendida. Protocolo de pesquisa APROVADO "ADREFERENDUM".

Cabe lembrar que conforme Resolução $C N / 196 / 96$, são deveres do (a) pesquisador (a): 1. Comunicar, de imediato, qualquer alteração no projeto e aguardar manifestação deste CEP (Comitê de Ética em Pesquisa), para dar continuidade à pesquisa; 2. Manter sob sua guarda e em local seguro, pelo prazo de 5 (cinco) anos, os dados da pesquisa, contendo fichas individuais e todos os demais documentos recomendados pelo CEP, no caso eventual auditoria; 3. Comunicar, formalmente a este Comitê, quando do encerramento deste projeto; 4. Elaborar e apresentar relatórios parciais e final; 5. Justificar, perante o CEP, interrupção do projeto ou a não publicação dos resultados.

Atenciosamente,

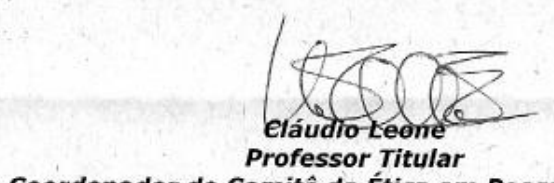

Coordenador do Comitê de Ética em Pesquisa - COEP

I/m. a Sr.a

Prof. a Tit. Maria Lucia Lebrão

Departamento de Epidemiologia da FSP/USP

Av. Dr. Arnaldo, 715 - Assessoria Acadêmica - CEP: 01246-904 - São Paulo - SP Telefones: (55-11) 3061-7779/7742 e-mail: coep@fsp.usp.br site www.fsp.usp.br 